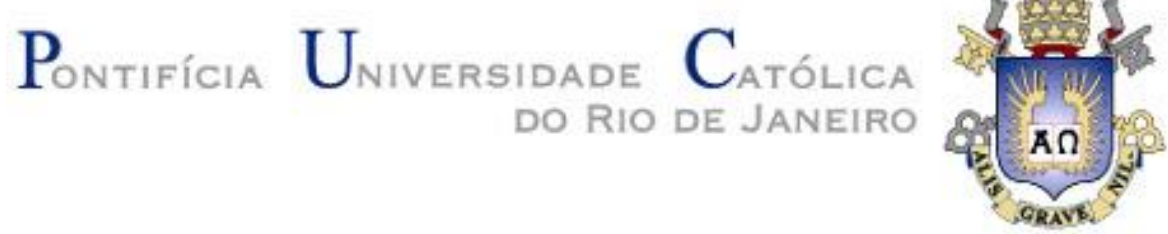

Bruno Castello Memoria

\title{
Estratégia Como Fator Determinante de Desempenho na Indústria Automobilística \\ Brasileira
}

Dissertação de Mestrado

Dissertação apresentada ao Programa de Pósgraduação em Administração de Empresas da PUC-Rio como requisito parcial para obtenção do título de Mestre em Administração de Empresas.

Orientador: Prof: Marcos Cohen

Rio de Janeiro

Abril de 2015 


\title{
Pontifícia Universidade Católica $_{\text {ata }}$

Bruno Castello Memoria

\author{
Estratégia como fator determinante de \\ desempenho na indústria automobilística \\ brasileira
}

\begin{abstract}
Dissertação apresentada como requisito parcial para obtenção do grau de Mestre pelo Programa de PósGraduação em Administração de Empresas da PUC-Rio. Aprovada pela Comissão Examinadora abaixo assinada.
\end{abstract}

Prof. Marcos Cohen

Orientador

Departamento de Administração - PUC-Rio

Prof. Jorge Ferreira da Silva Departamento de Administração - PUC-Rio

Prof. Luis Antonio da Rocha Dib Instituto Coppead de Administração/UFRJ

Prof ${ }^{\text {. }}$. Mônica Herz Vice-Decana de Pós-Graduação do CCS - PUC-Rio

Rio de Janeiro, 01 de abril de 2015 
Todos os direitos reservados. É proibida a reprodução total ou parcial do trabalho sem a autorização da universidade, do autor e do orientador.

\section{Bruno Castello Memoria}

Graduou-se em administração pela Pontifícia Universidade Católica do Rio de Janeiro em 2011.

Ficha Catalográfica

Memoria, Bruno Castello

Estratégia como fator determinante de desempenho na indústria automobilística brasileira / Bruno Castello Memoria; orientador: Marcos Cohen. - 2015.

$100 \mathrm{f}$; $30 \mathrm{~cm}$

Dissertação(mestrado)-Pontifícia

Universidade Católica do Rio de Janeiro, Departamento de Administração, 2015. Inclui bibliografia

1. Administração - Teses. 2. Estratégiadesempenho. 3. Tipologia de Michael Porter. 4. Estratégias genéricas. 5. Grupos estratégicos. 6 . Indústria automobilística. I. Cohen, Marcos. II. Pontifícia Universidade Católica do Rio de Janeiro. Departamento de Administração. III. Título.

CDD: 658 


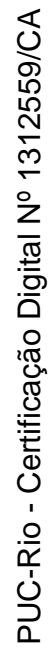

Dedicada a minha mãe, Claudia Maria Costa Castello. 


\section{Agradecimentos}

Ao professor Marcos Cohen, pelas orientações e ensinamentos fundamentais para a realização deste trabalho.

Ao professor Jorge Ferreira da Silva, pelos constantes ensinamentos ao longo do curso.

Aos professores Márcio Pezzela e Sandra Regina, pelo apoio e instruções.

À Luiza Gouveia, pela ajuda e apoio em todos os momentos.

À Renata Castello e Hector Gusmão, pela paciência e compreensão.

Ao Fábio Etienne, pela ajuda na realização deste trabalho.

Agradecimento especial ao meu pai, Ronaldo de Oliveira Memoria, pelo apoio e amor incondicional. 


\section{Resumo}

Memoria, Bruno Castello; Cohen, Marcos. Estratégia como fator determinante de desempenho na indústria automobilística brasileira. Rio de Janeiro, 2015. 100p. Dissertação de Mestrado - Departamento de Administração, Pontifícia Universidade Católica do Rio de Janeiro.

Este trabalho tem como objetivo observar a possível relação teórica entre grupos estratégicos da indústria automobilística brasileira e o desempenho das empresas pertencentes a estes grupos estratégicos. Para cumprir este objetivo, foram analisadas 30 montadoras de automóveis, identificando os grupos estratégicos formados, utilizando a tipologia de Michael Porter como base. Após a identificação das estratégias competitivas foi realizada análises sobre o desempenho dos grupos, observando como os grupos estratégicos se apresentam dentro desta indústria. Os dados foram analisados estatisticamente (Z-score, Shapiro-Wilks, análise fatorial, K-means clusters, ANOVA e MANOVA), permitindo análises mais consistentes sobre o coalinhamento estratégico das empresas da indústria em questão. Como resultados, foram encontrados cinco grupos estratégicos, com diferenças significantes entre os seus desempenhos médios para algumas variáveis dependentes, especialmente para a variável Satisfação dos clientes. Esta diferença entre o desempenho médio dos grupos estratégicos indica a importância do estudo das estratégias competitivas das empresas de determinada indústria, sugerindo possível relação teórica entre a estratégia e o desempenho.

\section{Palavras-chave}

Estratégia-desempenho; Tipologia de Michael Porter; Estratégias Genéricas; Grupos Estratégicos; Indústria Automobilística. 


\section{Abstract:}

Memoria, Bruno Castello; Cohen, Marcos (Advisor). Strategy as Key Performance Factor in Brazilian Automotive Industry. Rio de Janeiro, 2015. 100p. MSc. Dissertation - Departamento de Administração, Pontifícia Universidade Católica do Rio de Janeiro.

This study aims to evaluate the possible theoretical relationship between strategic groups of the Brazilian automobile industry and the performance of companies belonging to these strategic groups. To achieve this goal, were analyzed 30 car assemblers companies, identifying strategic groups, using Michael Porter's typology as a base. After the identification of competitive strategies, analysis was conducted on the performance of the groups, observing how the strategic groups present within this industry. Data were statistically analyzed (Z-score, Shapiro-Wilks, factor analysis, K-means clustering, ANOVA and MANOVA), allowing more consistent analyzes of the strategic co-alignment of industry companies concerned. As a result, five strategic groups were found, with significant differences between their average performances for some dependent variables, highlighting the Consumer Satisfaction variable. This difference between the average performances of strategic groups indicates the importance of studying the competitive strategies of the particular industry companies, suggesting a possible theoretical relationship between strategy and performance.

\section{Keywords}

Strategy-performance; Michael Porter's typology; generic strategies; strategic groups; automotive industry. 


\section{Sumário}

1 O problema 14

1.1 introdução 14

$\begin{array}{ll}1.2 \text { Objetivos } & 15\end{array}$

1.2.1 Objetivo final 15

1.2.2Objetivos intermediários 15

$\begin{array}{ll}1.3 \text { Hipótese do estudo } & 16\end{array}$

$\begin{array}{ll}1.4 \text { Delimitação do estudo } & 16\end{array}$

$\begin{array}{ll}1.5 \text { Relevância do estudo } & 16\end{array}$

2 Referencial teórico 18

$\begin{array}{ll}2.1 \text { Ambiente competitivo } & 18\end{array}$

2.1.1 Ameaça de novos entrantes $\quad 19$

2.1.2 Ameaça de produtos substitutos 20

2.1.3 Rivalidade entre empresas existentes 20

2.1.4 Poder de barganha do fornecedor 20

2.1.5Poder de barganha do cliente $\quad 21$

2.2 Estratégia e vantagem competitiva 21

2.3 Tipologia de Porter 23

2.3.1 Riscos das estratégias genéricas 25

2.3.1.1 Riscos da estratégia em liderança em custo total 25

2.3.1.2 Riscos da estratégia de diferenciação 26

2.3.1.3 Risco de estratégias baseadas em enfoque 27

2.3.2 Críticas à tipologia de Porter 27

2.3.2.1 Críticas à liderança em custo 28

2.3.2.2 Críticas à estratégia de diferenciação 29

2.4 Análise estrutural dentro da indústria 29

2.4.1 Dimensões da estratégia competitiva 31

2.5 Desempenho 32

2.5.1 Desempenho e ambiente competitivo 33

2.5.2 Desempenho de grupos estratégicos 34 
3 A indústria automobilística brasileira 36

3.1 Histórico e evolução 36

3.2 Estratégias usadas pelas empresas dessa indústria 39

3.3 Indústria automobilística na atualidade $\quad 40$

3.4 Análise das Cinco Forças na indústria atual 43

4 Método de pesquisa $\quad 46$

4.1 Seleção de universo, amostra e sujeitos 46

4.2 Coleta de dados $\quad 47$

4.2.1 Seleção das variáveis de estratégia competitiva 48

4.2.1.1 Qualidade 48

4.2.1.2 Canais de distribuição 48

4.2.1.3 Qualidade no serviço de pós-venda 49

4.2.1.4 Produtos no segmento high price $\quad 49$

4.2.1.5 Produtos no segmento de entrada 49

4.2.1.6 Serviços adicionais oferecidos 50

4.2.1.7 Abrangência de atuação 50

4.2.1.8 Linhas de produtos 50

4.2.1.9 Investimento em propaganda 51

4.2.2Seleção das variáveis de desempenho 51

4.2.2.1 Receita bruta $(\mathrm{R} \$)$

4.2.2.2 Market-share $\quad 51$

4.2.2.3 Market-share por segmento 51

4.2.2.4 Crescimento do market-share 52

4.2.2.5 Satisfação do cliente 52

4.2.2.6 Preço médio 52

4.3 Tratamento dos dados $\quad 54$

4.4 Limitações do método $\quad 57$

5 Apresentação e análise dos resultados 58

5.1 Análise amostral $\quad 58$

5.2 Análise da normalidade das variáveis 61

5.3 Análise de correlação 63

5.4 Redução do espaço estratégico 67 
5.5 Formação dos grupos estratégicos $\quad 69$

5.6 Grupos estratégicos 72

5.6.1 Análises dos grupos estratégicos 73

5.6.1.1 Grupo 1 - estratégia de liderança em custo total 74

5.6.1.2 Grupo 2 - estratégia de diferenciação 74

5.6.1.3 Grupo 3 - estratégia de enfoque em custo 75

5.6.1.4 Grupo 4 - estratégia de enfoque em diferenciação 76

5.6.1.5 Grupo 5 - stuck-in-the-middle 77

5.7 Comparação de desempenho entre grupos 78

5.8 Comparação com os resultados obtidos por Silva (2007) 89

6 Conclusões 92

6.1 Discussão dos resultados obtidos 92

$\begin{array}{ll}6.2 \text { Sugestão para novas pesquisas } & 96\end{array}$

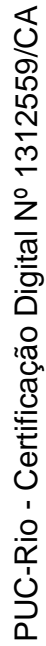

7 Referência bibliográfica 98 


\section{Lista de figuras}

Figura 1 - Modelo de cinco forças de Porter 19

Figura 2 - Modelo das estratégias genéricas de Porter (1980) 25

Figura 3 - Perspectiva neoclássica 34

Figura 5 - Quantidade de modelos distintos por montadora 58

Figura 6 - Quantidade de concessionárias por montadora 59 


\section{Lista de tabelas}

Tabela 1 - Dimensões estratégicas 32

Tabela 2 - Grupos estratégicos das montadoras de automóveis $\quad 39$

Tabela 3 - Total de veículos comercializados - (em milhares) 41

Tabela 4 - Empresas contidas na amostra 47

Tabela 5 - Identificação da variável no SPSS 53

Tabela 6 - Comparação entre variáveis de estratégia utilizadas por

Silva (2007) 54

Tabela 7 - Nota recebida por montadora na variável pós-venda $\quad 59$

Tabela 8 - Preço médio das montadoras 60

Tabela 9 - Market-share e market-share por segmento 61

Tabela 10 - Estatística descritiva das variáveis 62

Tabela 11 - Teste Kolmogorov-Smirnov e Shapiro-Wilk das variáveis 62

Tabela 12 - Matriz de correlação de Pearson das variáveis estratégicas 64

Tabela 13 - Matriz de Correlação de Pearson das variáveis de desempenho 66

Tabela 14 - Teste KMO e Bartlett's 67

Tabela 15 - Variância dos Fatores $\quad 68$

Tabela 16 - Cargas dos fatores após rotação varimax 68

Tabela 17 - Fatores resultantes da redução fatorial das variáveis estratégicas

Tabela 18 - Matriz dos quartis usados para formação da matriz inicial dos centroides $\quad 70$

Tabela 19 - Matriz dos centroides iniciais - Distribuição teórica $\quad 70$

Tabela 20 - Matriz Inicial dos centroides com percentis aplicados $\quad 71$

Tabela 21 - Matriz final dos centroides $\quad 71$

Tabela 22 - Teste de Wilcoxon $\quad 72$

Tabela 23 - Número de casos por cluster 72

Tabela 24 - Grupos Estratégicos 73

Tabela 25 - Matriz das variáveis por grupos estratégicos 74

Tabela 26 - Análise de variância para a variável Satisfação 78

Tabela 27 - Teste de Bonferroni para a variável Satisfação 79

Tabela 28 - Teste de Kruskal-Wallis 80 
Tabela 29 - Teste de igualdade de desempenho dos grupos estratégicos

Tabela 30 - Teste de Bonferroni - comparação de desempenho entre grupos estratégicos

82

Tabela 31 - Comparação de desempenho por grupo estratégico $\quad 86$

Tabela 32 - Comparação dos grupos estratégicos 91

Tabela 33 - Resumo dos resultados dos testes 96 


\section{1 \\ O problema}

\section{1 Introdução}

O dia 16 de julho de 1956 é considerado a data de nascimento da indústria automobilística brasileira, sendo marcada pela criação do Grupo de Executivos da Indústria Automobilística (GEIA) pelo então Presidente da República, Juscelino Kubitschek (Associação Nacional dos Fabricantes de Veículos Automotores Anfavea, 2012). Apesar de já existirem montadoras no país desde 1919, ano em que a Ford passou a montar o famoso Ford T no Brasil, apenas em 1956 foi produzido e montado o primeiro veículo em solo nacional. Este veículo era a camioneta DKW, contando com $60 \%$ do seu peso nacionalizado. O final da década de 50 e início da década de 60 foram marcados pelo interesse de diversas montadoras no mercado brasileiro em instalar suas fábricas no Brasil. Dessa forma, a indústria automobilística brasileira começou o seu crescimento, mantendo o foco na produção e na redução de custos, com o objetivo de abastecer o potencial mercado brasileiro. A partir do início da década de 90, importantes fatos políticos, econômicos e tecnológicos ocorreram, modificando a estrutura da indústria. Além da entrada de novas empresas no setor, diversos fatores contribuíram para o aumento da competição, forçando algumas empresas a repensarem suas estratégias de atuação. Em um novo ambiente de competição, as empresas mudaram seu foco, não se restringindo apenas à produção, mas sim, atentando aos importantes fatores que impactam a rentabilidade e que moldam a escolha estratégica, como as necessidades e preferencias dos consumidores.

A escola do posicionamento analítico, conforme proposta por Porter (1980) a partir da teoria básica de economia industrial (BAIN, 1956), busca explicar o desempenho das empresas a partir das suas posturas estratégicas e das influências que tais posturas possam ter sobre o ambiente competitivo da indústria hospedeira. 
Utilizando as empresas atuantes na indústria automobilística brasileira como objeto de estudo, este trabalho visa identificar grupos estratégicos dentro desta indústria, procurando identificar se existem diferenças significativas entre os grupos estratégicos identificados. Para classificar as empresas em grupos estratégicos, foi utilizada a tipologia de Michael Porter (1980), a qual classifica a escolha estratégica em três opções genéricas: liderança em custo, diferenciação ou enfoque, este último podendo ser classificado como enfoque em custo e enfoque em diferenciação. Há também as empresas que não possuem estratégia claramente definida, não apresentando padrões estratégicos, ou que fracassaram em perseguir uma das três estratégias, sendo classificadas como stuck-in-the-middle (Porter, 1980). As estratégias foram operacionaliza das através das variáveis relacionadas às dimensões estratégicas - padrões de comportamento que caracterizam a estratégica seguida (PORTER, 1980).

Através da realização desta análise, esse estudo pretende responder a seguinte questão de pesquisa: há diferença significativa no desempenho dos grupos estratégicos identificados na indústria automobilística brasileira?

\section{2 \\ Objetivos}

\subsection{1}

\section{Objetivo final}

Verificar se existem diferenças significativas de desempenho entre diferentes grupos estratégicos de montadoras do setor automobilístico brasileiro.

\section{2 .2}

\section{Objetivos intermediários}

- Identificar grupos estratégicos existentes dentro da indústria automobilista brasileira.

- Gerar dimensões estratégicas relevantes que possam caracterizar estratégias previamente propostas.

- Identificar variáveis de desempenho relevantes para o estudo.

- Identificar possíveis fatores que expliquem desempenhos distintos entre grupos estratégicos. 


\section{3}

\section{Hipótese do estudo}

A hipótese que este estudo pretende verificar é se há diferença significativa de desempenho entre os grupos estratégicos dentro da indústria automobilística brasileira.

\section{4}

\section{Delimitação do estudo}

O presente estudo está limitado a estudar empresas que comercializem automóveis no mercado brasileiro, não incluindo montadoras de motos ou de veículos utilizados para transporte de cargas. Para estarem dentro da amostra deste estudo, as empresas devem, necessariamente, possuir pelo menos um canal de venda direto dentro do território nacional, excluindo-se, assim, empresas que apenas permitem a importação de veículos diretamente pelo cliente. Por não existirem dados suficientes para classificar sua atuação sob a ótica estratégica, estas empresas foram deixadas à parte neste estudo.

Em respeito à amplitude temporal, este estudo considerou dados dentro do período de 2007 a 2012.

\section{5}

\section{Relevância do estudo}

A indústria estudada é de extrema importância para a economia brasileira, uma vez que apresenta números expressivos tanto na geração de emprego, quanto em termos econômicos. Em 2012, a indústria automobilística (excluindo empresas produtoras de máquinas agrícolas e rodoviárias) apresentou uma receita líquida de 73 bilhões de reais, representando 15\% do PIB industrial, além de proporcionar mais de 130 mil empregos diretos, sem contar a participação de indústrias diretamente ligadas, como a de autopeças e de serviços de manutenção (ANFAVEA, 2014). 
Profissionais interessados em melhor entender esta indústria, sobretudo em termos de posicionamento estratégicos das empresas participantes, poderão considerar este estudo relevante a fim de adquirir informações em termos de análise estratégica.

Este estudo pode vir a ser relevante para a academia, uma vez que revisa e testa teorias e conceitos clássicos ligados a estratégia competitiva, atualizando e colaborando para os estudos ligados ao tema em questão. Ele também dá continuidade a um estudo realizado por Silva (2007) utilizando a mesma metodologia, o que pode ajudar os pesquisadores a avaliarem a evolução dessa indústria durante um período maior de tempo. 


\section{2 \\ Referencial teórico}

\section{1}

\section{Ambiente competitivo}

A conceituação básica parte do princípio de que o ambiente é função da natureza da competição e da estrutura da indústria. Indústria, por sua vez, é definida como um grupo de empresas produzindo bens ou serviços que são substitutos aproximados entre si, para atender um conjunto de necessidade e demanda (PORTER, 1980).

Entretanto, não há um consenso sobre a definição clara de uma indústria, ainda mais quando o assunto é referente aos limites da indústria. Uma empresa fabricante de televisões pode ser considerada na indústria de fabricantes de televisões, na indústria de aparelhos eletrônicos, na indústria de entretenimento ou de uma forma mais ampla, na indústria de divulgadores de informações (SILVA, 1997). A definição referente à amplitude da indústria estará condicionada à análise do que se pretende fazer.

Seja qual for a indústria, as empresas buscam o desempenho superior que compense os investimentos e os riscos incorridos. Para isso, as empresas buscam adotar estratégias que melhor se adaptem ao ambiente ou que possam influenciálo em prol dos objetivos da empresa (SILVA, 1997).

Foi escolhido, para operacionalizar o conceito de ambiente competitivo o modelo das cinco forças, criado por Michael Porter. Este modelo fornece um contexto no qual é possível analisar cada força que atua na indústria, evidenciando, que a competição não se dá apenas pelas empresas participantes. Cada força atuante exerce maior ou menor impacto sobre a indústria, sendo que as cinco forças em conjunto determinam o nível de concorrência, assim como a rentabilidade esperada da indústria. Analisando o modelo das Cinco Forças de Porter, se busca identificar a força ou as forças mais impactantes que predominam, tornando cruciais sob o ponto de vista da formulação estratégica (SILVA, 1997). 
A seguir, o modelo das cinco forças, seguido da análise individual de como cada força atua individualmente, todas baseadas nos conceitos de Porter (1980).

Figura 1 - Modelo de cinco forças de Porter

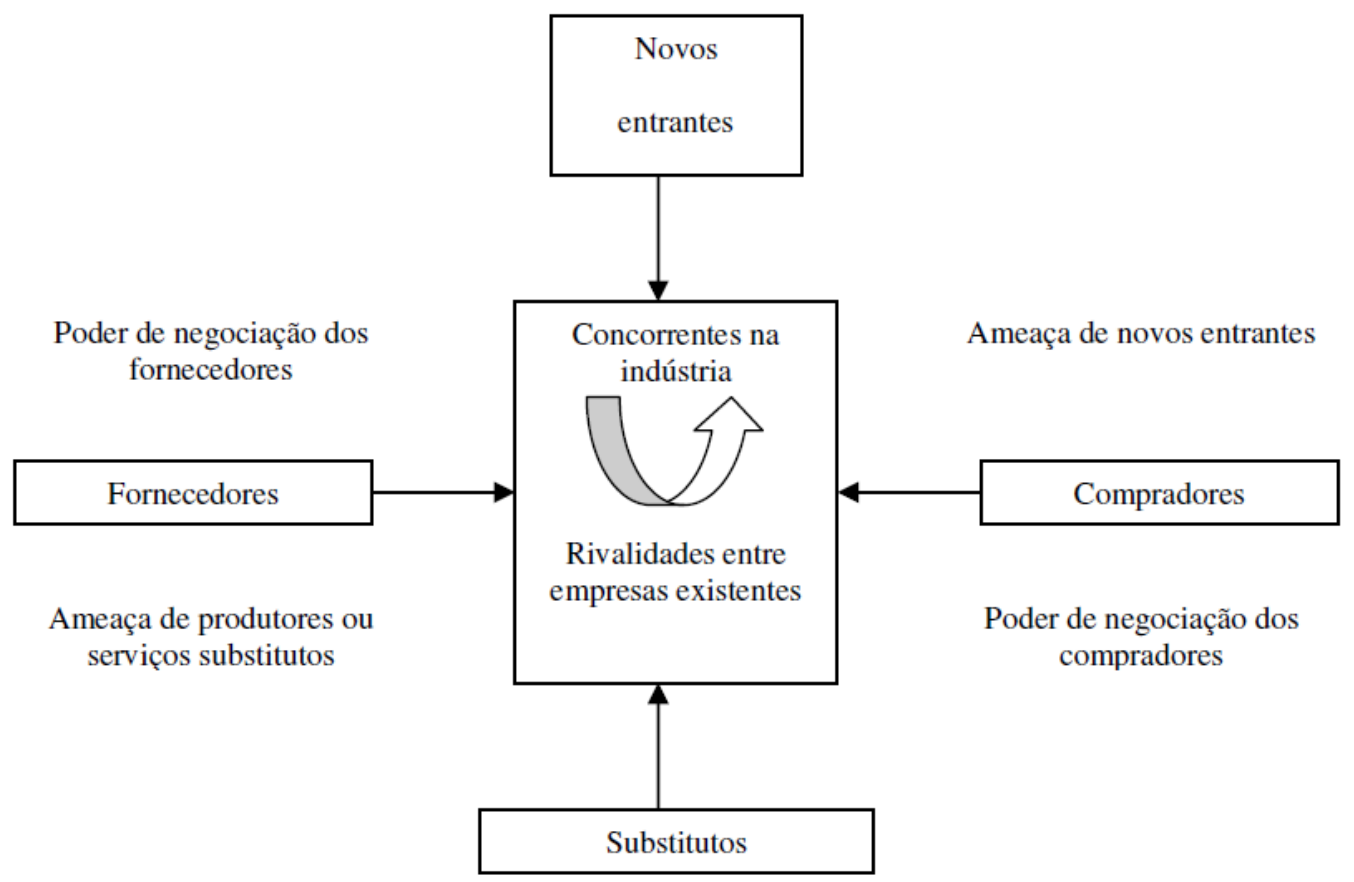

Fonte: Porter (1980)

\subsection{1}

\section{Ameaça de novos entrantes}

Refere-se ao grau de dificuldade encontrada por novos concorrentes que desejam entrar na indústria. Estes novos entrantes aumentam a competição dentro da indústria, podendo forçar os preços para baixo ou aumentar os custos das empresas já atuantes. Em ambos os casos, a lucratividade média da indústria é reduzida (PORTER, 1980).

Empresas já atuante na indústria visam à elevação de barreiras de entrada, como mecanismo de dificultar a entrada de novos participantes. Está barreira pode ser elevada através do uso de economia de escala, pelos altos custos de mudanças, pela diferenciação de produto, pela dificuldade de obter canais de distribuição ou pela alta necessidade de capital para iniciar as atividades neste mercado. Leis também atuam como barreira de entrada em situação que limitam o número de participantes ou em indústrias que são excessivamente reguladas. Por fim, outra 
forma de desencorajar novos entrantes é através de sinais que mostram possíveis retaliações contra novas empresas no setor. Potenciais entrantes podem se sentir influenciados ao saberem da possibilidade de retaliação de empresas já atuantes na indústria.

\subsection{2}

\section{Ameaça de produtos substitutos}

Refere-se ao grau em que os produtos e serviços oferecidos pela indústria podem ser substituídos por produtos e serviços de outras indústrias. Produtos substituídos limitam o potencial de rentabilidade limitando os preços em determinados patamares. Quanto mais atrativo for o preço e a performance de produtos substitutos, maiores são as chances de estes produtos serem vendidos (PORTER, 1980). A identificação por produtos substitutos se dá pela procura de produtos que desempenham a mesma função dos produtos da indústria em análise. Um exemplo de produtos substitutos enfrentados pelas companhias aéreas são as videoconferências. Uma vez que o consumidor opte por viajar a fim de estabelecer comunicação com contato visual, os serviços de videoconferência se tornam substitutos para a indústria de turismo, por preços consideravelmente inferiores.

\subsection{3}

\section{Rivalidade entre empresas existentes}

Empresas dentro de uma indústria estão em constante luta por melhores posições. A intensidade desta rivalidade é consequência da interação de inúmeros fatores, como: taxa de crescimento da indústria, concentração de empresas concorrentes, equilíbrio no porte e nos recursos, proporção nos custos fixos em relação ao valor agregado, nível do custo de mudança e intensidade das barreiras de entrada e saída (PORTER, 1980).

\subsection{4}

\section{Poder de barganha do fornecedor}

Fornecedores podem exercer pressões para o aumento dos preços, redução da qualidade ou negociar prazos e formas de pagamento. Fornecedores poderosos possuem grande poder de barganha nestas negociações. Realizando estas 
negociações, fornecedores modificam a estrutura das indústrias, sobre tudo alterando a rentabilidade média para as empresas. A quantidade de poder que os fornecedores possuem em uma negociação está condicionada a fatores como: concentração de fornecedores em relação às empresas compradoras, volume de compra das empresas, importância do fornecedor no produto final da empresa, diferenciação do fornecedor e à possibilidade do fornecedor se integrar para frente (PORTER, 1980).

\subsection{5}

\section{Poder de barganha do cliente}

Clientes pressionam a indústria pela redução de preços, por melhores qualidades ou por novos serviços oferecidos. O poder de barganha dos compradores é consequência da concentração de clientes em relação ao número de empresas, da importância do volume de compra dos consumidores, do custo de mudança, da possibilidade do cliente se integrar verticalmente para trás, da quantidade de informações que o cliente domina e por fim, da diferenciação do produto ofertado, incluindo a existência ou não de produtos substitutos (PORTER, 1980).

\section{2}

\section{Estratégia e vantagem competitiva}

De acordo com Chandler (1962), estratégia pode ser descrita como a definição tanto dos objetivos de longo prazo da empresa, quanto do curso das ações e da alocação de recursos para o atingimento desses objetivos. Já Para Mintzberg (1987), a estratégia é responsável por criar um padrão de ações dentro da organização, ou seja, uma consistência de comportamento.

Por outro lado, Foss (1996) entende estratégia como posicionar e administrar a empresa de modo a aumentar sua rentabilidade, protegendo-a de forças tanto do macro ambiente, quanto da indústria, e explorando e protegendo sua fonte de rentabilidade.

Em seu livro Estratégia Competitiva (1980), Porter afirma que estratégia é a busca por um posicionamento favorável dentro de uma indústria, tendo como 
objetivo, garantir uma posição rentável e sustentável perante as forças que determinam a competitividade desta indústria.

Na mesma linha de pensamento, Barney e Hesterly (2006) afirmam que o principal objetivo do planejamento estratégico é tornar possível que a estratégica da empresa gere vantagem competitiva. Estes mesmo autores definem vantagem competitiva como a capacidade de criar e oferecer maior valor econômico do que seus concorrentes. Valor econômico por ser entendido como os benefícios percebidos pelo consumidor, menos todos os custos agregados ao produto ou serviço (BARNEY e HESTERLY, 2006).

Segundo Barney (2006), conseguir uma vantagem competitiva não é o suficiente para garantir vantagens duradouras. É essencial que esta vantagem competitiva seja sustentável, isto é, garanta vantagens para a empresa por um longo período de tempo. Para que esta situação seja válida, Barney (2006) cita quatro condições: (1) deve ser diferente; (2) deve ser única entre concorrentes atuais e potenciais, (3) não pode ser imitável e (4) não deve utilizar conhecimento e mão-de-obra que possam ser copiados. A vantagem competitiva surge, afirma Porter (1985), do valor que uma empresa é capaz de criar para seus compradores, valor este que excede o custo da empresa em criá-lo. Valor é o que os compradores estão dispostos a pagar, e valor superior provém da oferta de preços inferiores aos dos concorrentes por benefícios equivalentes ou o fornecimento de benefícios únicos que mais do que compensam um preço superior. Porter (1980) classifica as vantagens competitivas em duas formas básicas: diferenciação ou liderança em custo.

Para entender de forma detalhada a real origem dessa vantagem competitiva, deve-se atentar para as atividades da empresa, sejam elas atividades de concepção de produto ou serviço, de produção, de marketing, de distribuição, de venda ou de suporte pós-venda. Todas estas atividades podem contribuir para a posição de custo ou de diferenciação da empresa, tornando-se origens de vantagem competitiva. 


\section{3}

\section{Tipologia de Porter}

De acordo com Porter (1980), empresas com estratégias definidas apresentam desempenho superior a empresas sem estratégia ou a empresas com estratégias inconsistentes. Porter desenvolveu estratégias genéricas para classificar as empresas em de sua tipologia, são elas: liderança em custo, diferenciação, enfoque em custos e enfoque em diferenciação. Além das quatro estratégias citadas, há as empresas classificadas como stuck-in-the-middle (sem posicionamento), que seriam as empresas que falharam em desenvolver umas das outras quatro estratégias descritas anteriormente, e por isso, carecem tanto uma estratégia claramente definida, bem como de consistência interna (DESS E DAVIS, 1984), apresentando, por isso, rendimentos abaixo da média da indústria (PORTER, 1980). Isso não significa que essas empresas não possuam atividades estratégicas típicas das estratégias genéricas citadas, apenas que essas empresas não seguem unicamente um padrão estratégico. As opções estratégicas criadas por Porter são explicadas de forma mais detalhadas abaixo:

- Liderança em Custo:

Para esta estratégia funcionar é imprescindível que a empresa possua custo total menor do que seus concorrentes. Essa vantagem em relação aos custos garante uma defesa perante pressões vindas de qualquer força da indústria, deixando a empresa em uma melhor posição (em relação aos seus concorrentes) para lidar com essas pressões (PORTER, 1980). Uma empresa nessa posição de custos possui maior fôlego para absorver pressões vinda dos fornecedores poderosos ou de uma possível guerra de preços dentro da indústria. Raciocínio semelhante se faz com outras pressões vindas de outras forças da indústria. (Silva, 1997).

- Diferenciação:

Nesta opção, o produto ou serviço pela empresa, é considerado único de forma extensiva pelo mercado. Não agrada apenas a um grupo ou segmento, pelo contrário, é reconhecido com único pelo mercado em geral (PORTER, 1980). 
Porter (1980) enfatiza a importância desta estratégia, tornando viável ganhos acima da média, criando uma posição defensável contra cópias ou pressões de outras forças do mercado, como fornecedores, clientes, concorrentes, novos entrantes ou produtos substitutos.

É importante citar, que para alguns autores (CARNEIRO, CAVALCANTI E SILVA, 1997, DESS \& DAVIS, 1984) e inclusive para o próprio Porter (1980), suas estratégias genéricas são consideradas, em alguns momentos, como apenas três, aglutinando enfoque em custo e enfoque em diferenciação como uma única estratégia denominada por enfoque. Dessa forma, seriam três estratégias possíveis (liderança em custo, diferenciação e enfoque), além da possibilidade da stuck-inthe-middle.

- Enfoque:

Esta estratégia está baseada na premissa de que empresas conseguem atender melhor um público-alvo mais segmentado do que ao mercado de forma ampla. Este mercado-alvo deve ser estreito o suficiente, de forma que a empresa que lhe atenda, consiga entender com profundidade suas necessidades e as características de demanda. Este mercado-alvo pode ser segmentado através de características demográficas, sociais, psicológicas ou geográficas. Conforme afirma Porter (1985), a indústria deve apresentar segmentos com necessidades específicas ou apresentar possibilidades de sistema de produção ou de entrega do produto que se diferencie dos demais sistemas de outros segmentos desta mesma indústria.

A opção estratégica de enfoque gera duas alternativas à empresa: (1) enfoque em custos, focando em obter vantagem competitiva no segmento de atuação, ou (2) enfoque em diferenciação, no qual se busca a diferenciação dentro desde mesmo segmento (PORTER, 1985).

- Stuck-in-the-middle:

Para Porter (1980), stuck-in-the-middle (expressão traduzida para o português como "meio-termo") não é considerada uma escolha estratégica e sim, a falta ou a inconsistência de uma estratégia. As empresas que procurassem posicionamento híbrido, ou que fracassassem na implementação de umas das 
estratégias genéricas, seriam assim classificadas (CARNEIRO et al., 1997). Devido à inconsistência estratégica ou à falta de ferramentas para competir nesta indústria, esta situação apresenta quadros de baixa rentabilidade, contemplando empresas com baixo market-share, baixa posição para investimentos e baixa diferenciação. Não raro, afirma Porter (1980), estas empresas ainda sofrem com problemas de cultura organizacional e por conflitos internos de cunho organizacional.

Figura 2 - Modelo das estratégias genéricas de Porter (1980)

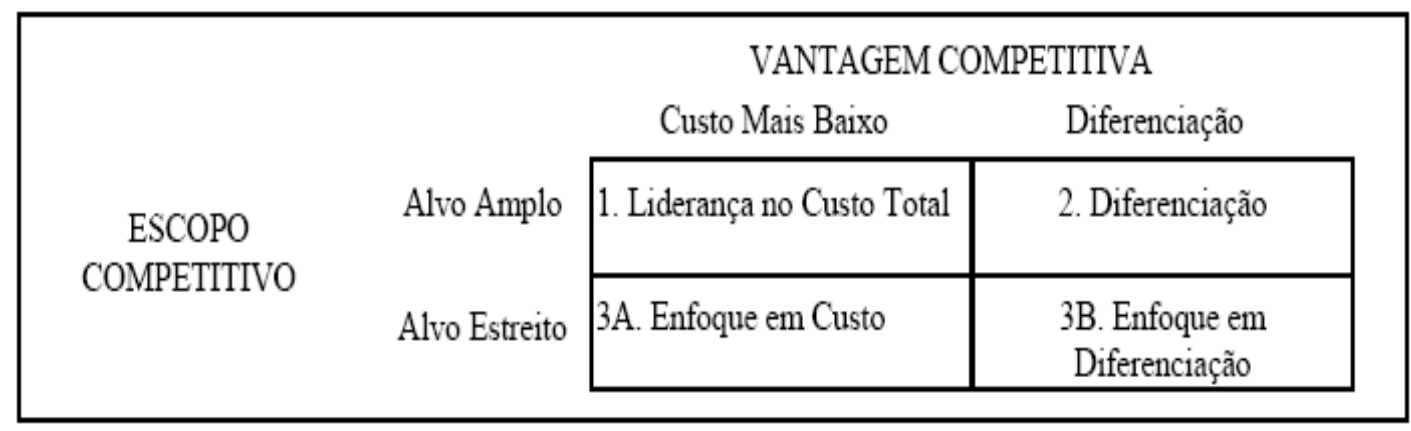

Fonte: Porter (1980)

\subsection{1}

\section{Riscos das estratégias genéricas}

De acordo com Porter (1980), existem dois riscos gerais, independentemente da escolha estratégica, que podem comprometer o desempenho da organização, são eles: fracasso na implementação ou na manutenção da estratégia; e desvalorização do valor entregue ao cliente, oriundo da vantagem competitiva de determinada organização, conforme a indústria evolui. Além desses riscos mencionados, Porter (1980) destaca que cada escolha estratégica possui seus riscos específicos, descritos abaixo:

\subsubsection{1}

\section{Riscos da estratégia em liderança em custo total}

- Mudanças tecnológicas que anulem investimentos realizados em redução de custo ou efeitos referentes à aprendizagem.

- Novos entrantes ou imitadores que consigam processos mais baratos.

- Extrema atenção em redução de custos deixando a organização míope a mudanças no mercado. 
- Inflação dos preços que não permitam a organização de manter os preços inferiores.

Tanto as mudanças tecnológicas, quanto os novos entrantes ou imitadores podem representar riscos para empresas que seguem esta opção estratégica. Mudanças tecnológicas, além de poderem anular benefícios oriundos da aprendizagem, podem anular investimentos realizados com o objetivo de reduzir custos, gerando a necessidade de novos investimentos. Novos entrantes ou imitadores, por sua vez, geram riscos com a possibilidade de desenvolverem processos com menor custo. Além desses riscos, empresas seguidoras desta estratégia devem ter atenção com o excesso de foco na redução de custo, ocasionando perda de visão sobre mudanças exigidas pelo mercado.

Por fim, empresas devem ter consciência do risco ocasionado pela possível inflação dos custos, refletindo em aumento dos preços. Esta inflação pode anular ou reduzir a vantagem na diferenciação por preço, tornando produtos de empresas seguidoras da estratégia de diferenciação mais atrativos.

\subsubsection{2}

\section{Riscos da estratégia de diferenciação}

- Diferença de preço entre competidores de baixo custo e de diferenciação que se torne grande o suficiente que não compense os diferencias do produto.

- Empresas imitando fatores de diferenciação

- Fator de diferenciação tornando-se desvalorizado pelos consumidores.

Três são os fatores de riscos específicos da estratégia da diferenciação. O primeiro fator de risco diz respeito à diferença entre o preço das empresas que buscam diferenciação e empresas de baixo custo. Quanto maior for esta diferença, mais os fatores de diferenciação devem ser atrativos para compensar os preços inferiores de organizações de baixo custo. O segundo risco da estratégia de diferenciação é gerado por empresas que consigam imitar atributos de diferenciação, fato comum em indústrias maduras. Por fim, o terceiro risco desta estratégia, diz respeito às mudanças no ambiente, tornando $\mathrm{o}$ fator de 
diferenciação algo não valorizado pelos consumidores. Empresas seguidoras desta estratégia devem estar atentas às mudanças do ambiente, estando aptas a adaptar seus fatores de diferenciação de acordo com novas exigências do mercado.

\subsubsection{3}

\section{Risco de estratégias baseadas em enfoque}

Um dos riscos sofridos por empresas que seguem estratégias baseadas em enfoque é que a diferença entre o custo de empresas que seguem estratégia de liderança em custo total e empresas que atuam de forma focada pode se tornar substancialmente grande, não compensando as vantagens de custo em servir um segmento específico ou não compensar a diferenciação de atuação em escopo estreito (PORTER, 1980).

Outro risco referente à estratégia baseada em enfoque pode ocorrer em caso de mudanças nos desejos dos consumidores, no qual suas exigências se aproximam das exigências do mercado como um todo, anulando a segmentação.

O terceiro risco desta opção estratégica é o fato de concorrentes que atuam de forma focada desenvolverem submercados, desfocalizando a organização.

\subsection{2}

\section{Críticas à tipologia de Porter}

Além das críticas feitas diretamente às estratégias de liderança em custo e de diferenciação, muitos autores (DESS e DAVIS, 1984; MILLER e DESS, 1993; HILL, 1988), possuem opiniões divergentes à de Michael Porter em relação à busca por ambas as estratégias simultaneamente. Porter (1980) afirma que apenas em algumas situações específicas a adoção de ambas as estratégias poderia gerar vantagem competitiva, apesar de afirmar que está vantagem não seria sustentável. Buscar implantar ambas estratégias simultaneamente geraria conflitos organizacionais, deixando a empresa como meio-termo (stuck-in-the-middle). Abaixo, as raras circunstâncias em que a implementação de ambas as estratégias poderia ser bem sucedida: 
- Quando todos os concorrentes estivessem competindo no meio-termo (Stuck-in-the-middle);

- Quando o custo fosse fortemente determinado pela parcela de mercado ou pelas inter-relações entre indústrias que um concorrente pode explorar e outros não;

- Quando a empresa fosse pioneira em uma inovação tecnológica importante e detivesse direitos exclusivos sobre ela.

Contudo, alguns autores (DESS \& DAVIS, 1984; MILLER \& DESS, 1993), identificaram empresas que obtiveram sucesso em suas respectivas indústrias utilizando estratégia de diferenciação e liderança em custo simultaneamente.

Faulkner e Bowman (1992) afirmam não existir argumento teórico que impossibilite o sucesso de ambas as estratégias sendo utilizadas simultaneamente, afirmando que atributos diferenciais do produto podem causar um aumento na participação de mercado, podendo gerar economias de escala e curva de experiência, ambas reduzindo o custo unitário.

\subsubsection{1}

\section{Críticas à liderança em custo total}

Mintzberg (1988) critica esta opção estratégica, uma vez que existindo paridade de preços e atributos semelhantes entre os produtos, a estratégia de possuir liderança em custos não garante uma vantagem competitiva sustentável, uma vez que o cliente não perceberia nenhuma diferença. Sendo assim, a empresa não conseguiria aumentar seu volume de venda, para adquirir economia de escala e experiência suficiente para manter-se como líder em custos. Carneiro, Cavalcanti e Silva (1997) consideram a afirmação duvidosa, pois em situação de paridade de preços, a empresa que deter menores custos, obterá maiores margens. Não havendo diferenças em relação ao ambiente competitivo, em suma, esta empresa obteria maiores lucros.

Outra crítica feita à estratégia de liderança em custo foi feita por Faulkner e Bowman (1992). Na prática, afirmam os autores, gerentes e pesquisadores associam, incorretamente, liderança em custo a atuação em segmento de baixos preços. Existe a possibilidade da adoção de tal estratégia em todos os segmentos de mercado, não se restringindo apenas ao segmento de menores preços. 
Por fim, há uma dificuldade na implementação de tal estratégia, devido à dificuldade de obter informações sobre o custo dos concorrentes, o que dificulta a compreensão do real líder em custo.

\subsubsection{2}

\section{Críticas à estratégia de diferenciação}

De acordo com o Carneiro, Cavalcanti e Silva (1997), a estratégia de diferenciação inclui uma série de opções estratégicas distintas, as quais necessitam estrutura e competência distintas, merecendo, dessa forma, ser destrinchada em novas estratégias mais detalhadas. Baseado no conceito de diferenciação, Henry Mintzberg (1988), além de criticar a insuficiência de detalhamento da tipologia de Porter, propôs uma nova tipologia de estratégias genéricas, consistindo em seis formas de diferenciação, sendo elas: por preço, por imagem, por suporte, por qualidade, por projeto e por fim, não diferenciação.

Além de Mintzberg, Kim e Lim (1988) também subdividiram a estratégia genérica de diferenciação em duas escolhas possíveis: diferenciação em produto e diferenciação em marketing. A primeira foca em atributos do produto em si, como atributos, funcionalidades e qualidade, enquanto a segunda opção foca em ações de marketing, como propaganda e níveis de serviços.

\section{4}

\section{Análise estrutural dentro da indústria}

Embora o conceito de grupos estratégicos tenha sido introduzido por Hunt (1972), foi no trabalho de Porter (1976) e posteriormente, no trabalho de Porter e Caves (1977) que o conceito ganhou força (DRAVONE, PETERAF \& SHANLEY, 1998). Para analisar uma indústria de forma mais profunda, afirma Porter (1980), deve-se identificar as estratégias seguidas pelos competidores relevantes desta indústria, permitindo a criação do mapa estratégico desta indústria com a formação de grupos de empresas que seguem estratégias semelhantes. Esta forma de análise está situada entre uma análise mais ampla da indústria, no qual se atenta para a estrutura desta indústria, e uma análise individual de cada empresa nela situada, no qual se estuda as estratégias de 
atuação das empresas. Esta forma de análise chama-se análise estrutural dentro da indústria ou análise de grupos estratégicos.

Por definição, grupos estratégicos são grupos que contém empresas que seguem estratégias semelhantes dentro de determinadas dimensões estratégicas (PORTER, 1980). Empresas do mesmo grupo estratégico tendem a sofrer impactos semelhantes de variáveis externas, assim como a movimentos estratégicos de concorrentes. Também tendem a se assemelhar-se em outras características, como tamanho da empresa, market-share e até mesmo, desempenho médio (PORTER, 1980).

O conceito de grupos estratégicos surgiu como uma ferramenta de análise que objetiva explicar a diferença de desempenho entre empresas de uma mesma indústria (SILVA, 1997). Uma vez percebido que grupos estratégicos apresentam desempenho superior do que outros grupos, e que empresas do mesmo grupo apresentam semelhança entre seus desempenhos, uma análise com profundidade intra-grupos se fez necessária, com o objetivo de identificar o que leva esses grupos a apresentarem melhores desempenhos do que outros grupos estratégicos.

Visto que determinados grupos estratégicos apresentam desempenhos diferentes, Caves e Porter (1977) citam a importância de entender as barreiras de mobilidade como um importante fator limitador da entrada de uma nova empresa em determinado grupo estratégico. Empresas que visam entrar em um determinado grupo estratégico costumam encontram determinadas barreiras, que geralmente são: presença de alta economia de escala, altos custos de mudança, diferenciação de produtos, vantagens de custos, difícil acesso aos canais de distribuição, alta necessidade de capital e variáveis políticas, que dificultam a entrada destas empresas em determinado grupo estratégico (PORTER, 1980). O nível de dificuldade para uma nova empresa entrar em um grupo estratégico varia de acordo com as dimensões estratégicas de cada grupo, isto é, cada grupo apresenta uma determinada intensidade de barreira de entrada e barreira de mobilidade.

Estas semelhanças entre as empresas dentro dos grupos estratégicos, isto é, a presença de semelhantes estratégias competitivas e de condições similares 
impostas pelo mercado, explicam, em parte, o desempenho semelhante entre empresas do mesmo grupo estratégico.

\subsection{1}

\section{Dimensões da estratégia competitiva}

O ambiente competitivo oferece um contexto geral para todas as empresas, porém, deve-se identificar razões para justificar porque determinadas empresas apresentam constantemente desempenhos superiores e como isto está relacionado com sua postura estratégica (PORTER, 1980).

Ainda de acordo com Porter (1980) as estratégias podem variar de inúmeras formas dentro de uma indústria, entretanto, analisando as dimensões estratégicas utilizadas pelas empresas, pode-se, então, identificar semelhanças e diferenças entre as estratégias competitivas adotadas pelas empresas. Cada estratégia genérica utiliza um determinado balanceamento das dimensões estratégicas, focando em certas dimensões, em detrimento de outras. Este balanceamento determina como a empresa irá competir no mercado.

Porter (1980) destaca 13 categorias de dimensões estratégicas, sendo elas: especialização, identificação de marca, push versus pull, seleção de canais de distribuição, qualidade do produto, liderança tecnológica, integração vertical, posição de custo, oferta de serviços, política de preço, grau de alavancagem, relacionamento com a matriz principal, relacionamento com instituições governamentais.

Para este trabalho, foram utilizadas as dimensões estratégicas que mais se adequam à indústria estudada, além de dimensões já utilizadas em trabalhos semelhantes (SILVA, 2007). As dimensões estratégicas utilizadas estão explicadas com detalhes no capítulo de metodologia, sendo elas: qualidade do produto, controle da distribuição, abrangência de atuação, quantidade de linhas de produtos, proporção de produtos presentes no segmento highprice, proporção de produtos presentes no segmento de entrada, serviços adicionais oferecidos, qualidade no serviço de pós-venda.

Sendo assim, através da análise de como as empresas utilizam as dimensões estratégicas estudadas, torna-se possível a identificação das estratégias seguidas 
pelas mesmas, viabilizando a formação dos grupos estratégicos, contendo as empresas com estratégias competitivas semelhantes.

A tabela 1 detalha as dimensões estratégicas utilizadas neste trabalho, assim como a sua forma de operacionalização.

Tabela 1 - Dimensões Estratégicas

\begin{tabular}{|l|l|l|}
\hline \multicolumn{1}{|c|}{ Dimensão } & \multicolumn{1}{|c|}{ Explicação } & \multicolumn{1}{c|}{ Operacionalização } \\
\hline $\begin{array}{l}\text { Qualidade do } \\
\text { Produto }\end{array}$ & $\begin{array}{l}\text { Grau de preocupação das empresas com a } \\
\text { qualidade do produto }\end{array}$ & $\begin{array}{l}\text { Variável definida como quantidade } \\
\text { de recalls realizados }\end{array}$ \\
\hline $\begin{array}{l}\text { Controle da } \\
\text { Distribuição }\end{array}$ & $\begin{array}{l}\text { Nível de controle da distribuição dos } \\
\text { veículos, caracterizando o grau de } \\
\text { descentralização de seus pontos de venda. }\end{array}$ & $\begin{array}{l}\text { Quantidade de concessionárias } \\
\text { próprias e Terceirizadas }\end{array}$ \\
\hline $\begin{array}{l}\text { Abrangência de } \\
\text { atuação }\end{array}$ & $\begin{array}{l}\text { Opção de segmentação geográfica de atuação } \\
\text { por unidade federativa. }\end{array}$ & $\begin{array}{l}\text { Definida como o número de } \\
\text { estados em que a empresa possui } \\
\text { atuação no Brasil }\end{array}$ \\
\hline $\begin{array}{l}\text { Linhas de produtos } \\
\text { Grau de diversificação de modelos distintos } \\
\text { comercializados }\end{array}$ & $\begin{array}{l}\text { Quantidade de modelos distintos } \\
\text { ofertados ao mercado }\end{array}$ \\
\hline $\begin{array}{l}\text { Proporção de } \\
\text { produtos presentes } \\
\text { no segmento } \\
\text { highprice }\end{array}$ & $\begin{array}{l}\text { Proporção da quantidade total de modelos } \\
\text { distintos, destinados a competir no segmento } \\
\text { highprice do mercado }\end{array}$ & $\begin{array}{l}\text { Percentual de modelos no } \\
\text { segmento highprice }\end{array}$ \\
\hline $\begin{array}{l}\text { Proporção de } \\
\text { produtos presentes } \\
\text { no segmento de } \\
\text { entrada }\end{array}$ & $\begin{array}{l}\text { Proporção da quantidade total de modelos } \\
\text { distintos, destinados a competir no segmento } \\
\text { de entrada do mercado }\end{array}$ & $\begin{array}{l}\text { Percentual de modelos no } \\
\text { segmento de entrada }\end{array}$ \\
\hline $\begin{array}{l}\text { Serviços adicionais } \\
\text { oferecidos }\end{array}$ & $\begin{array}{l}\text { Grau em que as montadoras oferecem } \\
\text { serviços extras, não enquadrados nos serviços } \\
\text { básicos oferecidos }\end{array}$ & $\begin{array}{l}\text { Quantidade de serviços adicionais } \\
\text { oferecidos que não se encontram } \\
\text { na oferta básica }\end{array}$ \\
\hline $\begin{array}{l}\text { Qualidade no servinvestimento na qualidade do } \\
\text { de pós-venda }\end{array}$ & Quantidade de recall realizado \\
\hline
\end{tabular}

\section{5}

\section{Desempenho}

O objetivo principal da estratégia competitiva é, além de garantir uma posição de defesa contra as pressões e ameaças do ambiente, garantir que esta posição esteja se refletindo em melhores resultados para a empresa. Contudo, ao analisar e mensurar desempenho nota-se a existência de uma grande variedade de técnicas disponíveis. Uma das formas sugerida por Barney (1996) consiste em relacionar o valor criado pela empresa com o valor esperado pelos acionistas. Nesta visão, o desempenho é visto como a comparação entre o valor produzido pelos ativos produtivos da empresa (incluindo pessoas) com o valor esperado 
pelos sócios. Este conceito, porém, não permite uma comparação objetiva entre empresas, pois está baseado em conceitos subjetivos e individuais de cada empresa.

Indicadores financeiros apresentam uma mensuração mais objetiva, enquanto índices de satisfação de stakeholders apresentam uma forma mais subjetiva de mensuração (CARNEIRO e SILVA, 2010). Índices mercadológicos, como market-share, também se apresentam como opção para avaliação de desempenho.

Apesar da notória preferência para indicadores financeiros para medir desempenhos (SILVA, 1997), este trabalho utilizará, além de indicadores financeiros já conhecidos, indicadores mercadológicos e de satisfação de stakeholders. Esta escolha se justifica pelo fato de tornar os resultados deste trabalho comparáveis com o trabalho realizado por Silva (2007), uma vez que este utilizou os mesmos indicadores de desempenho.

\subsection{1}

\section{Desempenho e ambiente competitivo}

De acordo com Barney (2006), durante muito tempo o foco dos estudos sobre a indústria se virou para tentar entender a relação entre o ambiente competitivo e o desempenho das empresas nele inserido. Os primeiros estudos que objetivaram entender a relação entre desempenho e ambiente competitivo tiveram origem na década de 30, nos conceitos de Organização Industrial, realizados para auxiliar o governo americano a detectar as indústrias que necessitavam de regulamentos para controlar a sua competitividade.

Os estudos realizados deram origem ao modelo teórico chamado de Structure-Condut-Performance (SCP), no qual o termo structure refere-se a estrutura de indústria, conduct refere-se a estratégia de uma empresa e performance está diretamente ligada ao desempenho tanto individual, quanto da indústria em geral. Neste modelo, o desempenho das empresas está diretamente condicionado a sua escolha estratégica, e esta, está condicionada a estrutura da indústria. Ou seja, os elementos da indústria servem como referência para a escolha estratégica (BARNEY, 1996). 
Em seus trabalhos, Porter (1980) acrescenta aos estudos de Organização Industrial, a sua visão de que as empresas afetam a estrutura da indústria através de suas estratégias, afetando assim, a natureza da competição. A natureza da competição se dá pela forma pela qual a competição é realizada, observando a concentração de empresas e o grau da barreira de entrada. Dessa forma, a estrutura da indústria molda a escolha estratégica das empresas, e esta escolha afeta o desempenho das empresas. A escolha estratégica também possui impacto sobre a estrutura indústria, que afeta a natureza da competição.

Figura 3 - Perspectiva neoclássica.

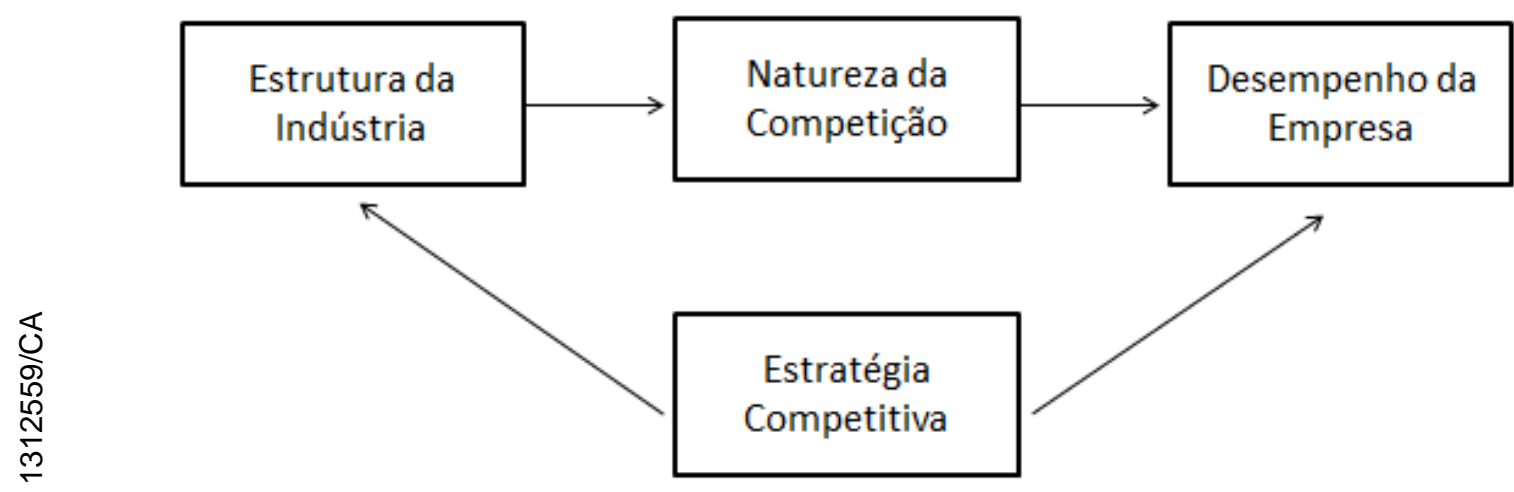

Fonte: Hill \& Deeds (1996)

Neste trabalho, para analisar como cada empresa é afetada por cada variável do ambiente competitivo, foi utilizada a abordagem neoclássica sugerida por Porter (1980), no qual se atenta à estrutura da indústria e à natureza da competição.

\subsection{2}

\section{Desempenho de grupos estratégicos}

É justamente na avaliação de desempenho que se justifica a formação de grupos estratégicos (SILVA, 1997). Diversos estudos (NEWMAN, 1973; CAVES e PORTER, 1977; DESS e DAVIS, 1984) dedicados à tentativa de se estabelecer uma relação grupos estratégicos-desempenho foram feitos, entre eles, destacam-se abaixo:

Newman (1973), utilizando a margem de contribuição como variável para medir o desempenho de grupos estratégicos, realizou um estudo na indústria de processamento químico para investigar a significância dos grupos estratégicos no 
desempenho. Dividindo a indústria em grupos homogêneos e heterogêneos, Newman (1973) concluiu que quanto maior a homogeneidade entre grupos estratégicos, maior o impacto positivo sobre o desempenho das empresas. Em contra partida, quanto maior for a heterogeneidade entre grupos de uma determinada indústria, menor é o impacto positivo nas empresas. Isso pode ser explicado, segundo a pesquisa, tanto pela congruência de objetivos (entre empresas do mesmo grupo estratégico), quanto por acordos tácitos entre essas empresas. Dessa forma, além de facilitar o alcance aos objetivos, também eleva as barreiras de mobilidade, dificultando a entrada de novas empresas neste grupo estratégico.

Outro estudo igualmente importante foi realizado por Caves e Porter (1977) no qual sugeriram que o impacto de grupos estratégicos no desempenho ocorre pela identificação de empresas com estratégias e diretrizes semelhantes, podendose desenvolver, assim, estratégias colaborativas de ganho mútuo entre elas, afetando positivamente o desempenho das mesmas.

Trabalho semelhante foi realizado por Dess e Davis (1984), o qual tinha por objetivo validar o conceito explicativo dos grupos estratégicos sobre a variação de rentabilidade média dentro de uma indústria. Os grupos estratégicos foram formados através da percepção de semelhança entre as estratégias intencionais das empresas, analisando suas respectivas dimensões estratégicas, utilizando tanto os conceitos, quanto a tipologia de estratégias genéricas de Porter (1980). Como resultado, este estudo expos que empresas pertencentes aos grupos apresentam melhores resultados do que as empresas não pertencentes a grupos estratégicos.

Por outro lado, é igualmente importante citar estudos que apresentaram incongruência na tentativa de estabelecer a relação grupos estratégicosdesempenho, dentre eles Fiegenbaum (1987) ressaltou a importância das variáveis escolhidas para operacionalizar o desempenho, enquanto Cool e Schendel (1987) destacaram que a pesquisa deve contemplar as empresas individualmente e não o grupo estratégico em si. 


\section{3 \\ A indústria automobilística brasileira}

\section{1}

\section{Histórico e evolução}

A indústria automobilística brasileira começou em 1919, marcada pelo início das operações da Ford no país, com sua primeira fábrica que realizava a montagem do clássico Ford T. Seis anos depois, foi a vez da General Motors se instalar no país. Apesar da chegada de duas grandes fabricantes americanas, a indústria de autopeças brasileira se resumia a um pequeno número de fábricas de pneus, mangueiras, molas e baterias, exigindo a importação de grande parte dos materiais utilizados. De acordo com a revista Quatro Rodas (2012), este cenário se configurou até a chegada da segunda guerra mundial, no qual o Brasil apresentava uma frota envelhecida, uma vez que as principais montadoras americanas focaram seus esforços em fabricações de automóveis militares. Este fato fez com que o mercado brasileiro suprisse a demanda por peças de reposição, incentivando o desenvolvimento da indústria de autopeças nacional.

No período pós-guerra, até aproximadamente o ano de 1952, o Brasil passou a importar grande parte da sua necessidade interna de automóveis. Até que, em 1952, sob o governo de Vargas, ocorreu um importante ato: a limitação da importação de autopeças e a proibição da importação de veículos completamente acabados.

Até o ano de 1956, só existiam no Brasil montadoras de automóveis, não havendo fabricação de peças no país. Dessa forma, as peças dos veículos eram importadas e apenas a montagem ocorria em solo nacional. Este fato perdurou até que o então presidente da república Juscelino Kubitschek formalizou a criação do grupo Geia - Grupo dos Executivos da Indústria Automobilística - com o objetivo de estimular a fabricação local. Através de benefícios e incentivos, a intenção do governo era fazer com que as fabricantes internacionais que se instalassem e produzissem automóveis em solo nacional. Neste mesmo ano, Juscelino Kubitschek instituiu um plano que restringia as importações e obrigava as 
montadoras transnacionais a optarem entre abandonar o mercado brasileiro ou que se comprometessem em um prazo de cinco anos, a fabricar veículos que contivessem de 90 a 95\% de peças produzidas em solos nacionais (SHAPIRO, HELEN. In: ARBIX \& ZILBOVICIUS, 1997, p.24).

Apesar de tais ações do governo, o início da década de 60 foi marcado por uma forte desaceleração da taxa de crescimento e forte aumento da taxa de inflação. A instabilidade política e os problemas econômicos contribuíram para um forte impacto na indústria automobilística brasileira, gerando uma crise que só acabaria no final da década.

No final da mesma década, sob comando dos militares, o governo adotou uma série de medida que contribuíram para a retirada desta indústria da crise, entre elas, medidas que possibilitavam créditos mais fáceis ao consumidor para o financiamento do automóvel. Em 1969, o crescimento da indústria já era de $34,5 \%$ maior do que no ano anterior. Outra medida importante tomada pelo governo foi o incentivo às exportações, medida que contribuiu para o aumento da produção nacional e para equilibrar a balança comercial nos anos seguintes. Em 1978 a produção anual ultrapassou a marca de um milhão de veículos, deixando o Brasil entre os dez maiores produtores do mundo (ANFAVEA, 2007).

A década de 80 foi marcada por uma forte crise na economia brasileira, afetando duramente a indústria automobilística. O elevado uso de capital estrangeiro, utilizado para financiar o desenvolvimento do país nas décadas anteriores, gerou altos níveis de endividamento externo, o que dificultou o país de conseguir novos empréstimos com países desenvolvidos. Outro fator que dificultou de novos empréstimos, foi a crise do petróleo, ocorrida na década anterior, que abalou fortemente as economias internacionais. O cenário interno do país era marcado pela superinflação. Como resultado deste cenário, as vendas internas de automóveis caem 43,5\%, número que representa pouco mais da metade de unidades vendidas no ano de 1979 (GUIMARÃES, 1989). No final desta década, a concentração de fabricantes se resumia a: Ford, Volkswagen, General Motors, Fiat, Mercedes-Benz, Toyota, e Volvo. Além da baixa atratividade do setor, altas barreiras de entrada oriundas da proteção comercial impediam a entrada de veículos importados no país.

A década seguinte foi marcada pela ascensão de ideias neoliberais, que defendiam a limitação da intervenção do Estado na Economia, propondo a total 
liberdade às leis do mercado, privatizações de estatais, abertura comercial, liberdade de ações aos capitais internacionais e a eliminação de medidas protecionistas. Tais medidas incentivariam a concorrência perfeita, aumentando assim, a produtividade do setor (QUATRO RODAS, 2012).

Essas ideias se fortaleceram com a abertura comercial decretada pelo então presidente da República Fernando Collor, fazendo com que as empresas aqui estabelecidas, tivessem que concorrer diretamente com os novos produtos importados, muitos deles, superiores tecnologicamente e sendo produzidos a um custo menor (QUATRO RODAS, 2012). Sem qualquer mecanismo de defesa e nenhum preparo feito por parte das empresas nacionais, esta nova estrutura de mercado exigiu uma reformulação completa das empresas nacionais. Durante o período em que as importações ficaram proibidas ou restringidas, afirma Botelho (2002), as empresas de mercado não se preocupavam com a qualidade dos produtos nem com preços, apoiavam seus padrões de organização do trabalho no taylorismo/fordismo, a baixa produtividade, baixa qualidade de produtos, baixo nível de automação da produção, conflitos na cadeia produtiva, conflitos com os trabalhadores e produtos antigos e ultrapassados, este era o cenário da indústria automobilística.

A década de 90 e a primeira década de 2000 demarcaram mudanças na estrutura de mercado, exigindo das empresas aqui estabelecidas mudanças imediatas para concorrerem em igualdade com as empresas que aqui aportaram. Estas mudanças, segundo Silva (2007), se caracterizaram em estratégias que priorizavam o relacionamento com o consumidor, automação de processos produtivos, investimento em mão de obra qualificada e adoção de novas práticas de gestão. Observando a expansão do mercado automobilístico brasileiro, novos entrantes passaram a investir no setor, principalmente investindo em produção solo nacional, sendo elas: Honda (1997), Mitsubishi (1998), Toyota (1998), Mercedes-Benz (1999), Renault (1999), PSA (Peugeot-Citroën - 2001) e Nissan (2002). Alguns anos depois, especialmente a partir de 2004, observou-se a entrada de fabricantes asiáticos no mercado brasileiro, principalmente oriundos da China, Coréia do sul e Índia. 


\section{2}

\section{Estratégias usadas pelas empresas dessa indústria}

Silva (2007) realizou um estudo com a intenção de analisar as estratégias de vinte montadoras de automóveis no mercado brasileiro, utilizando dados de 2001 a 2006. Para definir em qual grupo estratégico cada empresa estaria situada, o autor utilizou dez dimensões estratégicas, são elas: política de preço, foco, diversificação da linha de produto, assistência técnica, credibilidade da marca, propaganda, melhor compra, canais de distribuição, produtos em segmentos high price e produtos em segmento de entrada.

A classificação das empresas em seus respectivos grupos estratégicos está disposta na tabela 2:

Tabela 2 - Grupos estratégicos das montadoras de automóveis.

\begin{tabular}{|c|c|}
\hline Grupo Estratégico & Empresa \\
\hline Liderança através do Custo & $\begin{array}{l}\text { FIAT AUTOMÓVEIS S.A. } \\
\text { FORD MOTOR COMPANY BRASIL } \\
\text { GENERAL MOTORS DO BRASIL LTDA } \\
\text { RENAULT DO BRASIL S.A. } \\
\text { VOLKSWAGEN DO BRASIL LTDA } \\
\text { DAIMLER-CHRYSLER }\end{array}$ \\
\hline Liderança através da Diferenciação & $\begin{array}{l}\text { HONDA AUTOMÓVEIS DO BRASIL LTDA } \\
\text { TOYOTA DO BRASIL LTDA }\end{array}$ \\
\hline Enfoque em Custo & $\begin{array}{l}\text { MMC AUTOMOTORES DO BRASIL S.A. } \\
\text { PEUGEOT CITROEN DO BRASIL S.A. } \\
\text { CITROEN } \\
\text { KIA } \\
\text { SSANGYOUNG }\end{array}$ \\
\hline Enfoque em Diferenciação & $\begin{array}{l}\text { BMW } \\
\text { FERRARRI } \\
\text { PORSCHE } \\
\text { MASERATI }\end{array}$ \\
\hline Stuck-in-the-middle & $\begin{array}{l}\text { LAND ROVER DO BRASIL LTDA } \\
\text { NISSAN DO BRASIL AUTOMÓVEIS LTDA } \\
\text { AUDI DO BRASIL LTDA }\end{array}$ \\
\hline
\end{tabular}

Fonte: Silva, 2007

Em seu estudo, Silva (2007) concluiu que das vinte montadoras analisadas, apenas três (Land Rover, Nissan e Audi) foram classificadas como stuck-in-themiddle, ou seja, sem padrão estratégico ou com estratégia inconsistente. As 
dezessete empresas restantes, formaram quatro diferentes grupos estratégicos. Como liderança através do custo total, percebemos a presença da Fiat, Ford, General Motors, Volkswagen, Renault e Daimler-Chrysler. É importante ressaltar que este grupo estratégico foi considerado como de melhor desempenho na indústria, considerando-se as seguintes variáveis de desempenho: market-share, market-share por segmento, crescimento de market-share, receita bruta, preço médio e satisfação de cliente.

O grupo das empresas com estratégia em diferenciação foi formado pelas japonesas, Honda e Toyota. Este grupo apresentou o segundo melhor desempenho na indústria,

Já o terceiro grupo estratégico, das empresas que buscam a liderança através de enfoque em custo, foi formado pelas empresas MMC Automotores, Peugeot, Citroen, Kia e SsyanYoung. Em relação às variáveis de desempenho, este grupo apresentou resultados medianos, se destacando negativamente como pior grupo em satisfação com o cliente.

O grupo que enfoca em diferenciação, formado por BMW, Ferrari, Porsche e Maserati, é caracterizado pelo luxo e pelos altos investimentos em qualidade e tecnologia. Como já esperado, obteve resultados aquém da média nas variáveis de market-share, preço médio e receita bruta. Porém, este grupo obteve melhores resultados na variável satisfação do consumidor.

Por fim, o grupo formado pelas empresas classificadas como stuck-in-themiddle, formado por Land Rover, Nissan e Audi, obtiveram, de forma geral, resultados inconsistentes e aquém das médias, com exceção da variável satisfação dos consumidores, a qual teve resultado apenas mediano. Estes fracos resultados nas variáveis analisadas estão de acordo com a expectativa para este grupo estratégico, sendo consequência de estratégias inconsistentes seguidas por estas empresas (SILVA, 2007).

\section{3}

\section{Indústria automobilística na atualidade}

De acordo com dados levantados pela Associação Brasileira das Empresas Importadoras de Veículos Automotores (ABEIVA), o Brasil possui o quarto maior mercado mundial em quantidade de automóveis comercializados. Em 2012, o país comercializou 3.634.639 automóveis, apresentando um aumentando de 
$6,11 \%$ em relação ao ano anterior. A tabela 3 mostra o volume comercializado pelos oito países com maiores quantidades de automóveis comercializados nos últimos anos.

Tabela 3 - Total de veículos comercializados - (em milhares).

\begin{tabular}{|c|c|c|c|c|c|c|c|c|c|c|c|c|}
\hline & País & 2012 & & 2011 & & 2010 & & 2009 & & 2008 & & 2007 \\
\hline 10 & China & 16.366 & $1^{o}$ & 15.237 & $1^{\circ}$ & 14.834 & $2^{\circ}$ & 9.848 & $2^{\circ}$ & 6.492 & $2^{\circ}$ & 6.072 \\
\hline 20 & EUA & 14.492 & $2^{\circ}$ & 12.778 & $2^{\circ}$ & 11.589 & $1^{\circ}$ & 10.418 & $\mathbf{1}^{\mathrm{o}}$ & 13.221 & $1^{\circ}$ & 16.122 \\
\hline 3응 & Japão & 5.320 & $3^{\circ}$ & 4.170 & $3^{\circ}$ & 4.919 & $3^{\circ}$ & 4.577 & $3^{\circ}$ & 5.032 & $2^{\circ}$ & 5.297 \\
\hline 4음 & Brasil & 3.634 & $4^{\circ}$ & 3.425 & $4^{\circ}$ & 3.328 & $5^{\circ}$ & 3.011 & $6^{\circ}$ & 2.670 & $9^{\circ}$ & 2.338 \\
\hline 5은 & Alem & 3.298 & $5^{\circ}$ & 3.403 & 50 & 3.109 & $4^{\circ}$ & 3.982 & $4^{\circ}$ & 3.318 & $4^{\circ}$ & 3.374 \\
\hline 6o & Índia & 3.093 & $6^{\circ}$ & 2.802 & $\mathbf{7}^{\circ}$ & 2.640 & $9^{\circ}$ & 1.967 & $10^{\circ}$ & 1.675 & $12^{\circ}$ & 1.6524 \\
\hline 70 & Rússia & 2.935 & $7^{\circ}$ & 2.653 & $10^{\circ}$ & 1.910 & $10^{\circ}$ & 1.465 & $\mathbf{5}^{\circ}$ & 2.925 & $7^{\circ}$ & 2.561 \\
\hline 80 & Grã-Bretanha & 2.284 & $\mathbf{8}^{\circ}$ & 2.201 & $8^{\circ}$ & 2.253 & $\mathbf{8}^{\circ}$ & 2.181 & $8^{\circ}$ & 2.421 & $5^{\circ}$ & 2.741 \\
\hline
\end{tabular}

Fonte: ABEIVA, 2012

Segundo o relatório anual de 2012 da Federação Nacional da Distribuição de Veículos Automotores (FENABRAVE, 2012), pode-se considerar como um dos principais fatores incentivadores desde aumento, o anúncio do Governo Federal sobre redução do IPI para automóveis produzidos e vendidos no país. Este ato foi refletido em níveis menores de preços, resultando no aumento do volume de vendas das montadoras. Em contrapartida, destaca-se o aumento do nível de inadimplência da população brasileira, causando atitudes conservadoras na cessão de crédito por parte dos bancos, fato que impediu um crescimento ainda maior do setor.

Outro importante movimento que vem ocorrendo no setor automobilístico desde o início de 2000 é a constante expansão da classe média brasileira. De acordo com dados revelados pela Secretaria de Assuntos Estratégicos (SAE) da Presidência da República, trinta e cinco milhões de pessoas ascenderam à classe média na última década, composta atualmente por 104 milhões de pessoas. Como mensuração de classe média, este estudo utilizou a renda média familiar per capita variando entre $R$ \$ 291,00 e R\$ 1.019 por mês. Ainda de acordo com informações da SAE, a classe alta, por sua vez, também constatou crescimento, correspondendo atualmente por $20 \%$ da população brasileira.

Desta forma, a partir de 2000, grandes mudanças em fatores econômicos e demográficos, além de incentivos do governo contribuíram para o 
desenvolvimento e crescimento da indústria automobilística no Brasil. Este crescimento do mercado despertou o interesse de novas empresas, até então, ausentes no mercado brasileiro. Até a presente data, existem mais de quarenta diferentes marcas de automóveis operando no mercado nacional, variando em origem, posicionamento e estratégia. Percebemos, na última década, a entrada de uma série de novas empresas de origem distintas: japonesas (Lexus e Infiniti), chinesas (Chery, JAC Motors e Lifan), alemães (MINI e Smart) e italianas (Maserati e Lamborghini). Além de novos entrantes, também foi possível notar muitas empresas construindo fábricas em território nacional. Muitas empresas aumentaram sua capacidade produtiva, como a Honda, construindo a sua segunda fábrica no interior de São Paulo e a Toyota, construindo uma nova fábrica na cidade de Sorocaba, São Paulo. Outras empresas voltaram ou passaram a produzir seus automóveis em território brasileiro pela primeira fez, como é o caso da Mercedes-Benz, voltando a ter fábrica no Brasil e os casos da BMW e Hyundai, inaugurando suas produções no país, a primeira no estado de Santa Catarina e a segunda, em Piracicaba, São Paulo.

Outra importante mudança que vem afetando a indústria automotiva brasileira é a constante preocupação com questões relacionadas à preservação do meio ambiente. De acordo com o relatório de anual realizado pela CNI Confederação Nacional das Indústrias, publicado em 2012, pressões da sociedade tanto por processos produtivos, quanto por produtos mais sustentáveis forçaram as empresas a pensarem em fonte de energias alternativas (em especial o etanol), automóveis mais eficientes em relação ao consumo, planos de desenvolvimento de fontes neutras de gás carbônico. Além de pressões sofridas pela sociedade, o governo, com leis voltadas para sustentabilidade, exige que novos automóveis reduzam suas emissões de monóxido de carbono, óxido de nitrogênio, hidrocarbonetos, aldeídos totais e material particulado, para limites estipulados (CONFEDERAÇÃO NACIONAL DAS INDÚSTRIAS, 2012). Dados apresentados pelo ANFAVEA (2012), afirmam que um automóvel em 2011 emite 28 vezes menos que um automóvel produzido na década de 80 . 


\section{4}

\section{Análise das Cinco Forças na indústria atual}

Conforme analisado na situação da indústria atual, o entendimento do macro ambiente e suas mudanças, se torna fundamental para que as montadoras consigam se adaptar as mudanças exigidas nesta indústria. Utilizando o modelo das cinco forças de Porter para identificar as forças e entender a intensidades das mesmas sobre a indústria, pode-se perceber as seguintes características:

O grau de rivalidade, ao ser analisado pela concentração de concorrentes, pelo grau de diferenciação de produtos, pelo custo de mudança do consumidor e pela taxa de crescimento do mercado, se mostra com intensidade mediana. O mercado, ainda que em expansão, conta com mais de quarenta empresas atuando, algumas delas, não possuindo grandes diferenciais em seus produtos, o que torna a rivalidade ainda mais intensa. Além disso, de acordo com pesquisas realizadas pela revista Quatro Rodas, o custo de mudança do consumidor não é mais elevado quanto em costumava ser. Porém, o atributo marca ainda é algo valorizado pelos clientes, reduzindo a disputa entre marcas que compitam diretamente, reduzindo a rivalidade da indústria como um todo.

Já a pressão realizada por clientes, se mostra mediana. Considerando que a grande concentração de empresas gera opções de escolha para esta cliente, este variado número de opções faz o cliente ganhar barganha na negociação, principalmente em segmentos onde não há grandes diferenciais de produto. Outro fator importante a ser analisado, é o impacto da compra para o consumidor. No geral, um veículo é uma aquisição impactante no orçamento do cliente, fazendo com que este se esforce em negociações com o ofertante. $\mathrm{O}$ fácil acesso às informações, tanto de produto, quanto de mercado, mune o cliente de armas para negociar com os ofertantes. Porém, em segmentos de massa, mesmo havendo alguma diferenciação de produto, o mercado é tão extenso, que reduz este poder de barganha do consumidor. Neste mercado, a compra individual deste cliente não possui grande impacto para essas montadoras, que operam com baixas margens, mas focam em altas escalas de venda.

Já em segmentos no qual a diferenciação de produtos está presente, a venda costuma possuir maior impacto para as montadoras, aumentando, assim, o poder de barganha do consumidor. Por outro lado, se a empresa possuir diferenciais 
raros de serem encontrados, estes podem ser um fator a reduzir o poder de barganha do consumidor.

A força exercida pelos fornecedores nesta indústria é considerada baixa. Além de se apresentarem em altíssimo número, as montadoras não possuem grandes custos de mudanças em relação ao seu fornecedor. Além disso, o volume de compra destas montadoras lhe permite ter poder nestas negociações. De forma geral, contratos de fornecimentos para grandes montadoras são extremamente impactantes para os fornecedores, fator que agrega ainda mais poder às montadoras. É importante salientar que para alguns casos em que os fornecedores ofereçam peças que sejam de alto valor ou que sejam fontes de diferenciação para as montadoras, podem possuir o poder de barganha mais favorável, como é o caso de fornecedores de motor para carros esportivos.

A ameaça de novos entrantes na indústria automobilística brasileira se tornou real, com os incentivos apresentados pelo Governo Federal, e pela situação atual de mercado. Porém, mesmo se apresentando como um mercado convidativo, existem algumas barreiras que podem frear o surgimento de novos entrantes. $\mathrm{O}$ alto investimento inicial, a necessidade de economia de escala (exceto para nichos) e o fator marca, como sendo um fator decisivo na compra, dificultam a entrada de novos entrantes. A ameaça de novos entrantes no mercado brasileiro foi considerada mediana.

Por fim, a ameaça de produtos substitutos aparenta ser média, uma vez que há a opção de transporte público, através de ônibus, metrô e trem, e opções de outros tipos de transporte, como a moto, a bicicleta elétrica e a bicicleta convencional. Cada produto substituto possui a sua desvantagem, seja na comodidade, na segurança, na distância percorrida ou no fator tempo. Porém, fatores como o trânsito dos centros urbanos, pressões contra o consumo e pressões por comportamentos mais ecológicos, vem pressionando a indústria, em pró da utilização dos produtos substitutos.

Desta forma, a indústria automobilística brasileira apresenta forças medianas na rivalidade entre concorrentes, ameaça de novos entrantes, poder de barganha de cliente e em produtos substitutos. A força que mede o poder de barganha do fornecedor se mostrou baixa, não causando impactos negativos na rentabilidade da indústria. Segundo Porter (1980), podemos considerar esta indústria como atrativa, pois, de forma geral, não há nenhuma das forças 
pressionando a rentabilidade média. As empresas devem analisar qual das forças se apresenta mais impactante para o seu negócio e através de sua estratégia competitiva, buscar posições que garantam defesas contra esta força de maior impacto. 
4

\section{Método de Pesquisa}

\section{1}

\section{Seleção de universo, amostra e sujeitos}

O universo da pesquisa compreende todos os fabricantes e montadoras de automóveis destinados ao transporte pessoal - classificado como "auto" pela FENABRAVE- que comercializam seus produtos no mercado brasileiro através de concessionárias, totalizando trinta empresas. Esta pesquisa não inclui as categorias de comerciais leves, motos, ônibus, caminhões ou qualquer outra categoria de automóvel. Uma vez que este estudo utilizou dados de 2007 a 2012, empresas que finalizaram ou iniciaram suas atividades a partir de 2007, foram excluídas do universo da pesquisa.

O número de montadoras que se enquadram na amostra de pesquisa é de 30 empresas, correspondendo exatamente ao universo da pesquisa. Estas trinta empresas representam aproximadamente a totalidade das vendas de automóveis no Brasil. A tabela 4 apresenta as empresas estudadas: 
Tabela 4 - Empresas contidas na amostra

\begin{tabular}{|c|c|}
\hline Id. & Empresa \\
\hline 1 & AUDI DO BRASIL LTDA \\
\hline 2 & BMW DO BRASIL LTDA \\
\hline 3 & CHERY BRASIL FABRICAÇÃO E IMPORTAÇÃO DE VEÍCULOS LTDA \\
\hline 4 & CHRYSLER \\
\hline 5 & DODGE \\
\hline 6 & FERARRI \\
\hline 7 & FIAT AUTOMÓVEIS S.A. \\
\hline 8 & FORD MOTOR COMPANY BRASIL \\
\hline 9 & GENERAL MOTORS DO BRASIL LTDA \\
\hline 10 & HONDA AUTOMÓVEIS DO BRASIL LTDA \\
\hline 11 & HYUNDAI MOTOR BRASIL LTDA \\
\hline 12 & JAGUAR \\
\hline 13 & JEEP \\
\hline 14 & KIA MOTORS DO BRASIL LTDA \\
\hline 15 & LAMBORGHINI \\
\hline 16 & LAND ROVER DO BRASIL LTDA \\
\hline 17 & MERCEDES BENZ DO BRASIL LTDA \\
\hline 18 & MMC AUTOMOTORES DO BRASIL S.A. \\
\hline 19 & NISSAN DO BRASIL AUTOMÓVEIS LTDA \\
\hline 20 & PEUGEOT CITROEN DO BRASIL LTDA (CITROEN) \\
\hline 21 & PEUGEOT CITROEN DO BRASIL LTDA (PEUGEOT) \\
\hline 22 & PORSCHE \\
\hline 23 & RENAULT DO BRASIL S.A. \\
\hline 24 & SSANGYOUNG \\
\hline 25 & SUBARU \\
\hline 26 & SUZUKI VEÍCULOS BRASIL LTDA \\
\hline 27 & TOYOTA DO BRASIL LTDA \\
\hline 28 & TROLLER \\
\hline 29 & VOLKSWAGEN DO BRASIL LTDA \\
\hline 30 & VOLVO DO BRASIL VEÍCULOS LTDA \\
\hline
\end{tabular}

\section{2}

\section{Coleta de dados}

Os dados foram coletados através de fontes de dados secundários, tendo como principais fontes: websites das montadoras, revistas especializadas (Quatro Rodas), anuários de associações e federações (ABEIFA, ANFAVEA e FENABRAVE), revistas (Exame), jornal (Folha de São Paulo) e por fim ,em 
website de empresas especializadas em pesquisas (Ibope). Todas as pesquisas contemplaram edições e anuários dentro do período estudado - 2007 a 2012.

Para dados qualitativos, foram consideradas pesquisas anuais de opiniões realizadas pela revista Quatro Rodas, com o intuito de identificar percepções dos proprietários sobre os seus automóveis.

\subsection{1}

\section{Seleção das variáveis de estratégia competitiva}

Com base nas dimensões da estratégia competitiva apresentadas por Porter (1980) e, principalmente, em dimensões utilizadas em estudo semelhante realizado por Silva (2007) sobre esta indústria, foram definidas as dimensões estratégicas utilizadas para a classificação das empresas em seus respectivos grupos estratégicos, descritas a seguir:

\subsubsection{1}

\section{Qualidade}

Variável definida como quantidade de recalls realizados no período entre 2007 e 2012. Esta variável pretende apontar as empresas que apresentam processos produtivos menos falhos, usando o número de recalls coo uma proxy. Assim, empresas com menor número de recalls apresentariam maior qualidade.

Esta variável foi coletada observando os principais meios de informações utilizados pelas companhias para informar aos seus clientes a necessidade da realização de recalls. Os principais meios utilizados foram jornais de grande amplitude de atuação, como a Folha de São Paulo, e os próprios sites das empresas analisadas.

\subsubsection{2}

\section{Canais de distribuição}

Variável que apresenta o nível de capilaridade da empresa via canais de distribuição, sendo caracterizada pelo grau de descentralização de seus pontos de venda. Esta variável pretende identificar as empresas que possuem maior controle sobre sua distribuição. Para coletar dados sobre esta variável, foi observado o 
número de pontos de vendas de cada montadora, disponibilizados em seus respectivos websites.

\subsubsection{3}

\section{Qualidade no serviço de pós-venda}

Variável definida como a qualidade dos serviços pós-venda oferecido pelas empresas. Para mensurar esta variável, foram analisados: disponibilidade de peças, prazo de realização do serviço, qualidade do atendimento, pontualidade, transparência, relação custo-benefício, qualidade do trabalho executado e preço da mão-de-obra. Esta variável foi coletada através de pesquisas realizadas pela revista especializada Quatro-Rodas, a qual realiza pesquisas anuais com consumidores dos automóveis. Esta variável busca entender como as empresas estão orientadas em oferecer o serviço pós-venda como parte de suas respectivas estratégias competitivas.

\subsubsection{4}

\section{Produtos no segmento high price}

Quantidade de modelos distintos ofertados pelas montadoras dentro do segmento de luxo. Estes modelos apresentam alto desempenho, associado ao alto valor agregado e a altos preços. Para ser classificado como highprice, o modelo deve possuir preço de venda ao consumidor final superior a $\mathrm{R} \$ 90.000,00$. Em geral, são modelos esportivos, SUVs (veículo utilitário esportivo) de grande porte e sedãs pertencentes às categorias grande e premium. Esta variável visa identificar estratégias competitivas de empresas atuantes em nichos de luxo.

A coleta da quantidade de modelo de cada empresa no segmento highprice foi feita baseada nas informações disponíveis no website das empresas analisadas.

\subsubsection{5}

\section{Produtos no segmento de entrada}

Refere-se à quantidade de modelos inseridos no segmento de entrada, ou seja, modelos desprovidos de luxo, incluindo apenas os itens básicos, sendo altamente caracterizados pelo preço baixo. Para a sua mensuração, foram considerados modelos com preço de venda ao consumidor final não superior à $\mathrm{R} \$$ 
40.000,00. Esta variável pretende contribuir para a identificação de estratégias competitivas no segmento de massa.

Assim como na variável anterior, os respectivos websites foram as principais fontes para informações referentes aos diversos modelos oferecidos pelas montadoras.

\subsubsection{6}

\section{Serviços adicionais oferecidos}

Variável definida como a quantidade de serviços adicionais oferecidos que não se encontram na oferta básica. Esta variável inclui serviços de blindagem do veículo, atualização automática de software, acessórios oferecidos, opções de garantia, reparos estéticos e serviços de luxo, como carro extra de alto valor e motorista particular em caso de emergência. Esta variável pretende indicar a capacidade das empresas em oferecer serviços que agreguem valor ao produto.

Através de anúncios em mídias como televisão e internet, e de informações disponíveis em seus websites, foi possível coletar informações a respeito da variedade de serviços adicionais oferecidos ao cliente.

\subsubsection{7}

\section{Abrangência de atuação}

Variável que considera a segmentação geográfica de atuação. Definida como o número de estados em que a empresa possui atuação. Esta variável pretende identificar a extensão da área de atuação das empresas.

Para a obtenção dos dados, foram realizadas pesquisas nos websites das empresas, observando o endereço das respectivas concessionárias, obtendo-se assim, informações referentes aos estados onde estas empresas comercializam seus produtos.

\subsubsection{8}

\section{Linhas de produtos}

Variável definida como a quantidade de modelos distintos ofertados ao mercado. Esta variável busca entender como as empresas utilizam a extensão da linha de produto como estratégia competitiva. 
Foram analisados os websites das montadoras para obter informações sobre a quantidade de modelos distintos oferecidos por cada empresa.

\subsubsection{9}

\section{Investimento em propaganda}

Refere-se ao volume total de investimento direcionado a promover o produto ou a marca. Esta variável visa identificar empresas que utilizam a propaganda como arma competitiva. Como muitas das empresas da base não disponibilizaram informações sobre estes gastos no período considerado, esta variável foi descartada do estudo.

\section{2 .2}

\section{Seleção das variáveis de desempenho}

\subsubsection{1}

\section{Receita bruta $(\mathbf{R} \$)$}

Busca identificar o total de riqueza gerada por cada empresa. Esta variável é definida como preço médio de venda de cada modelo multiplicado pela respectiva quantidade de venda.

Esta variável foi obtida através da multiplicação do preço médio pelo volume vendido.

\subsubsection{2}

\section{Market-share}

Relação entre total de venda de uma empresa e total de venda da indústria automobilística. Esta variável visa identificar a participação das empresas em ralação às vendas totais da indústria.

Para a obtenção desta variável, foi realizada a razão entre o volume de venda, sobre o volume total vendido pelo mercado.

\subsubsection{3}

\section{Market-share por segmento}

Relação entre total de venda da empresa e a quantidade total vendida no mercado, incluindo todas as empresas. Esta relação se dá por segmento de atuação 
da empresa. Busca identificar a participação da empresa nos diversos segmentos de mercado.

A partir da segmentação do mercado, baseada no preço dos modelos, foi possível identificar seis segmentos de mercado. Foi realizada uma média ponderada da participação de cada empresa na venda em cada segmento para obter-se o market-share por segmento (Silva, 2007).

\subsubsection{4}

\section{Crescimento do market-share}

Variação percentual média do market-share das montadoras, para o período estudado.

Esta variável visa identificar quais empresas conseguiram crescer o número de clientes, aproveitando de melhor forma as oportunidades de crescimento do mercado.

\subsubsection{5}

\section{Satisfação do cliente}

Variável definida como a percepção de qualidade dos clientes das empresas. Busca identificar quais empresas apresentam melhores índices de qualidade na percepção de seus clientes. Os dados referentes à satisfação dos clientes foram adquiridos através das pesquisas anuais realizadas pela Revista Quatro Rodas, a qual busca identificar a satisfação dos proprietários dos automóveis com a respectiva montadora. Foi considerada a média simples entre os anos pesquisados.

\subsubsection{6}

\section{Preço médio}

Esta variável é definida pelo preço médio dos três modelos mais vendidos, ponderados pelo seu respectivo volume de venda. Esta variável visa identificar o preço médio cobrado pela montadora a fim de entender como a dimensão competitiva política de preço é utilizada pelas empresas. Esta variável foi obtida considerando os preços cobrados para o consumidor final. Estes dados foram encontrados tanto em anúncios, quanto diretamente no website das montadoras. 
A tabela 5 identifica o nome utilizado no SPSS para representar as variáveis de estratégia e de desempenho usadas neste trabalho.

Tabela 5 - Identificação da variável no SPSS

\begin{tabular}{|ll|}
\hline Variável & Identificação da Variável no SPSS \\
\hline Linhas de Produto & Linha_prod \\
\hline Canais de Distribuição & Canal \\
\hline Abrangência de atuação & Abrangencia \\
\hline Produtos no segmento high price & High_Price \\
\hline Produtos no segmento de entrada & Seg_Entrada \\
\hline Serviços auxiliares oferecidos & Serviços_Auxiliares \\
\hline Qualidade & Qualidade \\
\hline Qualidade no serviço pós-venda & Pos_venda \\
\hline Market-share & Market_share \\
\hline Market-share por segmento & Market_share_seg \\
\hline Receita bruta & Receita_bruta \\
\hline Preço médio & Preço_médio \\
\hline Crescimento do Market-share & Cresc_médio \\
\hline Satisfação do cliente & Satisfacao \\
\hline
\end{tabular}

Fonte: Própria

Para tornar possível a comparação entre os resultados obtidos neste trabalho, com os resultando obtido por Silva (2007), houve a tentativa de utilizar variáveis estratégicas e de desempenho semelhantes. A tabela 6 identifica as variáveis que foram mantidas do trabalho de Silva (2007), e as variáveis que não apresentaram equivalência. Para estas, as variáveis que pertencem apenas a este presente trabalho, foram julgadas de suma importantes para definição estratégica das empresas, o que justifica sua presença. Já para as variáveis utilizadas por Silva (2007) que não estão presentes neste estudo, justifica-se pela limitação em encontrar os dados de fontes confiáveis. As variáveis de desempenho mantiveramse equivalentes às utilizadas por Silva (2007). 
Tabela 6 - Comparação entre variáveis de estratégia utilizadas por Silva (2007)

\begin{tabular}{|c|c|}
\hline Memoria, 2015 & Silva, 2007 \\
\hline Variáveis de Estratégia & Variáveis de Estratégia \\
\hline Linhas de Produto & Diversificação da Linha de Produto \\
\hline Canais de Distribuição & Canais de Distribuição \\
\hline Produtos no segmento high price & Produtos no segmento high price \\
\hline Produtos no segmento de & Produtos no segmento de entrada \\
\hline Qualidade & Credibilidade da Marca \\
\hline Qualidade no serviço pós-venda & Assistência Técnica \\
\hline Abrangência de atuação & não há correspondência \\
\hline Serviços auxiliares oferecidos & não há correspondência \\
\hline Investimento em Propaganda * & Propaganda \\
\hline não há correspondência & Melhor Compra \\
\hline não há correspondência & Foco \\
\hline não há correspondência & Política de Preço \\
\hline Descartada no início por falta de dados suficientes para várias empresas no período.
\end{tabular}

\section{3}

\section{Tratamento dos dados}

A análise quantitativa dos dados seguiu metodologia utilizada em outros trabalhos semelhantes em indústrias nacionais como Financeira (COUTO, 2007), Seguros (SAMPAIO, 2009) e, principalmente, na própria indústria automobilística (SILVA, 2007). Os dados foram tratados estatisticamente com o uso do software PASW Statistics (também conhecido como SPSS - Statistical Package for the Social Sciences), versão 18, por meio das etapas indicadas abaixo, respeitando a ordem apresentada:

\section{$1^{0}$. Preparação da base de dados:}

Foi realizada com o objetivo de eliminar possíveis distorções de dados e de escalas. Por apresentar um período de referência de seis anos, foi calculada a média para representar cada variável de estratégia e de desempenho. Quanto às diferentes escalas utilizadas para cada variável, foi optado por padronizar a base de dados, transformando-a em Z-score. Dessa forma foi possível padronizar a variabilidade dos dados sob o parâmetro do desvio padrão (BLACK, 2010). 


\section{$2^{\circ}$. Teste da normalidade das variáveis:}

Foram utilizados os testes de Kolmogorov-Smirnov com correção de Lillieforse Shapiro-Wilk (mais recomendado para amostras com N menor ou igual a 30) para testar a normalidade da distribuição das variáveis de estratégias e de desempenho já normalizadas, uma vez que a distribuição normal é premissa para a escolha de alguns testes multivariados, como MANOVA. No teste de Kolmogorov-Smirnov, a hipótese nula (que se quer rejeitar) é que a distribuição é normal. Também foram verificadas as estatísticas de assimetria (Skewness) e curtose (Kurtosis).

\section{$3^{\text {o }}$. Análise de correlação:}

Foi realizado o teste de correlação de Pearson, com o objetivo de identificar a correlação entre as variáveis estudadas, e por ventura, eliminar duplicidade de variáveis que apresentem altos valores de correlação, já que não acrescentam poder explicativo do fenômeno estudado.

\section{$4^{\circ}$. Avaliação da conveniência de reduzir o espaço de estratégias competitivas:}

O uso da Análise Fatorial objetivou avaliar a conveniência reduzir a quantidade de informação levantada, tornando possível o uso de fatores em vez de uma análise individual das variáveis, sem perda significativa de poder explanatório. Foi realizada primeiramente, a análise fatorial sem rotação de eixos, e posteriormente, com o objetivo reduzir a carga total no primeiro fator e destacar os fatores com maiores cargas, foi realizada a análise com rotação ortogonal do tipo Varimax. Para facilitar a visualização das variáveis relevantes em cada fator, foram suprimidos os valores absolutos abaixo de 0,7 .

\section{$5^{\circ}$. Formação dos Grupos Estratégicos:}

Foi realizada a análise de Cluster K-means em função da tipologia escolhida (Porter, 1980), no qual, cada cluster representa um grupo estratégico com suas respectivas características. A técnica tem o objetivo de classificar cada uma das 30 empresas sem um grupo estratégico. Esta análise determina as distâncias euclidianas e forma os grupos, identificando os centroides mais próximos para 
cada um dos cinco grupos cinco estratégicos definidos a priori pela tipologia adotada: Liderança em Custo, Diferenciação, Enfoque em Custo, Enfoque em Diferenciação e Stuck-in-the-Middle

Definidos os clusters comparou-se a matriz-alvo contendo os centroides iniciais definidos pela teoria com a matriz final, mediante aplicação do teste Wilcoxon Signed Rank, que é um teste não paramétrico utilizado para descobrir se dados pareados de diferentes amostras são oriundos da mesma distribuição. A hipótese nula, a ser rejeitada, é de igualdade das matrizes, ou seja, que não há diferença significativa entre a matriz teórica dos grupos estratégicos e a matriz final, gerada pelo SPSS.

\section{$6^{\circ}$. Comparação do desempenho dos grupos estratégicos:}

Para os cinco grupos estratégicos formados no passo anterior, deve-se verificar se existem diferenças significativas no desempenho médio entre os mesmos, considerando todas as variáveis de desempenho incluídas no estudo.

Se as variáveis dependentes apresentam distribuição normal, pode-se testar as diferenças no desempenho por meio da análise múltipla de variância MANOVA, com a hipótese nula de os desempenhos dos grupos serem estatisticamente iguais entre si, usando especificamente os testes Wilks'Lambda e T2 de Hotelling. Estes procedimentos são seguidos do teste post hoc de Bonferroni a fim de ordenar os desempenhos entre pares de clusters e, assim, verificar qual grupo estratégico teve melhor desempenho.

Pode-se também utilizar a Análise de Variância (ANOVA) para verificar para cada variável de desempenho separadamente se o desempenho de cada grupo estratégico é diferente.

Se as variáveis dependentes tiverem distribuição não normal, utiliza-se o teste não paramétrico de Kruskal-Wallis, para descobrir se há diferença significativa entre as variáveis de desempenho de forma isolada e não mais multivariada. 


\section{4}

\section{Limitações do método}

O estudo sofreu limitações devido à dificuldade na coleta de dados, principalmente em relação à pouca informação disponibilizada diretamente pelas montadoras. Grande parte dos dados coletados foi encontrada em fontes secundárias formadas por revistas especializadas, o que pode gerar perda de informações ou alterações nos dados coletados. É importante ressaltar que, por existirem diferentes fontes para captação de dados referentes à mesma variável, apesar de parecerem semelhantes, pode ter havido alguma variação entre métodos utilizados pelas diferentes fontes, podendo ocasionar alguma discrepância entre os dados.

Outra limitação referente à coleta de dados diz respeito à dificuldade de obtenção de dados financeiros, a fim de mensurar de forma mais completa o desempenho das empresas. Pela não divulgação dos mesmos pela maior parte das empresas, estes dados se encontram ausentes neste trabalho.

Outra limitação da metodologia utilizada, citada por Couto (2007), pode estar relacionada com o lapso de tempo entre os resultados coletados para as variáveis de desempenho e a implementação das estratégias competitivas pelas empresas ou alterações no ambiente competitivo. Segundo Couto (2007, p 58) " $e$ possível que o desempenho observado não esteja completamente relacionado comas estratégias identificadas durante o período estudado".

Finalmente, mesmo se trabalhando com uma amostra bastante representativa da população total de quarenta empresas atuando na indústria automobilística nacional, como esta se limitou a trinta empresas, a aplicação de alguns dos métodos estatísticos multivariados previstos foi prejudicada pelo pequeno número de casos. 
5

\section{Apresentação e análise dos resultados}

\section{1}

\section{Análise amostral}

Ao analisar os dados coletados, a respeito da forma de atuação das trinta montadoras analisadas por este estudo, percebem-se alguns padrões interessantes sobre algumas variáveis.

A variável linha de produtos, referente à quantidade de modelos distintos oferecidos pelas montadoras, apresenta uma amplitude variando entre 1 (Dodge e Troller) e 16 (BMW e Volkswagen). A média de modelos oferecidos pelas empresas foi de 6,8 modelos por montadora. Segue a figura 4 , com o número de modelos das montadoras analisadas.

Figura 4 - Quantidade de modelos distintos por montadora

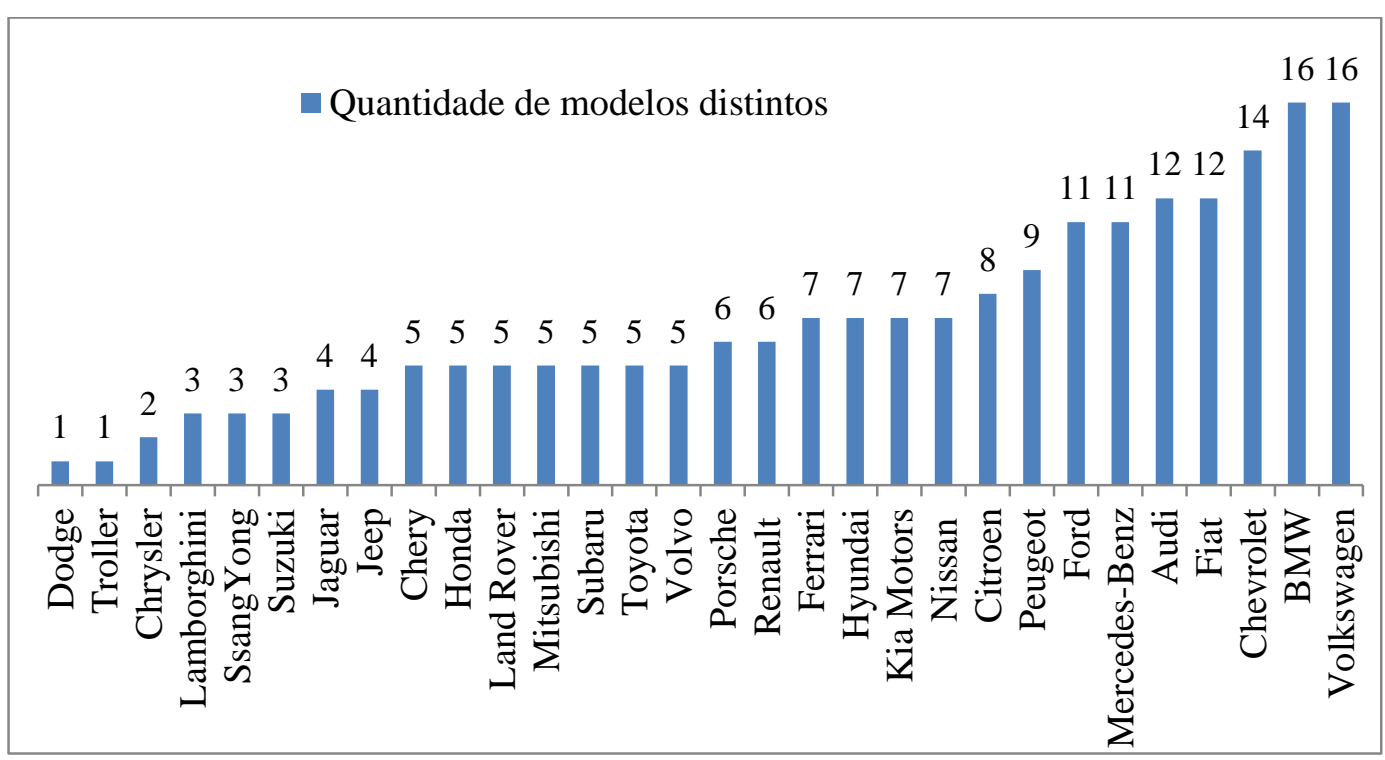

Fonte: website próprio das montadoras

A variável controle da distribuição apresentou uma grande amplitude, variando entre 1 (Ferrari e Lamborghini) e 554 (Fiat). A média de foi de 126 concessionárias por montadora. Acrescentaram para aumentar esta média, as montadoras Chevrolet, Fiat, Ford e Volkswagen, que, somadas apresentaram o 
número de 1997 concessionárias, com média de aproximadamente 450 concessionárias por empresa. Por outro lado, montadoras que possuem carros classificados como luxuosos e com alta tecnologia envolvida, como a Audi, BMW, Ferrari, Land Rover, Lamborghini, Mercedes-Benz, Porsche, Jaguar e Volvo, apresentam a média de 24 concessionárias por empresa. A figura 5 mostra o número total de concessionárias de cada montadora.

Figura 5 - Quantidade de concessionárias por montadora

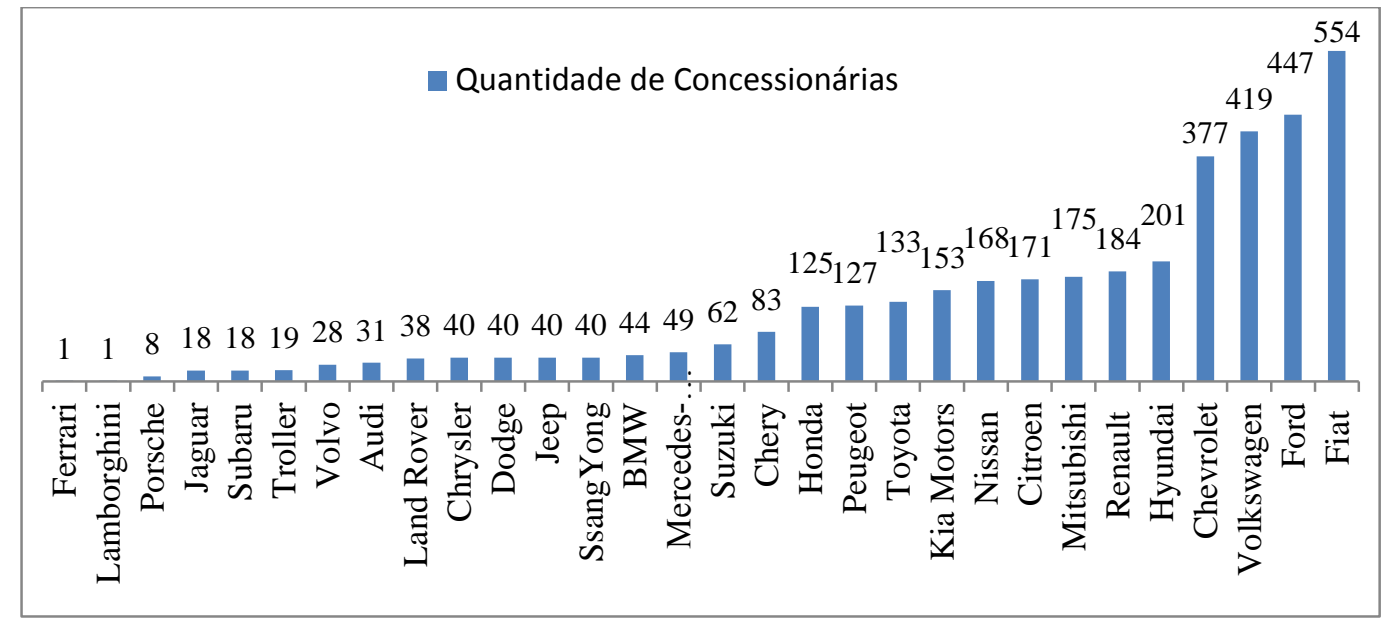

Fonte: website próprio das montadoras

A variável pós-venda, foi coletada através de pesquisas anuais realizadas pela revista Quatro-Rodas. A tabela 7 mostra as médias das notas recebidas pelas empresas nos anos de 2007 e 2012, em pesquisas realizadas pela revista Quatro Rodas.

Tabela 7 - Nota recebida por montadora na variável pós-venda.

\begin{tabular}{|c|c|}
\hline Empresa & Nota \\
\hline Chery & 74,6 \\
\hline Suzuki & 81,3 \\
\hline Troller & 81,3 \\
\hline Peugeot & 81,4 \\
\hline Jeep & 82,3 \\
\hline Kia Motors & 83,1 \\
\hline Nissan & 83,6 \\
\hline Citroen & 83,9 \\
\hline Volkswagen & 84,5 \\
\hline Dodge & 85,1 \\
\hline Chrysler & 86,3 \\
\hline Ford & 86,3 \\
\hline Chevrolet & 86,8 \\
\hline SsangYong & 87,3 \\
\hline Fiat & 87,7 \\
\hline
\end{tabular}

\begin{tabular}{|c|c|}
\hline Empresa & Nota \\
\hline Subaru & 89,9 \\
\hline Mitsubishi & 90,1 \\
\hline Land Rover & 90,4 \\
\hline Renault & 91,0 \\
\hline Volvo & 91,3 \\
\hline Porsche & 91,5 \\
\hline Mercedes-Benz & 92,3 \\
\hline Hyundai & 92,9 \\
\hline Jaguar & 93,1 \\
\hline Toyota & 93,4 \\
\hline Lamborghini & 94,1 \\
\hline Honda & 94,9 \\
\hline Audi & 95,3 \\
\hline BMW & 96,3 \\
\hline Ferrari & 96,7 \\
\hline
\end{tabular}


A variável destinada a estimar o preço médio cobrado pelas montadoras ao consumidor final apresentou um preço mínimo de $\mathrm{R} \$ 26.624$, referente ao preço médio da Chery. Na outra ponta, a Lamborghini apresentou o preço médio mais alto do mercado, de $\mathrm{R} \$ 2$ 2.126.557. A tabela 8 mostra o preço médio das montadoras analisadas.

Tabela 8 - Preço médio das montadoras

\begin{tabular}{|c|c|}
\hline Empresa & Preço Médio \\
\hline Chery & $\mathrm{R} \$ 26.624$ \\
\hline Fiat & $\mathrm{R} \$ 31.743$ \\
\hline Volkswagen & $\mathrm{R} \$ 32.056$ \\
\hline Chevrolet & $\mathrm{R} \$ 32.571$ \\
\hline Renault & $\mathrm{R} \$ 38.675$ \\
\hline Peugeot & $\mathrm{R} \$ 38.748$ \\
\hline Ford & $\mathrm{R} \$ 40.607$ \\
\hline Citroen & $\mathrm{R} \$ 43.757$ \\
\hline Nissan & $\mathrm{R} \$ 47.037$ \\
\hline Hyundai & $\mathrm{R} \$ 49.886$ \\
\hline Honda & $\mathrm{R} \$ 59.473$ \\
\hline Kia Motors & $\mathrm{R} \$ 77.021$ \\
\hline Suzuki & $\mathrm{R} \$ 77.113$ \\
\hline Mitsubishi & $\mathrm{R} \$ 81.332$ \\
\hline Troller & $\mathrm{R} \$ 86.953$ \\
\hline
\end{tabular}

\begin{tabular}{|c|c|}
\hline Empresa & Preço Médio \\
\hline SsangYong & $\mathrm{R} \$ 88.377$ \\
\hline Audi & $\mathrm{R} \$ 88.402$ \\
\hline Toyota & $\mathrm{R} \$ 88.441$ \\
\hline Dodge & $\mathrm{R} \$ 95.300$ \\
\hline BMW & $\mathrm{R} \$ 95.400$ \\
\hline Subaru & $\mathrm{R} \$ 119.365$ \\
\hline Jeep & $\mathrm{R} \$ 120.777$ \\
\hline Mercedes-Benz & $\mathrm{R} \$ 149.777$ \\
\hline Chrysler & $\mathrm{R} \$ 155.161$ \\
\hline Volvo & $\mathrm{R} \$ 161.787$ \\
\hline Land Rover & $\mathrm{R} \$ 186.604$ \\
\hline Jaguar & $\mathrm{R} \$ 297.771$ \\
\hline Porsche & $\mathrm{R} \$ 443.826$ \\
\hline Ferrari & $\mathrm{R} \$ 1.804 .531$ \\
\hline Lamborghini & $\mathrm{R} \$ 2.126 .557$ \\
\hline
\end{tabular}

Fonte: website próprio das montadoras

Em relação às variáveis de desempenho, destaca-se a variável market-share total e market-share por segmento de mercado. O quarteto Fiat, Volkswagen, Chevrolet e Ford respondem por um total de aproximadamente $75 \%$ das vendas do mercado. É importante notar a alta participação no market-share por segmento da montadora Porsche, representando 26,13\%. Este fato ocorre pelo fato desta empresa posicionar todos os seus modelos no segmento mais luxuoso do mercado (veículos com preço de venda acima de $\mathrm{R} \$ 200.000$ ). Este segmento conta com veículos da montadora Ferrari, Lamborghini, Jaguar e com apenas alguns modelos das empresas: Audi, BMW, Land Rover e Mercedes-Benz. Dessa forma, a Porsche consegue obter volume de venda superior às montadoras Audi, BMW, Land Rover e Mercedes-Benz por contar com mais modelos no segmento, e consegue maior volume do que Ferrari, Lamborghini e Jaguar pelo fato de seus veículos serem ofertados por preços consideravelmente inferiores.

A mesma lógica se aplica à Toyota e a Land Rover. No primeiro caso, percebe-se o domínio no segmento de veículos com preços de venda superiores à 
$\mathrm{R} \$ 90.000$ e inferiores a $\mathrm{R} \$ 120.000$, no qual a Toyota responde por mais de $50 \%$ das vendas do segmento. Já no caso da Land Rover, esta empresa possui relevantes participações de mercado nos segmentos que variam de $\mathrm{R} \$ 120.000$ a R\$ 199.000 (27\%) e no segmento mais luxuoso do mercado, o de veículos acima de $\mathrm{R} \$ 200.000(30 \%)$.

A tabela 9 mostra a participação das empresas, tanto no mercado total, quanto seus market-share médio por segmento de atuação.

Tabela 9 - Market-share e market-share por segmento

\begin{tabular}{|c|c|c|}
\hline Empresa & $\begin{array}{c}\text { Market- } \\
\text { share }\end{array}$ & $\begin{array}{c}\text { Market-share } \\
\text { Médio Por } \\
\text { Segmento }\end{array}$ \\
\hline Fiat & $23,93 \%$ & $27,83 \%$ \\
\hline Volkswagen & $21,83 \%$ & $20,92 \%$ \\
\hline Chevrolet & $19,65 \%$ & $20,09 \%$ \\
\hline Ford & $9,75 \%$ & $11,47 \%$ \\
\hline Renault & $4,91 \%$ & $7,50 \%$ \\
\hline Honda & $3,75 \%$ & $16,46 \%$ \\
\hline Toyota & $3,14 \%$ & $46,13 \%$ \\
\hline Peugeot & $2,65 \%$ & $3,14 \%$ \\
\hline Hyundai & $2,52 \%$ & $6,21 \%$ \\
\hline Citroen & $2,37 \%$ & $3,07 \%$ \\
\hline Mitsubishi & $1,36 \%$ & $6,62 \%$ \\
\hline Nissan & $1,35 \%$ & $1,37 \%$ \\
\hline Kia Motors & $1,13 \%$ & $4,88 \%$ \\
\hline Chery & $0,32 \%$ & $0,37 \%$ \\
\hline Mercedes- & $0,23 \%$ & $25,37 \%$ \\
\hline Benz & & \\
\hline
\end{tabular}

\begin{tabular}{|c|c|c|}
\hline Empresa & $\begin{array}{c}\text { Market- } \\
\text { share }\end{array}$ & $\begin{array}{c}\text { Market-share } \\
\text { Médio Por } \\
\text { Segmento }\end{array}$ \\
\hline BMW & $0,22 \%$ & $11,92 \%$ \\
\hline Suzuki & $0,15 \%$ & $4,31 \%$ \\
\hline Land Rover & $0,15 \%$ & $27,26 \%$ \\
\hline Subaru & $0,14 \%$ & $4,21 \%$ \\
\hline SsangYong & $0,09 \%$ & $1,68 \%$ \\
\hline Audi & $0,09 \%$ & $2,90 \%$ \\
\hline Dodge & $0,06 \%$ & $9,18 \%$ \\
\hline Volvo & $0,06 \%$ & $3,52 \%$ \\
\hline Jeep & $0,05 \%$ & $11,40 \%$ \\
\hline Troller & $0,04 \%$ & $0,25 \%$ \\
\hline Chrysler & $0,03 \%$ & $5,95 \%$ \\
\hline Porsche & $0,02 \%$ & $26,13 \%$ \\
\hline Jaguar & $0,00 \%$ & $1,69 \%$ \\
\hline Ferrari & $0,00 \%$ & $0,91 \%$ \\
\hline Lamborghini & $0,00 \%$ & $0,48 \%$ \\
\hline
\end{tabular}

Fonte: ABEIVA, 2012.

\section{2}

\section{Análise da normalidade das variáveis}

Com o objetivo de testar a normalidade das variáveis estudadas devido à premissa dos testes de análise de variância (ANOVA) e de MANOVA, foram verificadas as estatísticas de Assimetria (Skewness) e Curtose (Kurtosis) com intervalo de confiança em 95\%, e realizados os testes Shapiro-Wilk e Kolmogorov-Smirnov com correção de Lilliefors com as variáveis estudadas, com seus resultados apresentados nas tabelas 10 e 11. 
Tabela 10 - Estatística descritiva das variáveis

\begin{tabular}{|c|c|c|c|c|c|c|c|c|c|}
\hline & \multirow{2}{*}{\begin{tabular}{|l|}
$\mathrm{N}$ \\
Statistic \\
\end{tabular}} & \multirow{2}{*}{\begin{tabular}{|l} 
Minimu \\
$\mathrm{m}$
\end{tabular}} & \multirow{2}{*}{$\begin{array}{l}\text { Maximu } \\
\mathrm{m}\end{array}$} & \multirow{2}{*}{\begin{tabular}{|l} 
Mean \\
Statistic
\end{tabular}} & \multirow{2}{*}{$\begin{array}{l}\text { Std. } \\
\text { Deviation } \\
\text { Statistic }\end{array}$} & \multicolumn{2}{|c|}{ Skewness } & \multicolumn{2}{|l|}{ Kurtosis } \\
\hline & & & & & & Statistic & $\begin{array}{l}\text { Std. } \\
\text { Error }\end{array}$ & Statistic & $\begin{array}{l}\text { Std. } \\
\text { Error }\end{array}$ \\
\hline Linha_prod & 30 & 1 & 16 & 6,83 & 4,111 & 836 & ,427 & ,008 & ,833 \\
\hline Canal & 30 & 1 & 554 & 126,47 & 144,501 & ,676 & ,427 & 2,204 & ,833 \\
\hline Abrangencia & 30 & 1 & 27 & 19,43 & 8,097 & $-1,016$ & ,427 & ,056 & ,833 \\
\hline High_Price & 30 &, 00 & 1,00 &, 5537 & ,39998 &,- 206 & ,427 & $-1,686$ & ,833 \\
\hline Seg_Entrada & 30 &, 00 &, 60 &, 0930 & , 15985 & 1,881 & ,427 & 3,177 & ,833 \\
\hline Serviços_Auxiliares & 30 & 2 & 5 & 3,40 & 1,276 & ,239 & ,427 & $-1,665$ & ,833 \\
\hline Qualidade & 30 & 1 & 5 & 3,53 & 1,137 &,- 465 & ,427 &,- 107 & ,833 \\
\hline Pos_venda & 30 & 75 & 97 & 88,29 & 5,439 &,- 409 & ,427 &,- 324 & ,833 \\
\hline Market_Share & 30 &, 00 &, 24 &, 0330 &, 06717 & 2,405 & ,427 & 4,745 & ,833 \\
\hline Market_Share_Seg & 30 &, 00 &, 46 &, 1033 & ,11096 & 1,525 & ,427 & 2,249 & ,833 \\
\hline Rec_Bruta & 30 & $\begin{array}{l}214395 \\
43\end{array}$ & $\begin{array}{l}230405 \\
34869\end{array}$ & $\begin{array}{l}4002166 \\
639\end{array}$ & $\begin{array}{l}6513694 \\
883\end{array}$ & 2,060 & ,427 & 3,339 & ,833 \\
\hline Satisfacao & 30 & 720 & 859 & 785,83 & 45,600 & ,090 & ,427 & $-1,290$ & ,833 \\
\hline Cresc_médio & 30 &,- 22 & 2,46 &, 4420 & ,55522 & 2,024 & ,427 & 5,030 & , 833 \\
\hline Preço_médio & 30 & 26624 & $\begin{array}{l}212655 \\
7\end{array}$ & 226189 & 482522 & 3,521 & ,427 & 11,740 & ,833 \\
\hline
\end{tabular}

Tabela 11 - Teste Kolmogorov-Smirnov e Shapiro-Wilk das variáveis

\begin{tabular}{|l|l|l|l|l|l|l|}
\hline \multirow{2}{*}{} & \multicolumn{3}{|c|}{ Kolmogorov-Smirnova } & \multicolumn{3}{c|}{ Shapiro-Wilk } \\
\cline { 2 - 7 } & Statistic & df & Sig. & Statistic & df & Sig. \\
\hline Zscore(Linha_prod) &, 184 & 30 &, 011 &, 915 & 30 &, 020 \\
Zscore(Canal) &, 206 & 30 &, 002 &, 772 & 30 &, 000 \\
Zscore(Abrangencia) &, 180 & 30 &, 014 &, 850 & 30 &, 001 \\
Zscore(High_Price) &, 164 & 30 &, 038 &, 844 & 30 &, 000 \\
Zscore(Seg_Entrada) &, 386 & 30 &, 000 &, 655 & 30 &, 000 \\
Zscore(Serviços_Auxiliares) &, 228 & 30 &, 000 &, 790 & 30 &, 000 \\
Zscore(Qualidade) &, 186 & 30 &, 009 &, 888 & 30 &, 004 \\
Zscore(Pos_venda) &, 116 & 30 &, $200^{*}$ &, 962 & 30 &, 345 \\
Zscore(Market_Share) &, 318 & 30 &, 000 &, 550 & 30 &, 000 \\
Zscore(Market_Share_Seg) &, 218 & 30 &, 001 &, 821 & 30 &, 000 \\
Zscore(Rec_Bruta) &, 278 & 30 &, 000 &, 648 & 30 &, 000 \\
Zscore(Satisfacao) &, 109 & 30 &, $200^{*}$ &, 932 & 30 &, 054 \\
Zscore(Cresc_médio) &, 192 & 30 &, 006 &, 788 & 30 &, 000 \\
Zscore(Preço_médio) &, 399 & 30 &, 000 &, 410 & 30 &, 000 \\
\hline
\end{tabular}

a. Teste distribuição normal.

b. Calculado a partir dos dados. 
Os procedimentos estatísticos realizados neste trabalho são suficientemente robustos perante eventuais não normalidades das variáveis, com exceção dos testes de análise de variância, ANOVA e MANOVA (SILVA, 1997).

Pelo fato da amostra não superar trinta observações, foi realizado o teste Shapiro-Wilk, encontrando não conformidade de distribuição normal para todas as variáveis independentes, exceto para a variável: Qualidade do Serviço pós-venda. Em relação às variáveis de desempenho (dependentes), o teste indica distribuição não normal para todas as varáveis, exceto para a variável Satisfação do cliente. Ao ser analisado, o teste de Kolmogorov-Smirnov apresenta conclusões idênticas.

Corroborando o teste Shapiro-Wilk, ao analisar a curtose, o coeficiente de assimetria e a relação entre média e mediana das variáveis, nota-se que estas análises estão de acordo com os resultados dos testes de normalidade realizados.

Apesar de não apresentarem normalidade em suas distribuições, foi optado por manter as variáveis, uma vez que testes de análise de fator e de clusters são robustos quanto a não normalidade das mesmas (SILVA, 1997) e porque há testes não paramétricos para comparar o desempenho dos grupos formados.

\section{3}

\section{Análise de correlação}

As variáveis de estratégia e de desempenho foram analisadas sob a ótica da correlação de Pearson, objetivando identificar correlações entre as mesmas. Os valores variam entre 1 e -1 , o primeiro indicando correlação positiva e o segundo indicando correlação negativa. Valores próximos a zero indicam baixo grau de correlação. 
Tabela 12 - Matriz de correlação de Pearson das variáveis estratégicas

\begin{tabular}{|c|c|c|c|c|c|c|c|c|c|}
\hline & & $\begin{array}{c}\text { Linha_pr } \\
\text { od }\end{array}$ & Canal & $\begin{array}{c}\text { Abrange } \\
\text { ncia }\end{array}$ & $\begin{array}{c}\text { High_Pri } \\
\text { ce }\end{array}$ & $\begin{array}{c}\text { Seg_Ent } \\
\text { rada }\end{array}$ & $\begin{array}{c}\text { Ser_Auxi } \\
\text { liares }\end{array}$ & $\begin{array}{c}\text { Qualidad } \\
\mathrm{e}\end{array}$ & $\begin{array}{c}\text { Pos_ven } \\
\text { da }\end{array}$ \\
\hline $\begin{array}{l}\text { Linha_ } \\
\text { prod }\end{array}$ & $\begin{array}{l}\text { Pearson } \\
\text { Correlation } \\
\text { Sig. (2- } \\
\text { tailed) } \\
\text { N }\end{array}$ & 30 & $\begin{array}{r}, 594^{* *} \\
, 001 \\
30\end{array}$ & $\begin{array}{r}, 239 \\
, 203 \\
30\end{array}$ & $\begin{array}{r}-, 180 \\
, 342 \\
30\end{array}$ & $\begin{array}{r}, 256 \\
, 172 \\
30\end{array}$ & $\begin{array}{r}, 263 \\
, 160 \\
30\end{array}$ & $\begin{array}{r}-, 076 \\
, 689 \\
30\end{array}$ & $\begin{array}{r}, 175 \\
, 354 \\
30\end{array}$ \\
\hline Canal & $\begin{array}{l}\text { Pearson } \\
\text { Correlation } \\
\text { Sig. (2- } \\
\text { tailed) } \\
\mathrm{N}\end{array}$ & $\begin{array}{r}, 594^{* *} \\
, 001 \\
30 \\
\end{array}$ & 30 & $\begin{array}{r}, 632^{* *} \\
, 000 \\
30 \\
\end{array}$ & $\begin{array}{r}-, 569^{* *} \\
, 001 \\
30 \\
\end{array}$ & $\begin{array}{r}, 505^{* *} \\
, 004 \\
30\end{array}$ & $\begin{array}{r}-, 265 \\
, 157 \\
30\end{array}$ & $\begin{array}{r}-, 375^{*} \\
, 041 \\
30 \\
\end{array}$ & $\begin{array}{r}-, 194 \\
, 304 \\
30 \\
\end{array}$ \\
\hline $\begin{array}{l}\text { Abrang } \\
\text { encia }\end{array}$ & $\begin{array}{l}\text { Pearson } \\
\text { Correlation } \\
\text { Sig. (2- } \\
\text { tailed) } \\
\mathrm{N}\end{array}$ & $\begin{array}{r}, 239 \\
, 203 \\
30 \\
\end{array}$ & $\begin{array}{r}, 632^{\star *} \\
, 000 \\
30 \\
\end{array}$ & 30 & $\begin{array}{r}-, 709^{\star *} \\
, 000 \\
30 \\
\end{array}$ & $\begin{array}{r}, 501^{* *} \\
, 005 \\
30 \\
\end{array}$ & $\begin{array}{r}-, 568^{\star *} \\
, 001 \\
30 \\
\end{array}$ & $\begin{array}{r}-, 565^{\star \star} \\
, 001 \\
30 \\
\end{array}$ & $\begin{array}{r}-, 474^{* *} \\
, 008 \\
30 \\
\end{array}$ \\
\hline $\begin{array}{l}\text { High_P } \\
\text { rice }\end{array}$ & $\begin{array}{l}\text { Pearson } \\
\text { Correlation } \\
\text { Sig. (2- } \\
\text { tailed) } \\
\mathrm{N}\end{array}$ & $\begin{array}{r}-, 180 \\
, 342 \\
30 \\
\end{array}$ & $\begin{array}{r}-, 569^{* *} \\
, 001 \\
30 \\
\end{array}$ & $\begin{array}{r}-, 709^{* *} \\
, 000 \\
30 \\
\end{array}$ & 30 & $\begin{array}{r}-, 678^{* *} \\
, 000 \\
30 \\
\end{array}$ & $\begin{array}{r}, 602^{* *} \\
, 000 \\
30 \\
\end{array}$ & $\begin{array}{r}, 609^{* *} \\
, 000 \\
30 \\
\end{array}$ & $\begin{array}{r}, 548^{* *} \\
, 002 \\
30 \\
\end{array}$ \\
\hline $\begin{array}{l}\text { Seg_E } \\
\text { ntrada }\end{array}$ & $\begin{array}{l}\text { Pearson } \\
\text { Correlation } \\
\text { Sig. (2- } \\
\text { tailed) } \\
\mathrm{N}\end{array}$ & $\begin{array}{r}, 256 \\
, 172 \\
30\end{array}$ & $\begin{array}{r}, 505^{* *} \\
, 004 \\
30\end{array}$ & $\begin{array}{r}, 501^{\star *} \\
, 005 \\
30\end{array}$ & $\begin{array}{r}-, 678^{* *} \\
, 000 \\
30\end{array}$ & 30 & $\begin{array}{r}-, 422^{*} \\
, 020 \\
30\end{array}$ & $\begin{array}{r}-, 360 \\
, 051 \\
30\end{array}$ & $\begin{array}{r}-, 446^{*} \\
, 013 \\
30\end{array}$ \\
\hline $\begin{array}{l}\text { Serviço } \\
\text { s_Auxili } \\
\text { ares }\end{array}$ & $\begin{array}{l}\text { Pearson } \\
\text { Correlation } \\
\text { Sig. (2- } \\
\text { tailed) } \\
\mathrm{N}\end{array}$ & $\begin{array}{r}, 263 \\
, 160 \\
30\end{array}$ & $\begin{array}{r}-, 265 \\
, 157 \\
30\end{array}$ & $\begin{array}{r}-, 568^{* *} \\
, 001 \\
30\end{array}$ & $\begin{array}{r}, 602^{* *} \\
, 000 \\
30\end{array}$ & $\begin{array}{r}-, 422^{*} \\
, 020 \\
30\end{array}$ & 30 & $\begin{array}{r}, 609^{* *} \\
, 000 \\
30\end{array}$ & $\begin{array}{r}, 724^{* *} \\
, 000 \\
30\end{array}$ \\
\hline $\begin{array}{l}\text { Qualida } \\
\text { de }\end{array}$ & $\begin{array}{l}\text { Pearson } \\
\text { Correlation } \\
\text { Sig. (2- } \\
\text { tailed) } \\
\mathrm{N}\end{array}$ & $\begin{array}{r}-, 076 \\
, 689 \\
30\end{array}$ & $\begin{array}{r}-, 375^{*} \\
, 041 \\
30\end{array}$ & $\begin{array}{r}-, 565^{* *} \\
, 001 \\
30\end{array}$ & $\begin{array}{r}, 609^{* *} \\
, 000 \\
30\end{array}$ & $\begin{array}{r}-, 360 \\
, 051 \\
30 \\
\end{array}$ & $\begin{array}{r}, 609^{* *} \\
, 000 \\
30\end{array}$ & 30 & $\begin{array}{r}, 634^{* *} \\
, 000 \\
30 \\
\end{array}$ \\
\hline $\begin{array}{l}\text { Pos_ve } \\
\text { nda }\end{array}$ & $\begin{array}{l}\text { Pearson } \\
\text { Correlation } \\
\text { Sig. (2- } \\
\text { tailed) } \\
\text { N }\end{array}$ & $\begin{array}{r}, 175 \\
, 354 \\
30\end{array}$ & $\begin{array}{r}-, 194 \\
, 304 \\
30\end{array}$ & $\begin{array}{r}-, 474^{* *} \\
, 008 \\
30\end{array}$ & $\begin{array}{r}, 548^{* *} \\
, 002 \\
30\end{array}$ & $\begin{array}{r}-, 446^{*} \\
, 013 \\
30\end{array}$ & $\begin{array}{r}, 724^{* *} \\
, 000 \\
30\end{array}$ & $\begin{array}{r}, 634^{* *} \\
, 000 \\
30\end{array}$ & 30 \\
\hline
\end{tabular}

Nota-se a correlação positiva entre as variáveis abrangência e canal de distribuição $(0,632)$, sendo explicada pelo fato de que quanto maior for a abrangência de atuação, mais concessionárias são necessárias para suprir tal abrangência.

As variáveis high price (high_price) e segmento de entrada (seg_entrada), que indicam a quantidade de modelos nos respectivos segmentos de mercado, apresentam alta correlação negativa $(-0,678)$, sugerindo que as empresas focam 
suas atuações em um desses segmentos em especifico. Ou seja, esta correlação negativa indica que quanto maior o foco em um desses segmentos, menor será o foco no outro.

Analisando a variável pós-venda, percebe-se alta correlação com a variável serviços auxiliares $(0,724)$ e credibilidade da marca $(0,634)$. Analisando o mercado, percebe-se que empresas que atuam em segmentos de maior valor agregado, buscam diferenciar sua marca através da oferta de serviços. Estas empresas, no geral, conseguem oferecer ambos os serviços, sejam serviços pósvenda, sejam serviços auxiliares. Este segmento de maior valor agregado preza por esta oferta, o que força as empresas a oferecem ambos os serviços. Por estarem em segmentos de maior valor agregado, seus produtos apresentam melhores atributos, sendo um deles a qualidade. Isso explica a relação entre estas empresas (high price) e a credibilidade da marca, explicando uma razoável correlação identificada entre essas variáveis $(0,609)$.

A mesma análise foi realizada para as variáveis de desempenho, conforme consta na tabela 13. Nota-se elevada correlação positiva entre as variáveis marketshare e receita bruta $(0,984)$, uma vez que o cálculo da receita bruta tem como origem o market-share da empresa. Sendo assim, a preços equiparáveis, quanto maior o market-share, maior a sua receita bruta.

Outra correlação que se pode reparar é o fato da satisfação do cliente estar negativamente correlacionado com o market-share (-0,495), ainda que esta correlação não seja forte. Isso pode ser explicado pelo fato de que empresas com alta participação no mercado, em geral, atua em segmentos de menor valor agregado. Este segmento tem como característica a grande competição baseada em preços o que reduz investimento em atributos relacionados a satisfação do consumidor, tais como: qualidade, design, segurança, desempenho, etc. Desta forma, pela falta destes atributos em seus produtos, a satisfação do consumidor é afetada. 
Tabela 13 - Matriz de Correlação de Pearson das variáveis de desempenho

\begin{tabular}{|c|c|c|c|c|c|c|c|}
\hline & & $\begin{array}{l}\text { Zscore(Mar } \\
\text { ket_Share) }\end{array}$ & $\begin{array}{l}\text { Zscore(Marke } \\
\text { t_Share_Seg) }\end{array}$ & $\begin{array}{l}\text { Zscore(R } \\
\text { ec_Bruta) }\end{array}$ & $\begin{array}{l}\text { Zscore(S } \\
\text { atisfacao) }\end{array}$ & $\begin{array}{l}\text { Zscore(Cre } \\
\text { sc_médio) }\end{array}$ & $\begin{array}{l}\text { Zscore(Pre } \\
\text { ço_médio) }\end{array}$ \\
\hline $\begin{array}{l}\text { Zscore(Marke } \\
\text { t_Share) }\end{array}$ & $\begin{array}{l}\text { Pearson } \\
\text { Correlation } \\
\text { Sig. (2-tailed) } \\
\mathrm{N}\end{array}$ & $\begin{array}{l}1 \\
30 \\
\end{array}$ & $\begin{array}{c}, 418^{*} \\
, 021 \\
30 \\
\end{array}$ & $\begin{array}{c}, 984^{* *} \\
, 000 \\
30 \\
\end{array}$ & $\begin{array}{c}-, 495^{* *} \\
, 005 \\
30 \\
\end{array}$ & $\begin{array}{c}-, 301 \\
, 106 \\
30 \\
\end{array}$ & $\begin{array}{c}-, 198 \\
, 294 \\
30 \\
\end{array}$ \\
\hline $\begin{array}{l}\text { Zscore(Marke } \\
\text { t_Share_Seg) }\end{array}$ & $\begin{array}{l}\text { Pearson } \\
\text { Correlation } \\
\text { Sig. (2-tailed) } \\
\text { N }\end{array}$ & $\begin{array}{c}, 418^{*} \\
, 021 \\
30 \\
\end{array}$ & $\begin{array}{l}1 \\
30 \\
\end{array}$ & $\begin{array}{c}, 506^{* *} \\
, 004 \\
30 \\
\end{array}$ & $\begin{array}{c}, 112 \\
, 557 \\
30 \\
\end{array}$ & $\begin{array}{c}-, 287 \\
, 125 \\
30 \\
\end{array}$ & $\begin{array}{c}-, 205 \\
, 278 \\
30 \\
\end{array}$ \\
\hline $\begin{array}{l}\text { Zscore(Rec } \\
\text { Bruta) }\end{array}$ & $\begin{array}{l}\text { Pearson } \\
\text { Correlation } \\
\text { Sig. (2-tailed) } \\
\mathrm{N}\end{array}$ & $\begin{array}{c}, 984^{* *} \\
, 000 \\
30 \\
\end{array}$ & $\begin{array}{c}, 506^{* *} \\
, 004 \\
30 \\
\end{array}$ & 30 & $\begin{array}{c}-, 481^{* *} \\
, 007 \\
30 \\
\end{array}$ & $\begin{array}{c}-, 323 \\
, 081 \\
30 \\
\end{array}$ & $\begin{array}{c}-, 234 \\
, 214 \\
30 \\
\end{array}$ \\
\hline $\begin{array}{l}\text { Zscore(Satisf } \\
\text { acao) }\end{array}$ & $\begin{array}{l}\text { Pearson } \\
\text { Correlation } \\
\text { Sig. (2-tailed) } \\
\mathrm{N}\end{array}$ & $\begin{array}{c}-, 495^{\star *} \\
, 005 \\
30 \\
\end{array}$ & $\begin{array}{c}, 112 \\
, 557 \\
30 \\
\end{array}$ & $\begin{array}{c}-, 481^{* *} \\
, 007 \\
30 \\
\end{array}$ & 30 & $\begin{array}{c}, 137 \\
, 471 \\
30 \\
\end{array}$ & $\begin{array}{c}, 522^{* *} \\
, 003 \\
30 \\
\end{array}$ \\
\hline $\begin{array}{l}\text { Zscore(Cresc } \\
\text { médio) }\end{array}$ & $\begin{array}{l}\text { Pearson } \\
\text { Correlation } \\
\text { Sig. (2-tailed) } \\
\mathrm{N}\end{array}$ & $\begin{array}{c}-, 301 \\
, 106 \\
30 \\
\end{array}$ & $\begin{array}{c}-, 287 \\
, 125 \\
30 \\
\end{array}$ & $\begin{array}{c}-, 323 \\
, 081 \\
30 \\
\end{array}$ & $\begin{array}{c}, 137 \\
, 471 \\
30 \\
\end{array}$ & 30 & $\begin{array}{c}, 005 \\
, 977 \\
30 \\
\end{array}$ \\
\hline $\begin{array}{l}\text { Zscore(Preço } \\
\text { _médio) }\end{array}$ & $\begin{array}{l}\text { Pearson } \\
\text { Correlation } \\
\text { Sig. (2-tailed) } \\
\mathrm{N}\end{array}$ & $\begin{array}{c}-, 198 \\
, 294 \\
30\end{array}$ & $\begin{array}{c}-, 205 \\
, 278 \\
30\end{array}$ & $\begin{array}{c}-, 234 \\
, 214 \\
30\end{array}$ & $\begin{array}{c}, 522 * * \\
, 003 \\
30\end{array}$ & $\begin{array}{c}, 005 \\
, 977 \\
30 \\
\end{array}$ & 30 \\
\hline
\end{tabular}

Nota-se elevada correlação positiva entre as variáveis market-share e receita bruta $(0,984)$, uma vez que o cálculo da receita bruta tem como origem o marketshare da empresa. Sendo assim, a preços equiparáveis, quanto maior o marketshare, maior a sua receita bruta.

Outra correlação que se pode reparar é o fato da satisfação do cliente estar negativamente correlacionado com o market-share (-0,495), ainda que esta correlação não seja forte. Isso pode ser explicado pelo fato de que empresas com alta participação no mercado, em geral, atua em segmentos de menor valor agregado. Este segmento tem como característica a grande competição baseada 
em preços o que reduz investimento em atributos relacionados a satisfação do consumidor, tais como: qualidade, design, segurança, desempenho, etc. Desta forma, pela falta destes atributos em seus produtos, a satisfação do consumidor é afetada.

\section{4}

\section{Redução do espaço estratégico}

Para estudar a possibilidade da redução do espaço estratégico, foi realizado o teste Kaiser-Meyer-Olkin, com o objetivo de descobrir se as variâncias dos dados podem ser comuns às outras variáveis. $\mathrm{O}$ resultado encontrado de 0,831 , aliado com o grau de significância encontrado no teste de esfericidade, sugere a possibilidade da redução do espaço amostral em fatores.

Tabela 14 - Teste KMO e Bartlett's

\begin{tabular}{|c|c|c|}
\hline \multicolumn{2}{|c|}{ Kaiser-Meyer-Olkin Measure of Sampling Adequacy. } & ,831 \\
\hline Bartlett's Test of Sphericity & Approx. Chi-Square & 272,021 \\
\hline & DF & 55 \\
\hline & Sig. & ,000 \\
\hline
\end{tabular}

A análise de fatores foi realizada primeiramente sem rotação dos eixos, chegando-se à conclusão de que quatro fatores são capazes de explicar 87,59\% da variância original. Nesta primeira análise, notou-se que o primeiro fator recebeu uma grande quantidade de variáveis. Dessa forma, com o objetivo reduzir a carga total no primeiro fator e destacar os fatores com maior carga, a rotação ortogonal do tipo Varimax foi realizada, permitindo assim, uma melhor análise dos resultados.

Sendo assim, o espaço estratégico se manteve em quatro fatores, porém, elevando-se o auto-valor dos fatores 2,3 e 4, como por ser observado na tabela 15. 
Tabela 15 - Variância dos Fatores

\begin{tabular}{|c|c|c|c|c|c|c|c|c|c|}
\hline \multirow[t]{2}{*}{ Fatores } & \multicolumn{3}{|c|}{ Valores Iniciais } & \multicolumn{3}{|c|}{$\begin{array}{c}\text { Somatório dos valores } \\
\text { extraídos }\end{array}$} & \multicolumn{3}{|c|}{$\begin{array}{c}\text { Somatório da rotação dos } \\
\text { valores extraídos }\end{array}$} \\
\hline & Total & $\begin{array}{c}\% \text { of } \\
\text { Variance } \\
\end{array}$ & $\begin{array}{c}\text { Cumulati } \\
\text { ve } \%\end{array}$ & Total & $\begin{array}{c}\% \text { of } \\
\text { Variance }\end{array}$ & $\begin{array}{c}\text { Cumulati } \\
\text { ve } \%\end{array}$ & Total & $\begin{array}{c}\% \text { of } \\
\text { Variance }\end{array}$ & $\begin{array}{c}\begin{array}{c}\text { Cumulati } \\
\text { ve } \%\end{array} \\
\end{array}$ \\
\hline 1 & 5,151 & 51,507 & 51,507 & 5,151 & 51,507 & 51,507 & 2,809 & 28,092 & 28,092 \\
\hline 2 & 2,236 & 22,361 & 73,868 & 2,236 & 22,361 & 73,868 & 2,646 & 26,465 & 54,557 \\
\hline 3 & ,853 & 8,528 & 82,396 & ,853 & 8,528 & 82,396 & 1,739 & 17,392 & 71,949 \\
\hline 4 &, 520 & 5,204 & 87,599 &, 520 & 5,204 & 87,599 & 1,565 & 15,651 & 87,599 \\
\hline 5 & ,442 & 4,421 & 92,021 & & & & & & \\
\hline 6 & ,322 & 3,216 & 95,237 & & & & & & \\
\hline 7 & ,219 & 2,189 & 97,426 & & & & & & \\
\hline 8 & ,206 & 2,057 & 99,482 & & & & & & \\
\hline 9 & ,052 &, 518 & 100,000 & & & & & & \\
\hline 10 & $\begin{array}{r}2,914 \mathrm{E}- \\
016\end{array}$ & $\begin{array}{r}-2,914 \mathrm{E}- \\
015\end{array}$ & 100,000 & & & & & & \\
\hline
\end{tabular}

Método de Extração: Principal componente da análise.

Tabela 16 - Cargas dos fatores após rotação varimax

\begin{tabular}{|l|r|r|r|r|}
\hline \multirow{2}{*}{} & \multicolumn{4}{|c|}{ Fatores } \\
\cline { 2 - 5 } & 1 & 2 & 3 & 4 \\
\hline ZScore(Linha_prod) &, 757 & & & \\
ZScore(Canal) &, 922 & & & \\
ZScore(Abrangencia) & & & & \multirow{2}{*}{, 907} \\
ZScore(High_Price) & & & & \\
ZScore(Seg_Entrada) & & &, 777 & \\
ZScore(Serviços_Auxiliares) & & & & \\
ZScore(Qualidade) & & & & \\
ZScore(Pos_venda) & & & & \\
\hline
\end{tabular}

Método de Extração: Principal Componente da Análise.

Método de Rotação: Varimax com Normalização de Kaiser.

a. Rotação converge em 8 interações

Analisando os componentes dos fatores, percebe-se que o fator 1 se caracteriza pela linha de produção e pelos canais de distribuição. $\mathrm{O}$ fator 2 é composto pela variável Qualidade do produto. O terceiro fator é composto pela variável Serviços Auxiliares (serviços_auxiliares). Por fim, o quarto fator é representado pela variável Segmento de Entrada (seg_entrada). Os valores abaixo de 0,7 foram suprimidos para facilitar a visualização dos fatores. 
Segue, abaixo, um resumo com os fatores criados e suas respectivas identificações:

Tabela 17 - Fatores resultantes da redução fatorial das variáveis estratégicas

\begin{tabular}{|c|c|c|}
\hline Fator & Nome do Fator & Variáveis \\
\hline 1 & Gama de produtos e canal & Linha de produção e Canais de distribuição \\
\hline 2 & Qualidade do Produto & Qualidade \\
\hline 3 & Serviços & Serviços auxiliares \\
\hline 4 & Foco em Produtos de básicos & Segmento de Entrada \\
\hline
\end{tabular}

Apesar dos fatores reduzirem o espaço estratégico, a análise suprime variáveis de importante atuação na identificação da estratégia competitiva das empresas, sendo elas: abrangência, high price e Qualidade pós-venda. Além disso, três fatores são basicamente constituídos por apenas uma só variável. Dessa forma, não foi realizada a redução do espaço estratégico.

\section{5}

\section{Formação dos grupos estratégicos}

Definida a utilização de todas as variáveis, sem redução do espaço estratégico, foi realizada a análise de Clusters K-Means para a identificação das opções estratégicas das empresas. Este método é utilizado para unir objetos com características semelhantes, baseado no seu nível de correlação e coeficiente de associação (SILVA, 1997). Dessa forma, empresas com estratégias semelhantes farão parte do mesmo cluster, diferenciando-se estrategicamente de empresas pertencentes a outros clusters.

A análise do espaço estratégico utiliza a matriz inicial pré-fixada dos centroides de cada cluster, baseada na tipologia estudada, neste caso, a tipologia das estratégias genéricas de Michael Porter (1980). A partir da divisão dos quartis e dos pesos ou coordenadas auferidos a cada variável em relação aos clusters (baseados nos quartis), pode-se posicionar os centroides para a construção da matriz inicial, conforme mostra a tabela 18. 
Tabela 18 - Matriz dos quartis usados para formação da matriz inicial dos centroides

\begin{tabular}{|c|c|c|c|c|c|c|c|c|c|}
\hline & & $\begin{array}{c}\text { Linha_pr } \\
\text { od }\end{array}$ & Canal & $\begin{array}{c}\text { Abrangen } \\
\text { cia }\end{array}$ & $\begin{array}{c}\text { High_pr } \\
\text { ice }\end{array}$ & $\begin{array}{c}\text { Seg_Entr } \\
\text { ada }\end{array}$ & $\begin{array}{l}\text { Serviços_ } \\
\text { Auxiliares }\end{array}$ & $\begin{array}{c}\text { Qualida } \\
\text { de }\end{array}$ & $\begin{array}{c}\text { Pos_ve } \\
\text { nda }\end{array}$ \\
\hline \multirow{3}{*}{$1 \mathrm{~N}$} & Válidos & 30 & 30 & 30 & 30 & 30 & 30 & 30 & 30 \\
\hline & Missing & 0 & 0 & 0 & 0 & 0 & 0 & 0 & 0 \\
\hline & 25 &,- 689 &,- 665 &,- 578 & $-1,071$ &,- 581 & $-1,097$ &,- 469 &,- 820 \\
\hline \multirow[t]{2}{*}{ Quartis } & 50 &,- 324 &,- 491 & ,255 & 203 &,- 581 &,- 3135 &,- 029 & 0937, \\
\hline & 75 & 648 & 315 & 841 & 1,115 & ,559 & 1,254 & ,630 & ,856 \\
\hline
\end{tabular}

Com base na tipologia de Porter (1980), as estratégias competitivas são coordenadas com a utilização dos quartis Q1, Q2 e Q3, indicando o grau de utilização da variável em cada opção estratégica possível. Isto é, Q1, Q2 e Q3 representando, respectivamente, a menor, intermediária ou maior ênfase de cada estratégia genérica defendida por Porter. Empresas sem posicionamento mostram indiferença às variáveis estratégicas, ficando posicionadas em cluster com coordenadas na média amostral, ou seja, Q2 (SILVA, 1997). Dessa forma, a tabela 19 mostra os pesos dado, por cada cluster, às variáveis estudadas.

Tabela 19 - Matriz dos centroides iniciais - Distribuição teórica

\begin{tabular}{|c|c|c|c|c|c|}
\hline Variável & $\begin{array}{c}\text { Lid em } \\
\text { custo Total }\end{array}$ & Diferenciação & $\begin{array}{c}\text { Enfoque } \\
\text { em Custo }\end{array}$ & $\begin{array}{c}\text { Enfoque em } \\
\text { Diferenciação }\end{array}$ & $\begin{array}{c}\text { Sem } \\
\text { posicionamento }\end{array}$ \\
\hline Lin_Prod & Q3 & Q1 & Q1 & Q1 & Q2 \\
\hline Canal_Distr & Q3 & Q3 & Q2 & Q1 & Q2 \\
\hline Abrangência & Q3 & Q2 & Q2 & Q1 & Q2 \\
\hline HighPrice & Q1 & Q3 & Q1 & Q3 & Q2 \\
\hline Seg_Entrada & Q3 & Q1 & Q3 & Q1 & Q2 \\
\hline Serv_Aux & Q2 & Q3 & Q1 & Q3 & Q2 \\
\hline Qualidade & Q3 & Q1 & Q3 & Q1 & Q2 \\
\hline Pos_Venda & Q2 & Q3 & Q1 & Q3 & Q2 \\
\hline
\end{tabular}

Como a variável Qualidade foi medida com base no número de recalls, quanto menor o z-score dela, melhor a qualidade. Portanto, empresas que buscam maior diferenciação e qualidade de seus carros apareceriam em Q1 na tabela acima, isto é, teriam menor número de recalls.

Como consequência do uso desta teoria, o número de clusters é pré-fixado em cinco, representando as opções estratégicas disponíveis, isto é: liderança em 
custo total, diferenciação, enfoque em custos, enfoque em diferenciação e stuckin-the-middle. A tabela 20 mostra a matriz inicial dos centroides, com os seus respectivos percentis.

Tabela 20 - Matriz Inicial dos centroides com percentis aplicados

\begin{tabular}{|l|r|r|r|r|r|}
\hline & \multicolumn{5}{|c|}{ Cluster } \\
\cline { 2 - 6 } & \multicolumn{1}{|c|}{1} & \multicolumn{1}{c|}{2} & \multicolumn{1}{c|}{3} & \multicolumn{1}{c|}{4} & \multicolumn{1}{c|}{5} \\
\hline Zscore(Linha_prod) &, 64800 &,- 68000 &, 64800 &,- 68000 &,- 32000 \\
Zscore(Canal) &, 31500 &, 31500 &,- 49000 &,- 66500 &,- 49000 \\
Zscore(Abrangencia) &, 84100 &, 25000 &, 25000 &,- 57800 &, 25000 \\
Zscore(High_Price) & $-1,07100$ & 1,11500 & $-1,07000$ & 1,11500 &, 20000 \\
Zscore(Seg_Entrada) &, 55900 &,- 58000 &, 55900 &,- 58000 &,- 58000 \\
Zscore(Serviços_Auxiliares) &,- 31350 & 1,25000 & $-1,09000$ & 1,25000 &,- 31350 \\
Zscore(Qualidade) &, 63000 &,- 46900 &, 63000 &,- 46900 &,- 29000 \\
Zscore(Pos_venda) &, 09000 &, 85600 &,- 82000 &, 85600 &, 09300 \\
\hline
\end{tabular}

Utilizando a matriz original como base, o método de clusters calcula o novo posicionamento dos centroides, oferecendo a matriz final com o posicionamento de cada empresa em seu determinado cluster, conforme mostra a tabela 21.

Tabela 21 - Matriz final dos centroides

\begin{tabular}{|l|r|r|r|r|r|}
\hline & \multicolumn{5}{|c|}{ Cluster } \\
\cline { 2 - 6 } & 1 & \multicolumn{1}{|c|}{2} & \multicolumn{1}{c|}{3} & \multicolumn{1}{c|}{4} & \multicolumn{1}{c|}{5} \\
\hline Zscore(Linha_prod) & 1,20807 &,- 32431 &, 10135 &, 13783 &,- 93240 \\
Zscore(Canal) & 1,86666 &, 22168 &, 07462 &,- 71188 &,- 48568 \\
Zscore(Abrangencia) &, 86038 &, 81098 &, 78011 & $-1,15266$ &, 12291 \\
Zscore(High_Price) &,- 97922 &, 09709 & $-1,23423$ &, 92338 &, 03012 \\
Zscore(Seg_Entrada) & 1,18234 &,- 36283 & 1,35750 &,- 58179 &,- 58179 \\
Zscore(Serviços_Auxiliares) &,- 47030 &, 27434 &,- 70546 & 1,09738 &,- 98540 \\
Zscore(Qualidade) &,- 46922 &, 63051 & $-1,34900$ &, 76248 &,- 34354 \\
Zscore(Pos_venda) &,- 18939 &, 83385 & $-1,36339$ &, 88257 &,- 82295 \\
\hline
\end{tabular}

Com o objetivo de identificar se há significativa diferença entre as duas matrizes, isto é, matriz inicial e matriz final, foi realizado o teste não paramétrico Wilcoxon Signed Rank Test sobre as variáveis destas matrizes, cujo resultado eé apresentado na Tabela 22. A variável chamada de T (de T1 a T5) representa as variáveis da matriz inicial, enquanto a variável F (de F1 a F5), representam as variáveis da matriz final. Pelos resultados apresentados na tabela abaixo, analisando o grau de significância, não podemos rejeitar a hipótese nula de 
igualdade das matrizes, não podendo afirmar que houve diferenças significativas entre as matrizes estudadas. Assim, pode-se concluir que a matriz final corresponderia à matriz teórica, confirmando os cinco grupos estratégicos de Porter (1980).

Tabela 22 - Teste de Wilcoxon

\begin{tabular}{|c|c|c|c|c|c|}
\hline & $\mathrm{F} 1-\mathrm{T} 1$ & $\mathrm{~F} 2-\mathrm{T} 2$ & F3 - T3 & $\mathrm{F} 4-\mathrm{T} 4$ & F5 - T5 \\
\hline Z & $-1,071^{b}$ &,$- 153^{b}$ &,$- 051^{c}$ &,$- 153^{c}$ & $-1,071^{c}$ \\
\hline Asymp. Sig. (2-tailed) & 284 & 878 & ,959 & ,878 & 284 \\
\hline
\end{tabular}

a. Baseado em ranks positivos

b. Baseado em ranks negativos

\section{6}

\section{Grupos estratégicos:}

Com os cluster formados, pode-se analisar quais empresas estão classificadas em cada grupo estratégico. A tabela 23 mostra a quantidade de empresas em cada cluster.

Tabela 23 - Número de casos por cluster

\begin{tabular}{|ll|r|}
\hline & 1 & 5 \\
& 2 & 4 \\
Cluster & 3 & 4 \\
& 4 & 10 \\
& 5 & 7 \\
Válidos & & 30 \\
Missing & & 0 \\
\hline
\end{tabular}

No primeiro cluster, correspondente à estratégia de liderança em custos totais, foram classificadas cinco empresas. Já no cluster de número dois, ou seja, de estratégia de diferenciação, foram classificadas quatro empresas. Nos clusters de enfoque 3 e 4 , isto é, enfoque em custo e enfoque em diferenciação, foram classificadas quatro e dez empresas respectivamente. Por fim, o cluster de número 5, ou seja, stuck-in-the-middle, foi composto por sete empresas. Na tabela 24, pode-se identificar a composição detalhada de cada cluster, observando-se o grupo estratégico de cada empresa estudada. 
Tabela 24 - Grupos Estratégicos

\begin{tabular}{|c|c|}
\hline Grupo Estratégico & Empresa \\
\hline $\begin{array}{c}\text { 1-Liderança em } \\
\text { Custo }\end{array}$ & $\begin{array}{l}\text { GENERAL MOTORS DO BRASIL LTDA } \\
\text { FIAT AUTOMÓVEIS S.A. } \\
\text { FORD MOTOR COMPANY BRASIL } \\
\text { VOLKSWAGEN DO BRASIL LTDA } \\
\text { RENAULT DO BRASIL S.A. }\end{array}$ \\
\hline 2-Diferenciação & $\begin{array}{l}\text { HONDA AUTOMÓVEIS DO BRASIL LTDA } \\
\text { TOYOTA DO BRASIL LTDA } \\
\text { MMC AUTOMOTORES DO BRASIL S.A. } \\
\text { HYUNDAI MOTOR BRASIL LTDA }\end{array}$ \\
\hline $\begin{array}{c}\text { 3-Enfoque em } \\
\text { Custo }\end{array}$ & $\begin{array}{l}\text { PEUGEOT CITROEN DO BRASIL LTDA (PEUGEOT) } \\
\text { PEUGEOT CITROEN DO BRASIL LTDA (CITROEN) } \\
\text { NISSAN DO BRASIL AUTOMÓVEIS LTDA } \\
\text { CHERY BRASIL FABRICAÇÃO E IMPORTAÇÃO DE } \\
\text { VEÍCULOS LTDA }\end{array}$ \\
\hline $\begin{array}{l}\text { 4-Enfoque em } \\
\text { Diferenciação }\end{array}$ & $\begin{array}{l}\text { BMW DO BRASIL LTDA } \\
\text { FERRARI } \\
\text { PORSCHE } \\
\text { LAND ROVER DO BRASIL LTDA } \\
\text { AUDI DO BRASIL LTDA } \\
\text { JAGUAR } \\
\text { LAMBORGHINI } \\
\text { MERCEDES BENZ DO BRASIL LTDA } \\
\text { SUBARU } \\
\text { VOLVO DO BRASIL } \\
\end{array}$ \\
\hline $\begin{array}{l}\text { 5-Stuck-in-the- } \\
\text { middle }\end{array}$ & $\begin{array}{l}\text { SSANGYOUNG } \\
\text { KIA MOTORS DO BRASIL LTDA } \\
\text { SUZUKI VEÍCULOS BRASIL LTDA } \\
\text { DODGE } \\
\text { JEEP } \\
\text { CHRYSLER } \\
\text { TROLLER } \\
\end{array}$ \\
\hline
\end{tabular}

5.6.1

Análises dos grupos estratégicos

Para facilitar a análise dos grupos estratégicos, a tabela 25 mostra os clusters e suas variáveis mais representativas. 
Tabela 25 - Matriz das variáveis por grupos estratégicos

\begin{tabular}{|c|c|c|c|c|c|}
\hline & $\begin{array}{c}\text { Liderança em } \\
\text { Custos Total }\end{array}$ & Diferenciação & $\begin{array}{c}\text { Enfoque em } \\
\text { custos }\end{array}$ & $\begin{array}{c}\text { Enfoque em } \\
\text { Diferenciação }\end{array}$ & $\begin{array}{c}\text { Stuck-in-the- } \\
\text { Middle }\end{array}$ \\
\hline Market-share & $80,1 \%$ & $10,8 \%$ & $6,7 \%$ & $0,8 \%$ & $1,7 \%$ \\
\hline $\begin{array}{c}\text { Market-share } \\
\text { por Empresa }\end{array}$ & $16,35 \%$ & $2,69 \%$ & $1,67 \%$ & $0,08 \%$ & $0,22 \%$ \\
\hline $\begin{array}{c}\text { Receita Bruta } \\
\text { R\$ }\end{array}$ & 16.287 .719 .790 & 5.588 .556 .417 & 1.360 .842 .019 & 398.558 .161 & 548.848 .361 \\
\hline $\begin{array}{c}\text { Crescimento } \\
\text { do Market- } \\
\text { share }\end{array}$ & $10,69 \%$ & $24,16 \%$ & $40,56 \%$ & $40,01 \%$ & $77,59 \%$ \\
\hline $\begin{array}{c}\text { Satisfação } \\
\text { Cliente }\end{array}$ & 733,0 & 797,2 & 752,2 & 837,0 & 767,0 \\
\hline $\begin{array}{c}\text { Canal de } \\
\text { Distribuição }\end{array}$ & 396 & 159 & 105 & 24 & 56 \\
\hline $\begin{array}{c}\text { Abrangência } \\
\text { Linhas de }\end{array}$ & 26,4 & 26,0 & 24,3 & 10,1 & 20,4 \\
\hline Produto & 11,8 & 5,5 & 5,8 & 7,4 & 3,0 \\
\hline \begin{tabular}{c} 
Preço Médio \\
\hline
\end{tabular} & 35.130 & 69.893 & 547.402 & 100.100 \\
\hline
\end{tabular}

\subsubsection{1}

\section{Grupo 1 - Estratégia de liderança em custo total}

O cluster de liderança em custo total foi composto pelas empresas General Motors (sendo analisada a marca Chevrolet), Fiat, Ford, Renault e Volkswagen. Estas empresas dominam o mercado em relação às vendas $(80,1 \%)$ e em relação à receita bruta anual. Essas empresas têm como características a grande variedade na linha de produtos, assim como a grande abrangência nacional, tanto em estados de atuação, quando em número de revendas. Em relação ao preço médio, por terem grande participação no segmento de entrada, e por focarem na estratégia de liderança em custo total, essas empresas apresentam a menor média de preço médio por veículo $(\mathrm{R} \$ 35.130)$.

\subsubsection{2}

\section{Grupo 2 - Estratégia de diferenciação}

O cluster de diferenciação também se caracteriza pela grande abrangência em termos de estados nacionais, porém atua com reduzidos canais de venda. O 
foco está na busca em diferenciar o produto no mercado, em atributos que sejam valorizados e para os quais exista mercado em escala ampla. As empresas que fazem parte desse grupo são: Honda, Hyundai, Toyota e Mitsubishi (MMC).

Estas empresas têm como característica participar de diversos segmentos de mercado, disponibilizando poucos modelos por segmento. Porém, costumam possuir veículos considerados sucesso de venda, como é o caso do Honda Civic e Fit, do Toyota Corola e Hilux, do Hyundai HB20 e da Mitsubishi L200. A participação total deste grupo atinge 10,8\% do market-share, com preço médio de $\mathrm{R} \$ 69.783$ por veículo.

\subsubsection{3}

\section{Grupo 3 - Estratégia de enfoque em custo}

Oito empresas foram classificadas como seguidoras da estratégia de enfoque em custo, sendo elas: Chery, Citroen, Nissan e Peugeot. Apesar de atuarem de forma focada, estas quatro empresas possuem abrangência de atuação nacional, porém com escalas reduzidas de concessionárias e variedade de produto.

Notou-se, nesse grupo, alguma heterogeneidade entre algumas empresas. Destaca-se a Chery, atuando com preços extremamente competitivos nos segmentos em que atua. Já as empresas Citroen, Peugeot e Nissan, possuem como característica tanto a variada opção de modelos como o fato de competirem em diversos segmentos do mercado, como o segmento de compactos premium (Citroen C3, Peugeot 206 e Nissan March), dos sedãs médios (Citroen C4, Peugeot 307 e Nissan Versa), dos sedãs grandes (Citroen C5, Peugeot 407 e Nissan Altima) e no segmento de mono volume (Citroen Picasso e Nissan Livina).

Em relação ao preço, costumam competir em segmentos de entrada, com preços competitivos, porém, por atuarem de maneira focada, não apresentam volume suficiente para usufruir de redução de custo por economia de escala. Com isso, essas empresas não conseguem ter preços tão atraentes quanto as empresas que competem em liderança por custo de maneira ampla. 


\subsubsection{4}

\section{Grupo 4 - Estratégia de enfoque em diferenciação}

Esse grupo estratégico foi formado pelas empresas: Audi, BMW, Ferrari, Jaguar, Lamborghini, Land Rover, Mercedes-Benz, Porsche, Subaru e Volvo.

Como característica geral, nota-se o alto preço médio dos veículos (R $\$$ 547.402), a variada opção de serviços pós-venda e o alto investimento em atributos que agreguem valor ao produto, principalmente em qualidade, design, tecnologia e desempenho. Estas dimensões geram alta credibilidade e altos índices de satisfação por parte de seus consumidores. Por outro lado, este grupo estratégico possui reduzida área de atuação e baixo número de concessionárias, quando comparados aos demais grupos estratégicos.

Apesar de algumas características em comum, nota-se também alguma heterogeneidade entre estas empresas. Ferrari e Lamborghini formam um subgrupo com veículos extremamente exclusivos, atuando com um preço médio de $\mathrm{R} \$ 1.965 .544$ comprado ao preço médio do grupo de $\mathrm{R} \$$ 632.774. Cada empresa possui apenas uma concessionária em todo o país, ambas localizadas em São Paulo. O volume de produção dessas empresas é baixíssimo, sendo vendida uma média anual de 23 veículos por empresa. Já a outras empresas que formam este grupo estratégico, atuam de forma mais homogênea, possuindo diversos modelos e uma rede de concessionárias mais ramificada. Caso à parte, a Subaru fica abaixo da média do grupo tanto na diversidade de modelos (apenas 5), quanto em abrangência e canais de distribuição, contando com apenas 18 concessionárias, distribuídas por 7 estados. Seu foco está na categoria dos sedãs premium, apesar de apresentar problemas em relação ao seu volume de venda. Com seu alto preço médio por veículo ( $\mathrm{R} \$ 119.365)$, a empresa conquistou apenas $0,14 \%$ das vendas totais do mercado.

Outra característica presente em apenas algumas empresas deste grupo é a respeito da linha de produção. Marcas como BMW, Audi e Mercedes apresentam alta variedade de produtos, 16, 12 e 11 respectivamente. Este fato pode ser explicado devido à participação em diversos segmentos de mercado, com veículos competindo até em segmentos intermediários com preços a partir de $\mathrm{R} \$ 70.000$. 


\subsubsection{5}

\section{Grupo 5 - Stuck-in-the-middle}

Classificadas como stuck-in-the-middle, as empresas Chrysler, Dodge, Kia Motors, Jeep, SsangYoung, Suzuki e Troller representam o grupo das empresas que apresentam aparente inconsistência estratégica ou falha na implementação da mesma. Como característica do grupo, nota-se a relativa baixa abrangência de atuação (20 estados) e a limitada linha de produtos, apresentando uma média de3 modelos distintos por empresa. Destaca-se também o alto valor do preço médio do grupo, sendo o segundo maior dentre todos os grupos estratégicos (R $\$ 100.100)$

Apesar do alto preço médio de seus veículos, o que poderia sugerir qualidade ou variada oferta de serviços, estas empresas apresentam poucos serviços auxiliares oferecidos, baixos níveis de serviços pós-venda e baixo investimento em qualidade, ajudando a justificar os saltos nos níveis de recalls realizados pelas empresas.

Outra característica do grupo é o fato de nenhuma empresa participar do segmento de entrada do mercado. Este grupo concentra sua oferta em utilitários, sedãs premium, $S U V s$ e vans.

É importante citar o aparente bom resultado deste grupo na variável crescimento do market share. Este resultado pode ser justificado pelo fato dessas empresas apresentarem baixos volumes de venda, fazendo com que pequenas variações no número de veículos vendidos, gere altos índices de variação em percentual.

Dentre as empresas situadas neste grupo, destaca-se a nacional Troller, que concorre diretamente com a Jeep e com a Suzuki dentro da categoria dos utilitários. Apresenta apenas um modelo em sua linha de produção, o T4, comercializado em 15 diferentes estados, mas com uma participação extremamente discreta nas vendas totais da indústria (\% 0,04).

A Jeep, a Dodge e a Chrysler, todas controladas pelo grupo Chrysler Group, de propriedade da Fiat S.p.A., competem em segmentos distintos. Enquanto a primeira oferece SUVs como foco 'foco-da-estada', a segundo segue a linha dos sedãs premium, com apenas duas variedades de veículos. 
Por fim, destaca-se a coreana Ssang Young compete no restrito segmento das SUVs, apresentando três variedades de veículos a preços competitivos, mas sofre com o baixo volume de vendas. Apesar da larga abrangência de seus canais de distribuição, atuando em 19 estados, as vendas da empresa representam menos de $0,1 \%$ do volume total da indústria.

\section{7}

\section{Comparação de desempenho entre grupos}

Por ter sido a única variável de desempenho a apresentar distribuição normal, além de satisfazer todas as premissas da análise variância, a variável Satisfação dos Clientes (Satisfação) foi submetida ao teste de análise de variância (ANOVA) com o objetivo de descobrir se a mesma apresenta diferenças significativas entre clusters. Após o teste, a variável foi submetida ao teste de Bonferroni, com o objetivo de comparar e ordenar suas médias entre os clusters. Os resultados são apresentados nas tabelas 26 e 27.

Tabela 26 - Análise de variância para a variável Satisfação

\begin{tabular}{|l|r|r|r|r|r|}
\hline & Sum of Squares & df & Mean Square & F & Sig. \\
\hline Between Groups & 23,725 & 4 & 5,931 & 28,111 &, 000 \\
Within Groups & 5,275 & 25 &, 211 & & \\
Total & 29,000 & 29 & & & \\
\hline
\end{tabular}

Por apresentar grau de significância inferior ao p-valor, rejeita-se a hipótese nula de igualdade entre as médias da variável entre os grupos. Pode-se afirmar, dessa forma, que a média de pelo menos um dos grupos estratégicos é diferentes dos demais. 
Tabela 27 - Teste de Bonferroni para a variável Satisfação

\begin{tabular}{|c|c|c|c|c|c|c|}
\hline \multirow{2}{*}{$\begin{array}{l}\text { (I) Cluster } \\
\text { Number of } \\
\text { Case }\end{array}$} & \multirow{2}{*}{$\begin{array}{l}\text { (J) Cluster } \\
\text { Number of } \\
\text { Case }\end{array}$} & \multirow{2}{*}{$\begin{array}{c}\text { Mean } \\
\text { Difference (I-J) }\end{array}$} & \multirow[t]{2}{*}{ Std. Error } & \multirow[t]{2}{*}{ Sig. } & \multicolumn{2}{|c|}{ 95\% Confidence Interval } \\
\hline & & & & & $\begin{array}{l}\text { Lower } \\
\text { Bound }\end{array}$ & $\begin{array}{l}\text { Upper } \\
\text { Bound }\end{array}$ \\
\hline \multirow{4}{*}{1} & 2 & $-1,44187728^{*}$ & ,32480199 & ,002 & $-2,4416826$ &,- 4420720 \\
\hline & 3 &,- 40844052 & ,28128678 & 1,000 & $-1,2742973$ & ,4574163 \\
\hline & 4 & $-2,30810013^{\star}$ & ,27174884 &, 000 & $-3,1445973$ & $-1,4716030$ \\
\hline & 5 &,- 86622285 & ,32480199 & ,132 & $-1,8660282$ & ,1335825 \\
\hline \multirow{4}{*}{2} & 1 & $1,44187728^{*}$ & ,32480199 & ,002 & ,4420720 & 2,4416826 \\
\hline & 3 & $1,03343676^{*}$ & ,28128678 & ,011 & ,1675800 & 1,8992936 \\
\hline & 4 &,$- 86622285^{\star}$ & ,27174884 & ,038 & $-1,7027200$ &,- 0297257 \\
\hline & 5 &, 57565443 & ,32480199 & ,885 &,- 4241509 & 1,5754597 \\
\hline \multirow{4}{*}{3} & 1 & ,40844052 & ,28128678 & 1,000 &,- 4574163 & 1,2742973 \\
\hline & 2 & $-1,03343676^{\star}$ & ,28128678 & ,011 & $-1,8992936$ &,- 1675800 \\
\hline & 4 & $-1,89965961^{*}$ & ,21788380 & ,000 & $-2,5703494$ & $-1,2289698$ \\
\hline & 5 &,- 45778233 & ,28128678 & 1,000 & $-1,3236391$ & ,4080745 \\
\hline \multirow{4}{*}{4} & 1 & $2,30810013^{\star}$ & ,27174884 & ,000 & 1,4716030 & 3,1445973 \\
\hline & 2 & ,86622285 & ,27174884 & ,038 & ,0297257 & 1,7027200 \\
\hline & 3 & $1,89965961^{*}$ & ,21788380 & ,000 & 1,2289698 & 2,5703494 \\
\hline & 5 & $1,44187728^{*}$ & ,27174884 &, 000 & ,6053801 & 2,2783744 \\
\hline \multirow{4}{*}{5} & 1 & ,86622285 & 32480199 & ,132 &,- 1335825 & 1,8660282 \\
\hline & 2 &,- 57565443 & ,32480199 & ,885 & $-1,5754597$ & ,4241509 \\
\hline & 3 & ,45778233 & ,28128678 & 1,000 &,- 4080745 & 1,3236391 \\
\hline & 4 & $-1,44187728^{\star}$ & ,27174884 & ,000 & $-2,2783744$ &,- 6053801 \\
\hline
\end{tabular}

*. A diferença média é significante no nível de 0,05 (5\%) e está em negrito.

Visto que há diferença em pelo menos um dos clusters, o teste de Bonferroni procura identificar quais clusters apresentam tais diferenças, permitindo ordenar as diferenças das médias entre eles. Comparando o resultado entre a diferença das médias, assim como o grau de significância, pode-se concluir que, para a variável satisfação, o cluster 4, isto é, o grupo estratégico de enfoque em diferenciação, possui desempenho superior quando comparado a todos os outros grupos estratégicos.

Como as demais variáveis de desempenho não apresentaram distribuições normais, optou-se por realizar o teste não paramétrico de Kruskal-Wallis para identificar se há diferença entre as variáveis de desempenho dos grupos estratégicos. Este teste analisa três ou mais amostras, não exigindo premissas 
quanto a sua distribuição, buscando identificar se as mesmas possuem origem da mesma população (BLACK, 2010).

Pelos valores de significância encontrados, indica-se a rejeição da hipótese nula, de que as médias dos grupos são iguais, para as variáveis: market-share, market-share por segmento, receita bruta, satisfação e preço médio. Dessa forma, para estas variáveis citadas, o teste sugere existir diferenças significativas entre pelo menos dois dos clusters. Já para a variável crescimento médio de market share, o teste não conseguiu identificar diferenças entre as médias dos grupos.

O resultado o teste de Kruskal-Wallis é apresentado na tabela 28, a seguir:

Tabela 28 - Teste de Kruskal-Wallis

\begin{tabular}{|c|c|c|c|c|}
\hline & Null Hypothesis & Test & Sig. & Decision \\
\hline 1 & $\begin{array}{l}\text { The distribution of Zscore } \\
\text { (Market_Share) is the same across } \\
\text { categories of Cluster Number of } \\
\text { Case. }\end{array}$ & $\begin{array}{l}\text { Independent- } \\
\text { Samples } \\
\text { Kruskal- } \\
\text { Villis Test }\end{array}$ & ,000 & $\begin{array}{l}\text { Reject the } \\
\text { null } \\
\text { hypothesis. }\end{array}$ \\
\hline 2 & $\begin{array}{l}\text { The distribution of Zscore } \\
\text { (Maket_Share_Seg) is the same } \\
\text { across categories of Cluster } \\
\text { Number of Case. }\end{array}$ & $\begin{array}{l}\text { Independent- } \\
\text { Samples } \\
\text { Kruskal- } \\
\text { Wiallis Test }\end{array}$ & .027 & $\begin{array}{l}\text { Reject the } \\
\text { null } \\
\text { hypothesis. }\end{array}$ \\
\hline 3 & $\begin{array}{l}\text { The distribution of Zscore } \\
\text { (Rec_Bruta) is the same across } \\
\text { categories of Cluster Number of } \\
\text { Case. }\end{array}$ & $\begin{array}{l}\text { Independent- } \\
\text { Samples } \\
\text { Kruskal- } \\
\text { Willis Test }\end{array}$ & .000 & $\begin{array}{l}\text { Reject the } \\
\text { null } \\
\text { hypothesis. }\end{array}$ \\
\hline 4 & $\begin{array}{l}\text { The distribution of Zscore } \\
\text { (Satisacao) is the same across } \\
\text { categories of Cluster Number of } \\
\text { Case. }\end{array}$ & $\begin{array}{l}\text { Independent- } \\
\text { Samples } \\
\text { Kruskal- } \\
\text { vilallis Test }\end{array}$ & ,000 & $\begin{array}{l}\text { Reject the } \\
\text { null } \\
\text { hypothesis. }\end{array}$ \\
\hline 5 & $\begin{array}{l}\text { The distribution of Zscore } \\
\text { (Cresc_médio) is the same across } \\
\text { categories of Cluster Number of } \\
\text { Case. }\end{array}$ & $\begin{array}{l}\text { Independent- } \\
\text { Samples } \\
\text { Kruskal- } \\
\text { Vilialis Test }\end{array}$ & .191 & $\begin{array}{l}\text { Retain the } \\
\text { null } \\
\text { hypothesis. }\end{array}$ \\
\hline 6 & $\begin{array}{l}\text { The distribution of Zscore } \\
\text { (Preço_médio) is the same across } \\
\text { categories of Cluster Number of } \\
\text { Case. }\end{array}$ & $\begin{array}{l}\text { Independent- } \\
\text { Samples } \\
\text { Kruskal- } \\
\text { vilialis Test }\end{array}$ & ,000 & $\begin{array}{l}\text { Reject the } \\
\text { null } \\
\text { hypothesis. }\end{array}$ \\
\hline
\end{tabular}

Apesar de a distribuição de quase todas as variáveis dependentes não ser normal, optou-se por realizar uma análise usando MANOVA, mesmo se sabendo não ser este robusto à quebra desta premissa. $\mathrm{O}$ objetivo aqui é apenas comparar 
os resultados da MANOVA com os testes anteriores e verificar se existe alguma possível compatibilidade de resultados.

Com o objetivo de identificar se existe diferença significativa entre o desempenho de cada cluster, considerando todas as variáveis de desempenho juntas e analisando o posicionamento do centroide de cada cluster, foram realizados os testes Wilks' Lambda de Hotelling's Trace (T de Hotelling). Nestes testes, a hipótese nula é de que os centroides dos vetores de desempenho dos clusters analisados possuem o mesmo posicionamento.

Analisando o resultado dos testes, observa-se o p-valor menor 0,05 rejeitando-se hipótese nula, ou seja, o teste sugere que existem evidências estatísticas para afirmar que pelo menos um grupo estratégico é diferente dos outros em relação ao seu desempenho.

Tabela 29 - Teste de igualdade de desempenho dos grupos estratégicos

\begin{tabular}{|l|l|r|r|r|r|r|}
\hline \multicolumn{1}{|l|}{ Effect } & Value & \multicolumn{1}{c|}{ F } & Hypothesis df & Error df & Sig. \\
\hline \multirow{3}{*}{ Intercept } & Pillai's Trace &, 456 & $1,884^{\mathrm{b}}$ & 8,000 & 18,000 &, 126 \\
& Wilks' Lambda &, 544 & $1,884^{\mathrm{b}}$ & 8,000 & 18,000 &, 126 \\
& Hotelling's Trace &, 837 & $1,884^{\mathrm{b}}$ & 8,000 & 18,000 &, 126 \\
& Roy's Largest Root &, 837 & $1,884^{\mathrm{b}}$ & 8,000 & 18,000 &, 126 \\
\hline \multirow{3}{*}{ QCL_1 } & Pillai's Trace & 3,059 & 8,530 & 32,000 & 84,000 &, 000 \\
& Wilks' Lambda &, 001 & 12,336 & 32,000 & 67,976 &, 000 \\
& Hotelling's Trace & 25,651 & 13,226 & 32,000 & 66,000 &, 000 \\
& Roy's Largest Root & 12,406 & $32,565^{\mathrm{c}}$ & 8,000 & 21,000 &, 000 \\
\hline
\end{tabular}

Valor exato

b. A estatística é um valor superior a F que leva a um valor menor do nível de significância.

c. Design: Interceptado +Cluster

Por fim, foi realizado o teste Bonferroni (Tabela 30), com o objetivo de identificar tanto as variáveis de desempenho que apresentam diferenças entre grupos estratégicos, quanto quais são estes grupos estratégicos e seu ordenamento relativo. Ressalvas devem ser feitas, uma vez que o teste de Bonferroni foi realizado como post hoc do teste de análise multivariada, possuindo premissas de normalidades das variáveis. Dessa forma, as análises a seguir podem apresentar resultados pouco confiáveis. 
Um grau de significância abaixo do p-valor sugere haver diferença significativa entre as variáveis (Black, 2010), podendo, dessa forma, se afirmar que os desempenhos dos grupos são diferentes para a variável analisada. Os valores com asterisco indicam as variáveis, as quais, o teste sugere haver diferença estatística entre os grupos e estão marcados em negrito na tabela 30. Os valores que apresentam asterisco, podem ser compreendidos como valores significativos ao nível de 0,05 , para a diferença de suas respectivas médias.

Tabela 30 - Teste de Bonferroni - comparação de desempenho entre grupos estratégicos

\begin{tabular}{|c|c|c|c|c|c|c|c|}
\hline \multirow{2}{*}{$\begin{array}{l}\text { Variável } \\
\text { Dependente }\end{array}$} & \multirow{2}{*}{$\begin{array}{l}\text { (I) Cluster } \\
\text { Number of } \\
\text { Case }\end{array}$} & \multirow{2}{*}{$\begin{array}{l}\text { (J) Cluster } \\
\text { Number of } \\
\text { Case }\end{array}$} & \multirow{2}{*}{$\begin{array}{c}\text { Mean } \\
\text { Difference (I- } \\
\mathrm{J})\end{array}$} & \multirow[t]{2}{*}{ Std. Error } & \multirow[t]{2}{*}{ Sig. } & \multicolumn{2}{|c|}{ 95\% Confidence Interval } \\
\hline & & & & & & $\begin{array}{l}\text { Lower } \\
\text { Bound }\end{array}$ & $\begin{array}{l}\text { Upper } \\
\text { Bound }\end{array}$ \\
\hline \multirow{5}{*}{$\begin{array}{l}\text { Zscore(Market } \\
\text { _Share) }\end{array}$} & 1 & $\begin{array}{l}2 \\
3 \\
4 \\
5\end{array}$ & $\begin{array}{l}2,0024774^{*} \\
2,1885812^{*} \\
2,4119058^{*} \\
2,3906368^{*}\end{array}$ & $\begin{array}{r}, 33626911 \\
, 33626911 \\
, 27456258 \\
, 29351974 \\
\end{array}$ & $\begin{array}{l}, 000 \\
, 000 \\
, 000 \\
, 000 \\
\end{array}$ & $\begin{array}{r}, 9673740 \\
1,1534778 \\
1,5667474 \\
1,4871245 \\
\end{array}$ & $\begin{array}{l}3,0375807 \\
3,2236846 \\
3,2570642 \\
3,2941491 \\
\end{array}$ \\
\hline & 2 & $\begin{array}{l}1 \\
3 \\
4 \\
5\end{array}$ & $\begin{array}{r}-2,0024774^{*} \\
, 1861038 \\
, 4094285 \\
, 3881594 \\
\end{array}$ & $\begin{array}{r}, 33626911 \\
, 35445877 \\
, 29656148 \\
, 31419412 \\
\end{array}$ & $\begin{array}{r}, 000 \\
1,000 \\
1,000 \\
1,000 \\
\end{array}$ & $\begin{array}{r}-3,0375807 \\
-, 9049909 \\
-, 5034469 \\
-, 5789927 \\
\end{array}$ & $\begin{array}{r}-, 9673740 \\
1,2771986 \\
1,3223038 \\
1,3553116 \\
\end{array}$ \\
\hline & 3 & $\begin{array}{l}1 \\
2 \\
4 \\
5\end{array}$ & $\begin{array}{r}-2,1885812^{*} \\
-, 1861038 \\
, 2233246 \\
, 2020556 \\
\end{array}$ & $\begin{array}{l}, 33626911 \\
, 35445877 \\
, 29656148 \\
, 31419412 \\
\end{array}$ & $\begin{array}{r}, 000 \\
1,000 \\
1,000 \\
1,000 \\
\end{array}$ & $\begin{array}{r}-3,2236846 \\
-1,2771986 \\
-, 6895508 \\
-, 7650966 \\
\end{array}$ & $\begin{array}{r}-1,1534778 \\
, 9049909 \\
1,1362000 \\
1,1692078 \\
\end{array}$ \\
\hline & 4 & $\begin{array}{l}1 \\
2 \\
3 \\
5\end{array}$ & $\begin{array}{r}-2,4119058^{*} \\
-, 4094285 \\
-, 2233246 \\
-, 0212690 \\
\end{array}$ & $\begin{array}{l}, 27456258 \\
, 29656148 \\
, 29656148 \\
, 24703368 \\
\end{array}$ & $\begin{array}{r}, 000 \\
1,000 \\
1,000 \\
1,000 \\
\end{array}$ & $\begin{array}{r}-3,2570642 \\
-1,3223038 \\
-1,1362000 \\
-, 7816879 \\
\end{array}$ & $\begin{array}{r}-1,5667474 \\
, 5034469 \\
, 6895508 \\
, 7391499 \\
\end{array}$ \\
\hline & 5 & $\begin{array}{l}1 \\
2 \\
3 \\
4 \\
\end{array}$ & $\begin{array}{r}-2,3906368^{*} \\
-, 3881594 \\
-, 2020556 \\
, 0212690 \\
\end{array}$ & $\begin{array}{r}, 29351974 \\
, 31419412 \\
, 31419412 \\
, 24703368 \\
\end{array}$ & $\begin{array}{r}, 000 \\
1,000 \\
1,000 \\
1,000 \\
\end{array}$ & $\begin{array}{r}-3,2941491 \\
-1,3553116 \\
-1,1692078 \\
-, 7391499 \\
\end{array}$ & $\begin{array}{r}-1,4871245 \\
, 5789927 \\
, 7650966 \\
, 7816879 \\
\end{array}$ \\
\hline \multirow[t]{2}{*}{$\begin{array}{l}\text { Zscore(Market } \\
\text { SShare_Seg) }\end{array}$} & 1 & $\begin{array}{l}2 \\
3 \\
4 \\
5\end{array}$ & $\begin{array}{r}-, 1216629 \\
1,4103883 \\
, 6308446 \\
1,0917474 \\
\end{array}$ & $\begin{array}{l}, 61230015 \\
, 61230015 \\
, 49994098 \\
, 53445939\end{array}$ & $\begin{array}{r}1,000 \\
, 299 \\
1,000 \\
, 518 \\
\end{array}$ & $\begin{array}{r}-2,0064449 \\
-, 4743937 \\
-, 9080735 \\
-, 5534252 \\
\end{array}$ & $\begin{array}{l}1,7631191 \\
3,2951703 \\
2,1697627 \\
2,7369200\end{array}$ \\
\hline & 2 & $\begin{array}{l}1 \\
3\end{array}$ & $\begin{array}{r}, 1216629 \\
1,5320512\end{array}$ & $\begin{array}{r}, 61230015 \\
, 64542103\end{array}$ & $\begin{array}{r}1,000 \\
, 256\end{array}$ & $\begin{array}{r}-1,7631191 \\
-, 4546835\end{array}$ & $\begin{array}{l}2,0064449 \\
3,5187858\end{array}$ \\
\hline
\end{tabular}




\begin{tabular}{|c|c|c|c|c|c|c|c|}
\hline & & $\begin{array}{l}4 \\
5 \\
\end{array}$ & $\begin{array}{r}, 7525075 \\
1,2134103 \\
\end{array}$ & $\begin{array}{l}, 53999798 \\
, 57210460\end{array}$ & $\begin{array}{r}1,000 \\
, 440 \\
\end{array}$ & $\begin{array}{l}-, 9097140 \\
-, 5476418 \\
\end{array}$ & $\begin{array}{l}2,4147290 \\
2,9744623 \\
\end{array}$ \\
\hline & & 1 & $-1,4103883$ & 61230015 & 299 & $-3,2951703$ & 4743937, \\
\hline & 2 & 2 & $-1,5320512$ & ,64542103 & ,256 & $-3,5187858$ & ,4546835 \\
\hline & 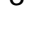 & 4 &,- 7795437 & ,53999798 & 1,000 & $-2,4417652$ & 8826778 \\
\hline & & 5 &,- 3186409 &, 57210460 & 1,000 & $-2,0796930$ & 1,4424112 \\
\hline & & 1 & -,6308446 & 49994098 & 1,000 & $-2,1697627$ & 9080735 \\
\hline & 4 & 2 &,- 7525075 & ,53999798 & 1,000 & $-2,4147290$ & 9097140 \\
\hline & $T$ & 3 & ,7795437 & ,53999798 & 1,000 & -,8826778 & 2,4417652 \\
\hline & & 5 & ,4609028 & ,44981460 & 1,000 &,- 9237163 & 1,8455219 \\
\hline & & 1 & $-1,0917474$ & ,53445939 &, 518 & $-2,7369200$ & ,5534252 \\
\hline & 5 & 2 & $-1,2134103$ & ,57210460 & ,440 & $-2,9744623$ & 5476418 \\
\hline & L & 3 & 3186409, & ,57210460 & 1,000 & $-1,4424112$ & 2,0796930 \\
\hline & & 4 &,- 4609028 & ,44981460 & 1,000 & $-1,8455219$ &, 9237163 \\
\hline \multirow{20}{*}{$\begin{array}{l}\text { Zscore(Rec_B } \\
\text { ruta) }\end{array}$} & \multirow{4}{*}{1} & 2 & $1,6425644^{\star}$ & ,31778293 & ,000 & 6643652 & 2,6207636 \\
\hline & & 3 & $2,1764231^{\star}$ & ,31778293 & ,000 & 1,1982239 & 3,1546224 \\
\hline & & 4 & $2,4393469^{*}$ & ,25946867 & ,000 & 1,6406506 & 3,2380433 \\
\hline & & 5 & $2,4162740^{*}$ & ,27738368 &, 000 & 1,5624317 & 3,2701163 \\
\hline & \multirow{4}{*}{2} & 1 & $-1,6425644^{*}$ & ,31778293 & ,000 & $-2,6207636$ & -,6643652 \\
\hline & & 3 & ,5338587 & ,33497262 & 1,000 &,- 4972538 & 1,5649713 \\
\hline & & 4 & ,7967825 & ,28025820 & ,088 &,- 0659081 & 1,6594732 \\
\hline & & 5 & ,7737096 & 29692149 & , 152 & -1402740 & 1,6876931 \\
\hline & \multirow{4}{*}{3} & 1 & $-2,1764231^{*}$ & ,31778293 & , 000 & $-3,1546224$ & $-1,1982239$ \\
\hline & & 2 &,- 5338587 & ,33497262 & 1,000 & $-1,5649713$ & 4972538 \\
\hline & & 4 & ,2629238 & ,28025820 & 1,000 &,- 5997668 & 1,1256144 \\
\hline & & 5 & 2398508 & 29692149 & 1,000 &,- 6741327 & 1,1538344 \\
\hline & \multirow{4}{*}{4} & 1 & $-2,4393469^{*}$ & 25946867 & ,000 & $-3,2380433$ & $-1,6406506$ \\
\hline & & 2 & -,7967825 & 28025820 & ,088 & $-1,6594732$ & 0659081 \\
\hline & & 3 & |2629238 & ,28025820 & 1,000 & $-1,1256144$ & ,5997668, \\
\hline & & 5 &,- 0230730 & ,23345315 & 1,000 &,- 7416883 & 6955424 \\
\hline & & 1 & $-2,4162740^{*}$ & 27738368 & ,000 & $-3,2701163$ & $-1,5624317$ \\
\hline & 5 & 2 &,- 7737096 & 29692149 & 152 & $-1,6876931$ & 1402740 \\
\hline & & 3 & -2398508 & 29692149 & 1,000 & $-1,1538344$ & 6741327, \\
\hline & & 4 & ,0230730 & ,23345315 & 1,000 &,- 6955424 & ,7416883 \\
\hline \multirow{9}{*}{$\begin{array}{l}\text { Zscore(Satisfa } \\
\text { cao) }\end{array}$} & \multirow{4}{*}{1} & 2 & $-1,4144652^{*}$ & ,30219681 & ,001 & $-2,3446872$ & -4842431 \\
\hline & & 3 &,- 2686387 & 30219681 & 1,000 & $-1,1988608$ & 6615833 \\
\hline & & 4 & $-2,2806880^{*}$ & 24674266 & ,000 & $-3,0402111$ & $-1,5211649$ \\
\hline & & 5 &,- 7456095 & 26377900 & ,091 & $-1,5575739$ & ,0663548 \\
\hline & \multirow{4}{*}{2} & 1 & $1,4144652^{*}$ & ,30219681 & ,001 & 4842431, & 2,3446872 \\
\hline & & 3 & $1,1458264^{*}$ & ,31854341 & ,014 & 1652863 & 2,1263666 \\
\hline & & 4 &,$- 8662229^{*}$ & 26651254 & ,033 & $-1,6866016$ & -,0458441 \\
\hline & & 5 & ,6688556 & ,28235855 & ,259 & -,2003003 & 1,5380116 \\
\hline & 3 & 1 & 2686387 & ,30219681 & 1,000 &,- 6615833 & 1,1988608 \\
\hline
\end{tabular}




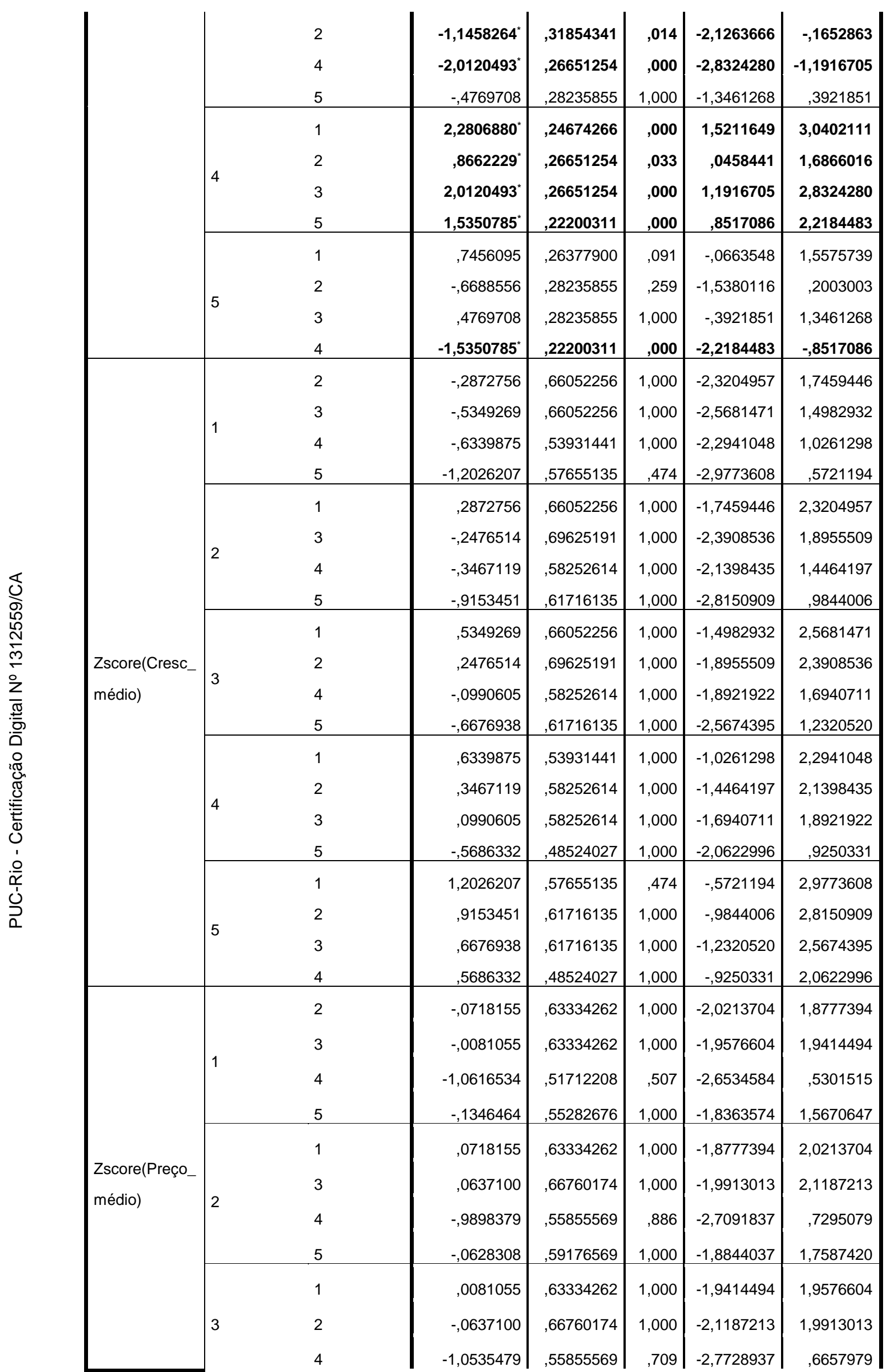




\begin{tabular}{|lll|r|r|r|r|r|} 
& 5 &,- 1265408 &, 59176569 & 1,000 & $-1,9481137$ & 1,6950320 \\
\cline { 2 - 7 } & 1 & 1,0616534 &, 51712208 &, 507 &,- 5301515 & 2,6534584 \\
& 2 &, 9898379 &, 55855569 &, 886 &,- 7295079 & 2,7091837 \\
& 3 & 1,0535479 &, 55855569 &, 709 &,- 6657979 & 2,7728937 \\
& 5 &, 9270071 &, 46527305 &, 574 &,- 5051962 & 2,3592103 \\
\hline & 1 &, 1346464 &, 55282676 & 1,000 & $-1,5670647$ & 1,8363574 \\
& 2 &, 0628308 &, 59176569 & 1,000 & $-1,7587420$ & 1,8844037 \\
& 3 &, 1265408 &, 59176569 & 1,000 & $-1,6950320$ & 1,9481137 \\
& 4 &,- 9270071 &, 46527305 &, 574 & $-2,3592103$ &, 5051962 \\
\hline
\end{tabular}

Analisando o resultado do teste de Bonferroni, pode-se identificar as diferenças entre as médias das variáveis de desempenho de cada grupo estratégico. Complementando a análise do teste de Kruskal-Wallis, o qual sugeriu haver diferença significativa nas variáveis market-share, market-share por segmento, receita bruta, satisfação e preço médio, quando comparadas entre os cinco grupos estratégicos, foi analisado o comportamento destas mesmas variáveis no teste de Bonferroni, para tentar identificar em quais grupos estratégicos elas apresentam tal diferença.

Para a variável market-share, o teste de Bonferroni sugere que o grupo estratégico 1, ou seja, liderança em custos totais, apresenta desempenho superior aos outros grupos estratégicos. O mesmo é sugerido para a variável receita bruta, na qual o grupo estratégico de liderança em custos totais se mostra superior.

Já na variável satisfação, como já havia sugerido o teste de análise de variância, pôde-se identificar o desempenho superior do grupo estratégico 4 (enfoque em diferenciação) em relação aos outros grupos. Na segunda posição, está o grupo que busca a liderança através da diferenciação em escopo amplo.

Assim como sugerido pelo teste Kruskal-Wallis, a variáveis crescimento médio do market-share não apresentou diferença significativa entre os clusters. Apesar do teste de Kruskal-Wallis ter sugerido haver diferenças entre as variáveis preço médio e market share por segmento entre os clusters, o teste de Bonferroni sugere não haver tal diferença, evidenciando possíveis imprecisões nos resultados.

Uma vez que muitas variáveis não apresentaram grau de significância suficiente para uma análise mais precisa dos dados, e com o objetivo de adicionar 
às análises deste estudo, foi criada a tabela 31 , com base na diferença algébrica das médias de cada variável de desempenho por grupo estratégico. Os resultados não passaram por tratamentos estatísticos e, devido a isso, não podem ser considerados seguros. Porém, foram trazidos a este trabalho como adição às analises. Estes dados foram apresentados de forma ordinal, detalhando o grupo estratégico com maior êxito por variável de desempenho e devem ser analisados com extrema cautela.

Tabela 31 - comparação de desempenho por grupo estratégico

\begin{tabular}{|c|c|c|c|c|c|c|c|c|}
\hline Cluster & Estratégia & $\begin{array}{l}\text { Número } \\
\text { de } \\
\text { empresas }\end{array}$ & $\begin{array}{c}\text { Market- } \\
\text { share }\end{array}$ & $\begin{array}{l}\text { Market- } \\
\text { share por } \\
\text { segmento }\end{array}$ & $\begin{array}{c}\text { Crescimento } \\
\text { do Market- } \\
\text { share }\end{array}$ & $\begin{array}{c}\text { Receita } \\
\text { Bruta }\end{array}$ & $\begin{array}{c}\text { Satisfação } \\
\text { Cliente }\end{array}$ & $\begin{array}{l}\text { Preço } \\
\text { Médio }\end{array}$ \\
\hline & & & \multicolumn{6}{|c|}{ Variáveis de Desempenho } \\
\hline 1 & $\begin{array}{l}\text { Liderança em } \\
\text { Custos Total }\end{array}$ & 5 & 10 & 10 & 50 & 10 & 50 & 50 \\
\hline 2 & Diferenciação & 4 & 20 & 20 & 40 & 2o & 20 & 3음 \\
\hline 3 & $\begin{array}{l}\text { Enfoque em } \\
\text { custos }\end{array}$ & 4 & 3음 & 50 & 20 & 3음 & 40 & 40 \\
\hline 4 & $\begin{array}{l}\text { Enfoque em } \\
\text { Diferenciação }\end{array}$ & 10 & 40 & 3음 & 3음 & 40 & 10 & 10 \\
\hline 5 & $\begin{array}{l}\text { Stuck-in-the- } \\
\text { Middle }\end{array}$ & 7 & 5은 & 40 & 10 & 50 & 3음 & 20 \\
\hline
\end{tabular}

Ao analisar todas as opções estratégicas, pode-se perceber a superioridade no desempenho médio das empresas optantes da estratégia de liderança em custo total (Grupo 1). Estas empresas apresentam superioridade nas variáveis de market-share, market-share por segmento e em receita bruta. Este grupo é formado pelas cinco empresas com maiores participações no mercado, são elas: General Motors (Chevrolet), Fiat, Volkswagen, Renault e Ford. Tem como características serem empresas extremamente fortes no segmento de entrada, e por terem participações em outros segmentos, o que agrega ao bom desempenho em seus market-share por segmento. A variável receita bruta está associada basicamente ao market-share e ao preço médio. Apesar de apresentarem o menor preço médio da indústria, seus volumes de venda são superiores aos outros grupos, que lhe garantem uma receita média de três vezes a receita média do grupo subsequente (grupo de diferenciação). Como consequência da opção 
estratégica, os atributos formadores de satisfação são comprometidos, atribuindo ao grupo o pior desempenho neste quesito. Esta estratégia parece exigir um tradeoff entre o preço (grande chamariz dos produtos) e o investimento em qualidade, design, desempenho e segurança, atributos de satisfação. Por fim, percebe-se o baixo valor na variável crescimento de market-share, o que é justificável ao observar o mercado e constatar que estas cinco empresas pertencentes ao Grupo 1 possuem um volume de atuação altíssimo, dominando grande parte do mercado. Sendo assim, estas empresas não possuem oportunidades para grandes crescimentos, e os crescimentos apresentados, próximo a 10\%, representam, em volumes de venda, quantidades altíssimas de veículos vendidos.

O grupo 2 das empresas optantes pela estratégia de diferenciação, em seu escopo amplo, obteve a segunda posição em todas as variáveis de desempenho, com exceção da variável market-share, o qual se encontra em segundo com 10,8\% de participação. Em relação às receitas brutas, este grupo apresenta a segunda posição, respondendo por pouco mais de $23 \%$ da receita total da indústria.

Este grupo também pode ser caracterizado por empresas que investem em atributos que agregam valor ao produto de maneira geral. Não focam em agregar valores únicos, nem luxuosos aos seus produtos, pois, esta prática poderia ter grandes impactos no preço final do produto. $\mathrm{O}$ preço final, apesar de não ser o principal fator decisório de compra, ainda possui alguma parcela de consideração na decisão do cliente. Dessa forma, estas empresas procuram se diferenciar de maneira ampla, agradando seus consumidores com atributos não excelentes, mas considerados satisfatórios.

Outra característica marcante deste grupo 2 é a participação em grande número de segmentos apesar da pequena linha de produtos. Com exceção da Mitsubishi, todas as empresas possuem participação diferentes segmentos. Estas empresas, inclusive, estão entrando nos segmentos de entrada do mercado, como fez a Hyundai com o modelo HB20. Esta participação, com boa representatividade em outros segmentos, garante ao grupo a segunda posição na variável market-share por segmento.

O terceiro grupo estratégico corresponde às empresas adotantes da estratégia de enfoque em custo. Este grupo é formado por quatro empresas com atuações 
locais, apresentando a terceira posição no market-share total da indústria, apesar da baixa participação individual das empresas presentes neste grupo, são elas: Citroen, Chery, Nissan, Peugeot. Quanto ao market-share por segmento, por atuarem em poucos segmentos e em especial, nos segmentos básicos do mercado, estas empresas apresentam resultados discretos, uma vez que estes segmentos são dominados pelas cinco grandes empresas do grupo 1. Assim como o Grupo 1, a opção estratégica do Grupo 2 é caracterizada pela baixa satisfação de seus clientes, pois o preço final dos produtos ainda é um atributo extremamente importante no processo decisório do consumidor.

O quarto grupo estratégico é constituído por dez empresas adotantes da estratégia de enfoque em diferenciação. Este grupo é formado pelas empresas: Audi, BMW, Ferrari, Lamborghini, Jaguar, Mercedes-Benz, Land Rover, Porsche, Subaru e Volvo. Como principal característica dessas empresas, percebemos grande participação de veículos importados, com altíssima tecnologia envolvida, tanto no próprio produto, quanto no processo produtivo. Seus altíssimos preços médios de venda colocam este grupo como quarto em market-share, apenas a frente do grupo stuck-in-the-middle. Porém, deve-se destacar que a participação individual das empresas deste grupo é inferior a participação individual do grupo stuck-in-the-middle, que conta apenas com quatro empresas. Ainda assim, seu preço médio elevado supera o pequeno volume de venda, garantindo a esse grupo, a quarta maior média de receita bruta por empresa, no valor de R $\$ 398.558 .161$ anuais, superando a média de receita bruta por empresa do grupo stuck-in-themiddle de $\mathrm{R} \$ 168.738 .192$ anuais.

Em relação à satisfação dos consumidores, este grupo lidera com grande distância do segundo colocado, conforme constatado pelo teste ANOVA. Com grande ênfase nos atributos de qualidade, este grupo consegue atingir elevados níveis de satisfação, oferecendo produtos com altíssimo valor agregado.

Por fim, o grupo 5, stuck-in-the-middle foi formado pelas empresas que apresentam inconsistência estratégica, ou seja, não foi possível identificar padrões em suas formas de atuação. Este grupo foi formado por: Chrysler, Dodge, Jeep, Kia Motors, SsangYoung, Suzuki e Troller. Conforme afirma a teoria de Porter (1980), esta indefinição estratégica afeta profundamente o resultado das empresas, 
podendo ser percebida pela última posição nas variáveis market-share e receita bruta, e pela penúltima posição na variável marke-share por segmento. $\mathrm{Na}$ variável satisfação do consumidor, este grupo atingiu a terceira posição, superando as estratégias que focam em custo (amplo e enfoque). Esta posição pode ser entendida pelo fato destas empresas investirem algum esforço em oferecer produtos com qualidade e variedades de serviços, superando as ofertas das empresas com foco em custo (amplo e enfoque), mas ficando abaixo das empresas de diferenciação (amplo e enfoque), garantindo a terceira posição na variável satisfação do consumidor.

\section{8}

\section{Comparação com os resultados obtidos por Silva (2007)}

Ao comparar os resultados entre os cluster encontrados por Silva (2007), com os resultados deste presente estudo, notam-se algumas diferenças relevantes. No grupo estratégico das empresas que optam pela estratégia de liderança em custos totais, a grande diferença encontrada foi a presença da empresa DaimlerChrysler. Neste presente estudo, esta empresa foi classificada como pertencentes ao grupo stuck-in-the-middle.

Outra diferença significativa foi encontrada no grupo das empresas que buscam a liderança através da diferenciação, no qual se destacam a entrada da MMC Automotores e da Hyundai neste presente estudo. Em seu estudo, Silva (2007) classificou a empresa MMC Automotores como estratégia de liderança através do enfoque em custo.

Por fim, destacam-se a classificação de Silva (2007) da SsangYoung sendo pertencente ao grupo estratégico de enfoque em custo e as empresas Nissan, Audi e Land Rover como stuck-in-the-middle. No atual trabalho, observa-se a SsangYoung como stuck-in-the-middle, a Nissan como enfoque em custo e a Audi e a Land Rover, ambas classificadas como enfoque em diferenciação.

Estas diferenças encontradas podem ser justificadas tanto por questões metodológicas, exclusivas a cada trabalho, quando por mudanças na forma de atuação destas empresas. Sobre as questões metodológicas, pode-se justificar a desigualdade entre os grupos estratégicos pela diferença nas variáveis de 
estratégias utilizadas entre os trabalhos, assim como por diferenças na definição dos pesos de cada variável na formação das matrizes dos centroides.

A visão mercadológica também pode contribuir para justificar tais diferenças. Mudanças na estrutura do mercado, assim como em pressões vinda do macro e do microambiente podem ajudar a explicar as diferenças encontradas entre os estudos. Mudanças na estratégia das empresas citadas, apesar de complexas, também são fatores possíveis para explicar a diferença nos resultados. A tabela 32 mostra as diferenças entre os grupos estratégicos encontrados neste estudo e no trabalho realizado por Silva (2007). 
Tabela 32 - comparação dos grupos estratégicos

\begin{tabular}{|c|c|c|}
\hline $\begin{array}{c}\text { Grupo } \\
\text { Estratégico }\end{array}$ & Memoria, 2015 & Silva, 2007 \\
\hline $\begin{array}{l}\text { Liderança em } \\
\text { Custo }\end{array}$ & $\begin{array}{l}\text { GENERAL MOTORS DO BRASIL LTDA } \\
\text { FIAT AUTOMÓVEIS S.A. } \\
\text { FORD MOTOR COMPANY BRASIL } \\
\text { VOLKSWAGEN DO BRASIL LTDA } \\
\text { RENAULT DO BRASIL S.A }\end{array}$ & $\begin{array}{l}\text { GENERAL MOTORS DO BRASIL } \\
\text { LTDA } \\
\text { FIAT AUTOMÓVEIS S.A. } \\
\text { FORD MOTOR COMPANY BRASIL } \\
\text { VOLKSWAGEN DO BRASIL LTDA } \\
\text { RENAULT DO BRASIL S.A } \\
\text { DAIMLER-CHRYSLER }\end{array}$ \\
\hline Diferenciação & $\begin{array}{l}\text { HONDA AUTOMÓVEIS DO BRASIL LTDA } \\
\text { TOYOTA DO BRASIL LTDA } \\
\text { MMC AUTOMOTORES DO BRASIL S.A. } \\
\text { HYUNDAI MOTOR BRASIL LTDA }\end{array}$ & $\begin{array}{l}\text { HONDA AUTOMÓVEIS DO BRASIL } \\
\text { LTDA } \\
\text { TOYOTA DO BRASIL LTDA }\end{array}$ \\
\hline Enfoque em Custo & $\begin{array}{l}\text { PEUGEOT CITROEN DO BRASIL LTDA } \\
\text { (PEUGEOT) } \\
\text { PEUGEOT CITROEN DO BRASIL LTDA } \\
\text { (CITROEN) } \\
\text { NISSAN DO BRASIL AUTOMÓVEIS LTDA } \\
\text { CHERY BRASIL FABRICAÇÃO E IMPORTAÇÃO } \\
\text { DE VEÍCULOS LTDA }\end{array}$ & $\begin{array}{l}\text { MMC AUTOMOTORES DO BRASIL } \\
\text { S.A. } \\
\text { PEUGEOT CITROEN DO BRASIL } \\
\text { S.A. } \\
\text { CITROEN } \\
\text { KIA } \\
\text { SSANGYOUNG }\end{array}$ \\
\hline $\begin{array}{l}\text { Enfoque em } \\
\text { Diferenciação }\end{array}$ & $\begin{array}{l}\text { BMW DO BRASIL LTDA } \\
\text { FERRARRI } \\
\text { PORSCHE } \\
\text { LAND ROVER DO BRASIL LTDA } \\
\text { AUDI DO BRASIL LTDA } \\
\text { JAGUAR } \\
\text { LAMBORGHINI } \\
\text { MERCEDES BENZ DO BRASIL LTDA } \\
\text { VOLVO DO BRASIL VEÍCULOS LTDA }\end{array}$ & $\begin{array}{l}\text { BMW } \\
\text { FERRARRI } \\
\text { PORSCHE } \\
\text { MASERATI }\end{array}$ \\
\hline $\begin{array}{l}\text { Stuck in the } \\
\text { Middle }\end{array}$ & $\begin{array}{l}\text { SSANGYOUNG } \\
\text { JEEP } \\
\text { CHRYSLER } \\
\text { DODGE } \\
\text { KIA MOTORS DO BRASIL LTDA } \\
\text { SUZUKI VEÍCULOS BRASIL LTDA } \\
\text { SUBARU } \\
\text { TROLLER }\end{array}$ & $\begin{array}{l}\text { LAND ROVER DO BRASIL LTDA } \\
\text { NISSAN DO BRASIL AUTOMÓVEIS } \\
\text { LTDA } \\
\text { AUDI DO BRASIL LTDA }\end{array}$ \\
\hline
\end{tabular}




\section{Conclusões}

\section{1}

\section{Discussão dos resultados obtidos}

Este trabalho teve como objetivo principal realizar uma análise estratégica sobre a indústria automobilística brasileira, buscando identificar se existe diferença de desempenho entre os grupos estratégicos, à luz dos conceitos da tipologia de Porter. Por meio de dados obtidos sobre as dimensões estratégicas das 30 principais montadoras atuantes no mercado brasileiro, foi possível identificar suas estratégias competitivas e classificá-las em grupos estratégicos. Definidas as variáveis de desempenho, foi analisado o desempenho médio de cada grupo estratégico e feitas análises estatísticas sobre os grupos.

Ao analisar os grupos estratégicos formados, pôde-se perceber semelhanças na postura estratégica das empresas pertencentes ao mesmo grupo. Esta semelhança corrobora com as definições de grupo estratégico, definida por Porter (1985), em que as empresas pertencentes ao mesmo grupo estratégico competem utilizando armas competitivas semelhantes. Conforme foi possível analisar, o grupo formado pelas empresas que buscam a liderança através do custo total (General Motors, Fiat, Ford, Volkswagen e Renault) possuem grande semelhança na definição de suas estratégias, operacionalizadas pela ênfase dada a cada variável estratégica selecionada neste estudo. A mesma lógica pode ser aplicada para os grupos de liderança em diferenciação (Honda, Hyundai, Toyota e Mitsubishi), enfoque em custo (Chery, Citroen, Nissan e Peugeot) e enfoque em diferenciação (Audi, BMW, Ferrari, Jaguar, Lamborghini, Land Rover, MercedesBenz, Porsche, Subaru e Volvo). A conclusão não se aplica ao grupo stuck-in-themiddle, o qual apresentou empresas que apresentaram falhas na execução de suas respectivas estratégias ou que buscam um posicionamento híbrido. 
Ainda de acordo com teorias de Porter (1980), empresas pertencentes ao mesmo grupo estratégicos sofrem pressões semelhantes do macroambiente. Dessa forma, com a análise do Modelo de Cinco Forças (PORTER, 1980) e análise das variáveis do macroambiente, pode-se perceber como cada grupo se posiciona perante o macroambiente:

Empresas do grupo estratégico que busca liderança através da liderança em custo estão mais propensas a sofrerem pressão de variáveis econômicas, uma vez que seu público alvo é mais sensível a variações no preço final de seus produtos. Mudanças na taxa de renda, na política de crédito, na taxa básica de juros e em impostos que impactem o preço do produto final, podem afetar diretamente o nível de vendas destas empresas. Este impacto, pode causar uma pressão ainda maior dos produtos substitutos neste grupo estratégicos, como a opção pelo transporte público. Por outro lado, é importante citar a força das empresas deste grupo perante seus fornecedores. Pelo elevado nível de compra e pela existência de diversos fornecedores semelhantes, este grupo, como um todo, está em uma posição de segurança contra pressões de fornecedores que venham a exigir preços melhores ou menores prazos para pagamentos.

O grupo das empresas que buscam a liderança através da diferenciação, apesar da alta competitividade interna, também se coloca em uma posição de segurança perante seus fornecedores, uma vez que suas compras são de grande importância para seus fornecedores. Apesar de ainda ser impactado por questões econômicas, este impacto acontece de forma mais sutil quando comparado ao grupo 1 (liderança total em custo). A mesma conclusão pode ser feita para a ameaça de produtos substitutos. Tais produtos não oferecem grande ameaça, uma vez que os clientes deste grupo estratégico exigem fatores que não são oferecidos pelo transporte público, como altos níveis de segurança e conforto.

Já o grupo das empresas que buscam a liderança através do enfoque em custo, sofrem pressões de forma semelhante ao grupo 1. Os produtos substitutos continuam sendo uma ameaça constante, assim como as variáveis econômicas. A principal diferença entre estes dois grupos está na intensidade do poder de barganha, tanto com fornecedores, quanto com clientes. Por não apresentarem um volume de compras tão elevados, estas empresas não concentram tal força na 
negociação com seus fornecedores, não conseguindo, dessa forma, os melhores acordos. Pelo lado do consumidor, a lógica se repete. Por não apresentarem um volume relativamente alto, cada venda se torna mais impactante para a empresa, diminuindo seu poder de barganha.

Por fim o grupo das empresas que buscam a liderança através do enfoque em diferenciação são menos impactadas por variáveis econômicas, uma vez que sua demanda apresenta alta elasticidade em relação a variação do preço. Outro fator positivo para estas empresas, é o baixíssimo impacto de produtos substitutos. Porém, diferentemente de outros grupos estratégicos, este grupo é impactado de forma mais intensa por variáveis ambientais e sociais, uma vez que seus produtos são os menos eficientes em relação ao consumo de combustível. Pressões sociais contra o consumismo exagerado da população também impactam este grupo estratégico, uma vez que os custos de produção de um automóvel destas empresas são elevadíssimos em relação aos outros grupos estratégicos. Este grupo apresenta baixo poder de barganha com seus fornecedores, uma vez que a quantidade de fornecedores aptos a fornecerem produtos com tamanha qualidade não é elevada. Também atuam de forma negativa a alta rivalidade dentre as empresas do grupo e o elevado poder de barganha dos consumidores. Por possuírem baixo número de unidades vendidas, cada venda individual possui grande impacto para as empresas desde grupo. Tanto a rivalidade, quanto o poder de barganha dos fornecedores e dos consumidores, são fatores que pressionam estas empresas, limitando os preços em determinados patamares, afetando a rentabilidade do grupo estratégico.

Além de permitir estudar as estratégias competitivas das empresas pertencentes à indústria automotiva no Brasil, o presente estudo também permitiu analisar o desempenho destas empresas, correlacionando-o com suas opções estratégicas. Através da análise dos resultados, pôde-se verificar que existem diferenças estatisticamente significativas entre algumas variáveis de desempenho dos grupos estratégicos identificados, sugerindo a importância da escolha estratégica pelas empresas da amostra. Este resultado deve ser analisado com cautela, pois o teste que verificou esta diferença foi não paramétrico. Para a variável de desempenho Satisfação dos Clientes (Satisfação), por ter sido a única a apresentar distribuição normal, pôde-se concluir, após o teste de ANOVA e Bonferroni, não apenas que há diferença significativa entre os grupos, como qual 
grupo apresentou melhores resultados para esta variável. O grupo estratégico das empresas que buscam a liderança através da diferenciação no escopo estreito obteve os melhores resultados para esta variável, seguido pelo grupo de diferenciação no escopo amplo (não se pode afirmar a relação entre o desempenho do grupo stuck-in-the-middle quando comparado ao grupo diferenciação no escopo amplo).Este bom desempenho destes grupos estratégicos nesta variável é justificável, uma vez que o público-alvo destas empresas é exigente quanto a fatores que impactam a satisfação. As empresas pertencentes a estes grupos buscam investir em fatores como conforto, comodidade, segurança, potência, qualidade, entre outros fatores, que impactam na avaliação dos clientes quando julgam sua satisfação com o produto.

Para as variáveis de desempenho que não apresentaram distribuição normal, o teste de Kruskal-Wallis foi realizado com o objetivo de identificar se haveria diferença entre as variáveis dos grupos estratégicos. Com exceção da variável que mensura o crescimento médio de market share (cresc_médio), pôde-se constatar que há diferenças entre pelo menos dois grupos estratégicos por variável analisada. Isto significa que os grupos apresentam diferentes desempenhos perante as variáveis utilizadas, sugerindo a importância da escolha estratégica. Por limitações dos testes estatísticos não paramétricos, não foi possível identificar com clareza qual grupo estratégico possui melhor desempenho para tais variáveis.

Para finalizar este estudo, foram realizadas análises sobre o teste de Bonferroni da MANOVA que, mesmo não apresentando valor estatístico, objetivaram identificar se o teste sugeriria resultados que pudessem indicar possíveis comportamentos das variáveis alinhados à realizada da indústria. O resumo dos principais resultados obtidos nos testes se encontra na tabela 33, com marcações destacadas em negrito para afirmações que carecem de valor estatístico. 
Tabela 33 - Resumo dos resultados dos testes

\begin{tabular}{|c|c|c|c|}
\hline Variável/ Teste & Anova & Manova & Kruskal-Wallis \\
\hline Market-Share & Não se Aplica & $\begin{array}{l}\text { Grupo } 1>\text { todos } \\
\text { os grupos }\end{array}$ & $\begin{array}{l}\text { Há diferença em pelo menos } \\
\text { uma das amostras }\end{array}$ \\
\hline $\begin{array}{l}\text { Market-share por } \\
\text { Segmento }\end{array}$ & Não se Aplica & $\begin{array}{l}\text { Nada se pôde } \\
\text { concluir }\end{array}$ & $\begin{array}{l}\text { Há diferença em pelo menos } \\
\text { uma das amostras }\end{array}$ \\
\hline Receita Bruta & Não se Aplica & $\begin{array}{l}\text { Grupo } 1>\text { todos } \\
\text { os grupos }\end{array}$ & $\begin{array}{l}\text { Há diferença em pelo menos } \\
\text { uma das amostras }\end{array}$ \\
\hline Satisfação & $\begin{array}{l}\text { Grupo } 4>\text { todos } \\
\text { os grupos }\end{array}$ & $\begin{array}{l}\text { Grupo } 4>\text { todos } \\
\text { os grupos }\end{array}$ & Não se Aplica \\
\hline $\begin{array}{l}\text { Crescimento } \\
\text { Médio }\end{array}$ & Não se Aplica & $\begin{array}{l}\text { Nada se pode } \\
\text { concluir }\end{array}$ & $\begin{array}{l}\text { Há diferença em pelo menos } \\
\text { uma das amostras }\end{array}$ \\
\hline Preço Médio & Não se Aplica & $\begin{array}{l}\text { Nadase pode } \\
\text { concluir }\end{array}$ & $\begin{array}{l}\text { Não se pode afirmar que há } \\
\text { diferença entre as amostras }\end{array}$ \\
\hline
\end{tabular}

Dessa forma, mesmo o teste de MANOVA não possuindo valor estatístico confiável, uma vez que a premissa de normalidade foi violada, verificou-se que seus resultados parecem estar alinhados com a realidade da amostra analisada do mercado automobilístico. O grupo das empresas que optam por liderança através de custo totais (Chevrolet, Fiat, Ford, Renault e Volkswagen) aparenta fortemente possuir o maior market-share da indústria, assim como a maior receita de venda, uma vez que o alto volume de venda possui impacto direto nas receitas, apesar dos preços de venda serem inferiores aos demais grupos estratégicos.

As teorias utilizadas neste trabalho, sobre tudo a tipologia de estratégias genéricas de Porter (1980), se mostraram relevantes e com aparente capacidade de explicar a atuação, sob a ótica da estratégia competitiva, empresas atuantes na indústria automobilística no mercado brasileiro.

\section{2}

\section{Sugestão para novas pesquisas}

Assim como este trabalho contribuiu para atualizar os estudos sobre a indústria automobilística brasileira, sugere-se que novos estudos sejam feitos sobre esta indústria, a fim de atualizar as posturas estratégicas das empresas e tornar possíveis comparações temporais sobre suas atuações. Um possível foco de nova pesquisa, pouco tratado nesse estudo e em outros já realizados, é entender a postura estratégica das empresas frente a normas ambientais cada vez mais 
rígidas, à crescente preocupação dos consumidores de países mais desenvolvidos com o desempenho ambiental dos automóveis e ao surgimento de novas tecnologias baseadas em fontes renováveis de energia, como carros elétricos ou movidos a hidrogênio.

Apesar de ser mais comum encontrar trabalhos utilizando a tipologia de Porter (1980), outras tipologias podem ser aplicadas sobre esta indústria, com por exemplo, a tipologia de Mintzberg (1988) ou a de Miller \& Dess (1993).

Por fim, sugere-se aumentar o foco de análise do estudo, estudando os grupos estratégicos em si. Realizar análises que busquem identificar diferenças na atuação de empresas pertencentes ao mesmo grupo estratégico, que possam explicar diferenças de resultados. 


\section{Referências bibliográficas}

ABEIVA. Planilha: Volume de Venda, 2012. Disponível em: <http://www.abeiva.com.br>. Acesso em 20 de agosto de 2014.

ANFAVEA. Planilha: Anuário da Indústria Automobilística Brasileira. 2012. Disponível em <http://www.anfavea.com.br>. Acesso em 20 de agosto de 2014.

ANFAVEA. Indústria Automobilística Brasileira: 50 anos. 2007. Disponível em: <http://www.anfavea.com.br/50anos/8.pdf>. Acesso em 17 de julho de 2014.

ARBIX, G.; ZILBOVICIUS, M. De JK a FHC. A reinvenção dos carros. São Paulo: Edição Sociais, 1997.

BARNEY, J. B.; HESTERLY, W. S. Strategic Management and Competitive Advantage. New Jersey: Pearson Education, 3 ed, 2006.

BLACK, K. Business Statistic: For Contemporary Decision Making: Estados Unidos. John Wiley \& Sons, 6 ed, 2010.

BOTELHO, A. Reestruturação produtiva e proteção do espaço: O caso da Indústria Automobilística Instalada no Brasil. Revista do Departamento de Geografia, n. 15, p. 55-64, 2002.

CARNEIRO, J. M. T.; CAVAlCANTI, M. A. F. D.; SILVA, J. F. Porter Revisitado: Análise Crítica da Tipologia Estratégica do Mestre. Revista de Administração Contemporânea, v. 1, n. 3, p. 7-30, 1997.

CARNEIRO, J. M. T.; SILVA, J, F. Medidas Contábeis-Financeiras como Indicadores de Desempenho Organizacional: análise crítica de sua conceituação e operacionalização. Revista Eletrônica de Gestão de Negócios, v. 6, n. 3, 2010.

CAVES, R.; PORTER, M. E. From Entry Barriers to Mobility Barriers. Quarterly Journal of Economics, v. 91, n. 2, p. 241-262, 1977.

CHANDLER, A. D. Strategy and Structure: Chapters in the History of the Industrial Enterprise, Cambridge, Mass.: M.I.T. Press, 1962.

COUTO, B. T. Grupos Estratégicos na Indústria Financeira Brasileira: O Efeito do Posicionamento Estratégico no Desempenho dos Bancos, Dissertação de Mestrado, Departamento de Administração, Pontifícia Universidade Católica, Rio de Janeiro, Brasil, 2007.

CONFEDERAÇÃO NACIONAL DAS INDÚSTRIAS. Encontro da Indústria para a Sustentabilidade. Brasília, DF, 2012. 
COOL, K.; SCHENDEL, D. Strategic Group Formation and Performance: The Case of the U.S Pharmaceutical Industry, 1963-1982. Management Science, v. 33, n. 9, p. 1102-1124, 1987.

DESS, G. G.; DAVIS, P. S. Porter's (1980) Generic Strategies as Determinants of Strategic Group Membership and Organizational Performance, Academy of Management Journal, v. 27, n. 3, p. 467-488, 1984.

DRAVONE, D.; PETERAF, M.; SHANLEY, M. Do Strategic Groups Exist? An Economic Framework for Analysis. Strategic Management Journal, v. 19, p. 1029-1044, 1998.

FAULKNER, D.; BOWMAN, C. Generic strategies and congruent organizational structures: some suggestions. European Management Journal, v. 10, n. 4, p. 494-499, 1992.

FENABRAVE. Anuário: o desempenho da distribuição automotiva no Brasil, 2012. Disponível em: <http://www.fenabrave.org.br>. Acesso em: 20 de Agosto de 2014.

FIEGENBAUM, A. Dynamic Aspects of the Strategic Group and Competitive Strategy: Concepts and Empirical Examination in the Insurance Industry. Doctoral Dissertation, University of Illinois at Urbana-Champaign. 1987.

FOSS, N. J. Research in Strategy, Economics and Michael Porter. Journal of Management Studies, v. 33, n. 1, p. 1-24, 1996.

HILL, C. W. Differentiation versus low cost or differentiation and low cost: a contingency framework. Academy of Management Review, v. 13, n. 3, p. 101$412,1988$.

HILL, C. W.; DEEDS, D. L. The Importance of Industry Structure for the Determination of the Firm Profitability: A Neo-Austrian Perspective, Journal of Management Studies, v. 33 n. 4 p. 429-451, 1996.

HUNT, M. Competition in the major home appliance industry, 1960-1970, Ph.D. dissertation, Harvard University, MA, 1972.

GUIMARAES, E. A. AIndústria automobilística brasileira na década de 80.Pesquisa e Planejamento Econômico, v. 19, n. 2, p. 348-377, 1989.

KIM, L.; LIM, Y. Environment, Generic Strategies, and Performance in a rapidly developing country: A taxonomic approach. Academy of management Journal, v. 31, n. 4 , p. $802-827,1988$.

MILLER, A.; DESS, G. G. Assessing Porter's (1980): model in terms of its generability, accuracy and simplicity. Journal of Management Studies, v. 30, n. 4, p. 553-585, 1993.

MINTZBERG, H. Generic Strategies: Toward a Comprehensive Framework, Advances in Strategic Management, JAI Press Greenwich CT. v. 5, p. 1-67, 1988. 
MINTZBERG, H. The Strategic Concept I. Five ps for strategy. California Management Review, v. 30, n. 1, p. 11-24, 1997.

NEWMAN, H. H. Strategic Group and the Structure-Performance Relationship. A Review of Economics and Statistic, v. 60, p. 417-427, 1978.

NEWMAN, P. Strategic Group and the Structure-Performance Relationship. A study with respect to the chemical process industries. Unpublished Doctoral Dissertation, Harvard University. MA, 1973.

PORTER, M. E. Competitive Advantage: Creating and sustaining superior performance. New York: the Free Press, 1985.

PORTER, M. E. Competitive Strategy: Techniques for analyzing industries and competitors. New York: the Free Press, 1980.

PORTER, M. E. Interbrand choice of strategic and bilateral market power. Harvard University Press, Cambridge, MA, 1976.

PORTER, M. E. What is Strategy? Harvard Business Review, p.61-78, Novembro-Dezembro, 1996.

QUATRO-RODAS: Contém dados sobre o mercado. Disponível em: $<$ http://www.quatrorodas.com.br >. Acesso em 10 de agosto de 2014.

SAMPAIO, M. I. R. Análise da Indústria de Seguros à Luz da Tipologia de Porter, Dissertação de Mestrado, Departamento de Administração, Pontifícia Universidade Católica, Rio de Janeiro, Brasil, 2009.

SECRETARIA DE ASSUNTOS ESTRATÉGICOS: Disponível em: <http://www.sae.gov.br/site/>. Acesso em 16 de junho de 2014.

SILVA, J. F. Desempenho de Indústria: Impacto das Estratégias Competitivas e Colaborativas. Tese de Doutorado, Departamento de engenharia industrial, Pontifícia Universidade Católica, Rio de Janeiro, Brasil, 1997.

SILVA, F. V. V. Análise das Estratégias Competitivas na Indústria Automobilística, Dissertação de Mestrado, Departamento de Administração, Pontifícia Universidade Católica, Rio de Janeiro, Brasil, 2007. 